\title{
COMPORTAMENTO DE HERBICIDAS APLICADOS EM PRÉ-EMERGÊNCIA E EM PÓS-EMERGÊNCIA ATRAVÉS DO PULVERIZADOR DE GOTAS UNIFORMES
}

\author{
GREGORIO GONZALES BARRIGA \\ Pesquisador do CIAT Bolivia
}

Orientador: Prof. Dr. RICARDO VICTORIA FILHO

Dissertação apresentada à Escola Superior de Agricultura "Luiz de Queiroz", da Universidade de São Paulo, para obtenção do título de Mestre em Agronomia. Área de concentração: Fitotecnia.

PIRA CICABA

Estado de São Paulo - Brasil

Maio, 1984 
ii.

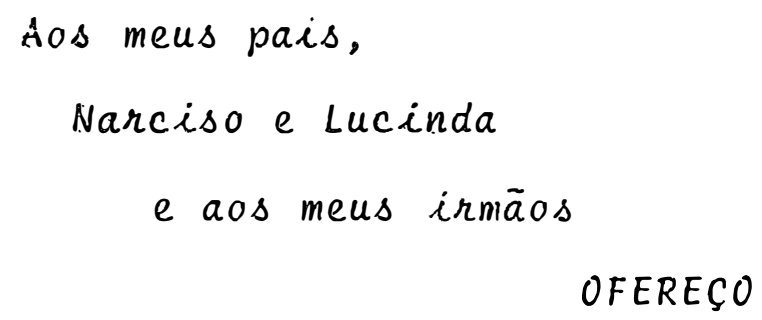

* Corina

DEDICO 
.iii.

AGRADEGIMENTOS

O autor expressa seus agradecimentos às seguintes pessoas e instituições:

- Ao Prof. Dr. Ricardo Victoria Filho, pela amizade e orientação durante o curso de pós-graduação e execução deste trabalho.

- Aos Profs. do Departamento de Agricuitura e Horticultura, pela amizade, esforço e dedicação na formação cientifica.

- À Escola Superior de Agricultura "Luiz de Queiroz", da Universidade de São Paulo, Piracicaba, SP, pela oportunidade de aperfeiçodmento.

- Ao Overseas Development Administration (ODA),

Inglaterra, pela concessão da bolsa de estudos, através do The British Council.

- Ao Dr. Frans E. Tollervey, da Mision Britanica en Agricultura Tropical, regional Bolivia, pela amizade e estimulo.

- Ao Centro de Investigación Agricola Tropical de Santa Cruz-Bolivia, pela oportunidade e facilidade oferecidas para a realização do curso de Pósmgraduação.

- Aos colegas do curso de Pós-graduação, Enge 
iv.

nheiros Agronomos Mecison Janer da Silva, Orlandina N.B. Ohashi, Francisco J. Salcedo, Roberto Arevalo e Renata Turbiani Pavezi, pela amizade e sugestões na condução do trabalho.

- Aos funcionārios do setor de Horticultura , em especial ao Sr. Luiz Ferrari, da ESALQ-USP; que direta ou indiretamente colaboraram para a realização deste trabalho.

- A Usina Santa Bārbara, pelas facilidades concedidas à condução dos experimentos de campo. 


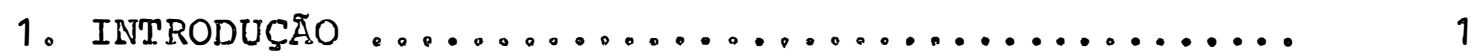

2. REVISÃO DE LITERATURA $\ldots \ldots \ldots \ldots \ldots \ldots \ldots \ldots$

2.1. A introdução da técnica de pulverização de

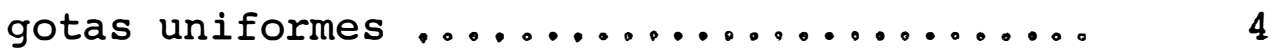

2.2. Características da técnica de aplicação de

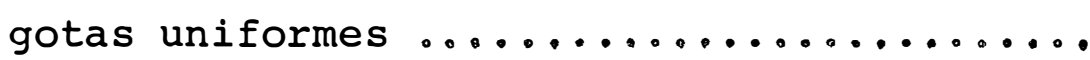

2.3. Comportamento e caracteristicas fisicas das gotas em função do tamanho .............

2.4. Influência do tamanho das gotas, do volume aplicado e de aditivos sobre a eficiência

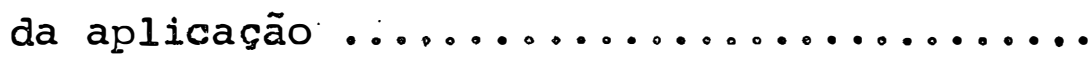

2.5. Algumas considerações referentes às vantagens do aplicador de gotas uniformes ......

2.6. Formulações requeridas para a aplicação com o pulverizador de gotas uniformes ........

2.7. Comportamento dos herbicidas aplicados em pré-emergência com equipamento convencionai vs. aplicador de gotas uniformes .........

2.8. Comportamento dos herbicidas aplicados em pós-emergência com o equipamento de gotas uniformes $\ldots \ldots \ldots \ldots \ldots \ldots \ldots \ldots \ldots$

2.9. Comportamento de outros herbicidas sistêmicos aplicados com o pulverizador de gotas

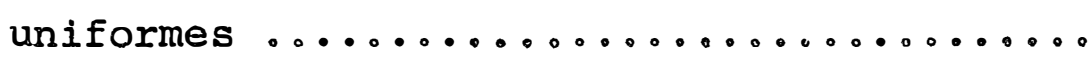


-vi.

página

2.10. Comportamento de herbicidas novos aplicados pelo pulverizador de gotas uniformes ...... 33

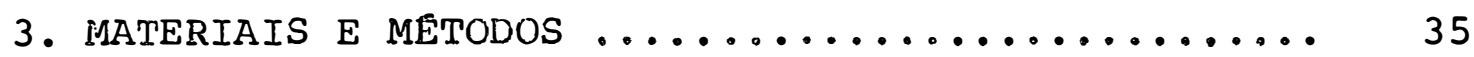

3.1. Locais dos experimento ................... 35

3.2. Experimentos de campo com herbicidas aplicados em pré-emergência ................... 37

3.2.1. Classificação e análises dos solos ... 37

3.2.2. Preparo do solo ................. 37

3.2.3。Cultivares utilizados .............. 39

3.2.4. Equipamentos de aplicação .......... 39

3.2.5. Delineamento experimental ......... 40

3.2.6. Herbicidas utilizados ............ 4i

3.2.7. Tratamentos ..................... 47

3.2 .8 . Semeadura ...................... 48

3.2 .9 . Adubação ...................... 48

3.2.10.Aplicação dos tratamentos e condições climatológicas ................... 51

3.2.11.Condições climáticas durante o ciclo das culturas ..................... 52

3.2 .12$. Avaliação dos experimentos ......... 52

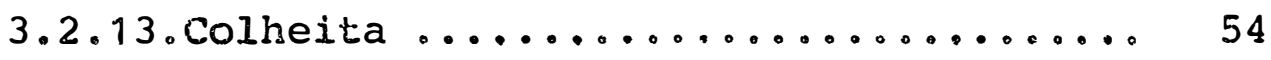

3.2.14.Análise estatística ............. 55

3.3. Experimentos de campo con herbiciảas aplicados em pós-emergência em grama-seda lCynodon dactylon (L。) Pers.) .................. 55 3.3.1. Classificação e análises de solos ... 56 
3.3.2. Escolha do local e preparo do solo .... 57

3.3.3. Herbicidas utilizados ........... 59

3.3.4. Adjuvantes utilizados ............ 62

3.3.5. Tratamentos ................. 62

3.3.6. Equipamentos de aplicação ......... 62

3.3.7. Delineamento experimental ......... 64

3.3.8. Aplicação dos tratamentos ......... 64

3.3.9. Condições climáticas na aplicação .... 65

3.3.10.Condições climáticas durante o trans curso do experimento ............ 65

3.3.11.Avaliação dos experimentos ........ 65

3.3.12.Análise estatistica ............ 66

3.4. Experimentos em casa de vegetação ........ 66

3.4.1. Solos utilizados .............. 67

3.4.2. Herbicidas utilizados ........... 67

3.4.3. Equipamentos de aplicação ........ 67

3.4.4. Delineamento experimental ......... 68

3.4.5. Tratamentos .................. 68

3.4.6. Adubação e condução das plantas de gra manseda $\ldots \ldots \ldots \ldots \ldots \ldots \ldots \ldots \ldots \ldots$

3.4.7. Aplicação dos tratamentos ........ 70

3.4.8. Condições climáticas durante o transcurso dos experimentos ........... 71

3.4.9. Avaliação dos experimentos ......... 71

3.4.10.Análise estatística ........... 72 
viii.

página

4. RESULTADOS E DISCUSSÃO .................... 74

4.1. Comportamento dos herbicidas aplicados em pré-emergência, no controle das plantas dani nhas, atravẻs do equipamento convencional e dio pulverizador de gotas uniformes ........ 74 4.1.1. Esperimentos na cultura do milho .... 74 4.1.2. Experimento na cultura da soja ...... 92

4.2. Comportamento dos herbicidas aplicados em pós-emergência no controle da gramamseda,com os equipamentos convencional e àe gotas uni-

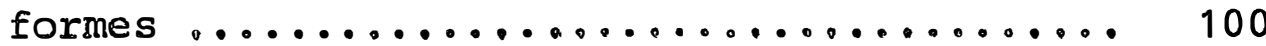

4.2.1. Experimento de campo ........... 100

4.2.2. Experimentos em casa-de-vegetação ... 121

5. CONCLUSOIES $\ldots \ldots \ldots \ldots \ldots \ldots \ldots \ldots \ldots \ldots \ldots \ldots \ldots \ldots$

6. IITERATURA CITADA ...................... 138

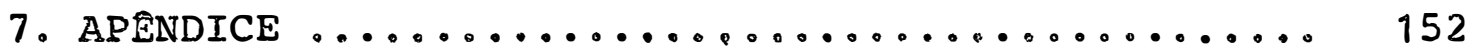


GREGORIO GONZALES BARRIGA, nasceu em 11 de $\underline{j u}$ nho de 1956, na provincia de Vallegrande, Departamento de Santa Cruz - Bolivia. Filho de Narciso Gonzales Jimenez e Lucinda Barriga de Gonzales.

Em 1979, graduou-se em Engenharia Agronômica pela Facultad de Ciencias Agricolas da Universidad Boliviana Gabriel René Moreno, Santa Cruz, S.C. - Bolivia.

Em maio de 1980, ingressou no Centro de Inves tigación Agricola Tropical (CIAT), de Santa Cruz - Bolivia, como pesquisador do Programa Control de Malezas.

Em marpo de 1982, iniciou o curso de Pós-graduąão em Fitotecnia, na Escola Superior de Agricultura "Luiz de Queiroz", finalizando em junho de 1984, quando retornou ao centro de pesquisa referido acima. 
COMPORTAMENTO DE HERBICIDAS APLICADOS EM PRE-EMERGENCIA

E EM POS-EMERGENCIA, ATRAVES DO PULVERIZADOR DE GOTAS UNIFORMES

Autor: GREGORIO GONZALES BARRIGA

Orientador: Prof. Dr. RICARDO VICTORIA FILHO

RESUMO

Com o objetivo de se estudar o comportamento de herbicidas aplicados em pré-emergência e em pós-emergência através do pulverizador de gotas uniformes, foram conduziảos experimentos de campo e em casa-de-vegetação em duas áreas experimentais.

Na Usina Santa Bārbara, município de Santa Bárbara D'Oeste, foram instalados dois experimentos de campo com herbicidas aplicados em pôs-emergência em grama-seda ( $C y$ nodon dactylon (L.) Pers.) em áreas de renovação do canavial (Saccharum spp.), e um experimento de campo na cultura äe mi tho (Zea mays L。) para herbicidas aplicados em pré-emergência. Em Piracicalua, foram conduzidos dois experimentos de campo com as culturas de nilho e soja (Glycine max (L。) Merr.) com a utilizaçắo àe herbicicias em prénemergência, aplicađos em dois experimentos em casa-વ̄e-vegetação com herbicidas a- 
plicados em pós-emergência sobre a grama-seda.

Os tratamentos utilizados tanto nos experimen tos de campo como em casa-de-vegetação, resultaram das combi nações do fatorial $4 \times 2 \times 2$, ou seja, quatro herbicidas, duas doses e dois equipamentos. Os herbicidas aplicados em pré-emergência nos experimentos com milho foram: atrazine,as misturas atrazine + metolachlor, atrazine + alachlor e atrazine + simazine. Para o experimento com soja, utilizaram-se alachlor, cyanazine, metribuzin e pendimethalin. Os herbici das pós-emergentes utilizados na grama-seda foram: glyphosate, fluazifop-butil, Dowco-453 e dalapon.

O volume de aplicação com o pulverizador convencional foi de 250 l/ha e 32 l/ha para o pulverizador de gotas uniformes, em todos os experimentos conduzidos.

O efeito dos tratamentos no controle das plan tas daninhas foi avaliado pela contagem por espécie botânica, agrupando-as depois em monocotiledôneas e dicotiledôneas, assim como através de avaliações visuais. A injúria às culturas foi avaliada somente através de avaliações visuais.

Os resultados mostraram que não houve efeito do equipamento em relação à injúria dos herbicidas sobre as culturas de milho e soja; assim mesmo, os niveis de controle das plantas daninhas atingidas pelo pulverizador de gotas uniformes, não diferiram daqueles obtidos pelo pulverizador 
convencional.

De uma forma geral, os experimentos de campo com herbicidas aplicados em pós-emergência tampouco mostraram diferenças no controle entre os dois equipamentos de pul verização. Os controles menores, observados nas avaliações de matéria seca da grama-seda com os herbicidas fluazifop-bü til e Dowco-453 no ano de 1983, poderiam ser atribuidos a uma maior suscetibilidade da pulverização de gotas uniformes pela lavagam da chuva. Somente as doses menores do glyphosa te, mostraram melhores controles com o pulverizador de gotas uniformes nos dois experimentos de campo, mas nem sempre em todas as avaliaçōes.

Os resultados dos experimentos em cada-de-vegetação mostraram melhores controles dos herbicidas glyphosa te, Dowco-453 e fluazifop-butil, quando aplicados com o pulverizador de gotas uniformes, somente no experimento de 1982 -83. Já no experimento conduzido em 1983-84, somente o Dowco 453 deu resultado significativamente melhor.

Através de cortes às 12,48 e 192 horas depois da aplicação dos herbicidas, observoumse que houve menor rebrote da grama-seca com os herbicidas glyphosate, Dowco-453 e fluazifop-butil, quando aplicados pelo pulverizador de gotas uniformes, sendo isto atribuido a uma maior absorção e translocação destes herbicidas atẻ às partes subterrâneas da planta. Para o dalapon não houve diferenças entre os equipamentos. 
EFFECTS OF HERBICIDES APPLIED PRE-EMERGENCE AND POST-EMERGENCE BY CONTROLLED DROP APPLICATION

Author: GREGORIO GONZALES BARRIGA

Adviser: Prof, Dr. RICARDO VICTORIA FILHO

SUMMARY

A series of field and greenhouse experiments have been carried out with the objective of studing herbicides pre-emergence and post-emergence performance, when applied with controlled drop sprayer.

Two field experiments with post-emergence herbicids for bermudagrass (Cynodon dactylon (L.) Pers) in sugar cane (Saccharum spp.) plantation for renewal, were esbablished at Santa Barbara Sugar Factory in Santa Barbara D'Oeste-SP. The same location, was used for pre-emergence herbicides research in corn crop (zea mays L.). Two field trials with pre-emergence herbicides in corn and soybeans crops (Glycine max $\left(I_{0}\right)$ Merr, ) and two greenhouse experiments with post-emergence herbicides in bermudagrass, were carried out in Piracicabams.

All treatments in field and greenhouse experiments were arranged in randomized blocks design, facto- 
rial $4 \times 2 \times 2$, this means, four herbicides, two rates and two equipments. The pre-emergence herbicides used in corn experiments were: atrazine, mixtures of atrazine + metolachlor, atrazine + alachlor and atrazine + simazine. For soybeans experiments were used alachlor, cyanazine, metribuzin and pendimethalin. The post-emergence herbicides used in bermudagrass were glyphosate, fluazifop-butil, Dowco-453 and dalapon. In all conducted experiments the volume rate for convencional sprayer was $2501 /$ ha and 32 1/ha for contro lled drop applicator.

The effects of treatments on weed control were evaluated by the counting of botanical species, gathering them in monocotiledoneous and dicotiledoneous groups, as well as visual evaluations. The crop damage was recorded visually only.

The results indicated no difference between sprayers in relation to herbicides damage on corn and soybeans crops. By other hand, weed control levels obtained by controlled drop application did not differ from conventional sprayer.

Similarly, field experiments with post-emergence herbicides showed no control differences between the two spraying equipments either. The lower controls observed in evaluations of bermudagrass dry matter with fluazifop-butil and Dowco-453 in 1983, could be attributed to a greater 
susceptibility to rain washing of controlled drop application .

Only glyphosate lower rates, chowed a better control with controlled drop applicator in field experiments, but not always in all evaluations 。

The results of greenhouse experiments indicated a better control of glyphosate, Dowco-453 and flua zifop-butyl herbicides, when sprayed with controlled drop applications in 1982-83 experiments only. However, in 198384 , trials, only Dowco-453 was significantly better.

Through cuts 12,48 ans 192 hours after herbicides application, a lower bermudagrass regrowth was observed with glyphosate, Dowco-453 and fluazifop--butyl when applied with controlled drop sprayer, being attributed to a greater uptake and translocations of these herbicides up to plants underground parts.

For dapalon there was no difference between equipments, 


\section{INTRODUCAOO}

O controle de pragas, plantas daninhas ou doenças incidentes em uma determinada cultura, tem sido feito, na maioria dos casos, através da aplicação de produtos quími cos tais como, inseticidas, herbicidas e fungicidas.

Nos últimos vinte anos, o consumo destes defensivos agrícolas, no Brasil, aumentou bastante. Assim, no período de 1964-74, passou de 16.200 para $101.000 t$, com uma média anual de crescimento da ordem de $29 \%$. No mesmo período, a média anual de crescimento do consumo de herbicidas foi de 45\%. Essa alta tasa de crescimento permitiu uma previsão de çonsumo de herbicidas em 1980 próxinı a dez vezes - consumo real de 1972 (SILVA, 1982). O crescimento acentua do no consumo de herbicidas é fruto da necessidade de aumentar a produção de alimentos, da crescente escassez de mão-de -obra nas áreas de produção agrícolá,e também da progressiva 
tecnificação dos sistemas de produção agrícola.

F'ormando parte muito importante nos mais diversos sistemas de produção agrícola, o controle químico das plantas daninhas baseia-se na aplicação de herbicidas que são geralmente pulverizados na superfície do solo, ou sobre as plantas daninhas, através do uso de equipamentos denomina dos pulverizadores e que são capazes de espalhar uma solução ou suspensão aquosa em gotículas de tamanho variável.

Muito embora o pulverizador tenha-se tornado um equipamento agrícola de vital importância na agricultura moderna (CUSSANS e TAYLOR, 1978), a aplicação tem sico deficiente, pois desde que foi desenvolvido no começo do sécu10, só teve mudanças em tamanho e formas (MATTHEWS, 1983).

Os equipamentos ainda utilizados para a aplicação de herbicidas são munidos de bicos hidráulicos, os quais produzem gotas desnecessariamente grandes e ineficientes,por um lado, e por outro,gotas pequenas sujeitas à deriva, que dependendo do tipo de herbicida poderá causar injụ rias às culturas vizinhas.

Por outro lado, o uso de grandes volumes de água para a pulverização convencionaj acarreta problemas do tipo técnico e econômico. Nos últimos anos, uma equipe de pesquisadores da Inglaterra, com o objetivo de tornar reduzi 
da a faixa de variação do tamanho das gotas, desenvolveu o pulverizador de gotas uniformes (CDA), equipamento este que por meio de um disco rotativo, produz gotas de tamanho muito uniforme e centradas em un! tamanho médio de $250 \mu \mathrm{m}$, as quais apresentam ótima eficiência biológica e são demasiado grandes para serem afetadas pela evaporação ou deriva.

O reduzido volume de aplicação é outra caracteristica muito importante do pulverizador de gotas uniformes, o qual utiliza volumes de aspersão entre $20-40$ 1/ha; vantagem esta que pode ser traduzida em pulverizações rápidas e sob condições metereológicas favoráveis, melhorando as sim a oportunidade de uso dos herbicidas (CUSSANS e TAYLOR, $1978)$.

De forma adicional, certas pesquisas tèm demonstrado que a eficiência biológica de alguns herbicidas foi incrementada, sugerindo inclusive a possibilidade de reduzir as doses comercialmente recomendadas na pulverização convencional.

Assim, a presente pesquisa foi desenvolvida com o objetivo de se estuciaro comportamento de herbicidas pré-emergentes nas culturas de milho e soja, e de pós-emergen tes no controle da grama-seda (Cunodon dactylon (L.) Pers), quando aplicados através do pulverizador de gotas uniformes. 


\section{REYISATO DE LITERATURA}

2.1. A introdução da técnica de pulverizacão de gotas uni formes

A apj.icação de defensivos agrícolas é feita principalmente através de pulverizadores; e em qualquer cate goria de equipamento para a pulverização o bico constitui-se uma das partes mais importantes, respondendo este por três funções essenciais: a. quebrar o liquido em pequenas go tas; b. espalhar as gotas dentro de uma área delimitada, e ə c. medir ou controlar a saída do líquido a empregar por unidade de área (SANTOS, 1976). Os bicos classificam-se de acordo com a energia neles empregada para a formação de gotas em: hidráulicos; gasosos; centrífugos; por energia cinética e térmicos. Destes, os bicos hidráulicos são os mais utilizados, na pulverização convencional de herbicidas principalmente. 
Para NiATTHEWS(1978), a aplicação de defensivos agrícolas sem dúvida é extremamente ineficiente, e até o momiento a aplicação geralmente é reduzida por equipamentos que utilizam grandes volumes de água. Os equipamentos que foram desenvolvidos no início do século continuam sendo usados com pequenas mudanças somente na forma do equipamento (MATTHEWS, 1983)

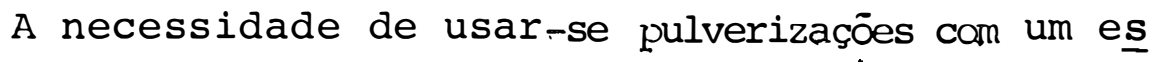
treito espectro no tamanho das gotas já era realçado por Fraser e Bals, citados por MATTHEWS (1978), há muitos anos, porém o progresso no desenvolvimento de equipamentos comercial mente aceitáveis têm sido lento, devido, sem dúvida, ao pouco interesse das indústrias agroquímicas para se envolver em pesquisa de equipamentos.

Nos últimos anos os bicos centrifugos, cujo princípio de funcionamento se baseia na força centrífuga gerada por um disco giratório acionado por energia elétrica,me receran muita atenção por parte dos pesquisadores visto que apresentam algumas características mais desejāveis que os bi cos hidráulicos.

No ano de 1940, Walton e Prewett, citados por FROST (1.978) observaram que pulverizaçẽes com tamanho unifor me de gotas eram produzidas quando se alimentava um líquido no centro de um disco em rotação. Segundo estes pesquisadores, os discos rotativos tinham sido usadós antes desta época, 
porêm com volume de líquido demasiado alto para a produção de pulverizações com tamanho uniforme de gotas, e assim,o po tencial deste tipo de aplicação não foi notado. Já em 1950, Hinze e Milborn, citados por FROST (1978), estudaram a produ ção de gotas pelos bicos rotativos e identificaram três dife rentes tipos de desintegração do líquido: a. formação direta das gotas a partir da bordadura do disco: b. formação de ligamentos a partir de um anel do líquido na bordadura do disco, estes ligamentos tornam-se instáveis e se desintegram a alguma distância do disco; c. formação de lâminas, neste caso o filme do lïquido na superfície do disco se estendem além da periferia do disco, e se rompem em uma forma irregular dando gotas de diferentes tamanhos.

Segundo FROST (1978), a transição entre os 3 estáçios está influenciada pelas mudanças no fluxo do líquido e normalmente primeiro acontecera a formação direta das gotas, seguida pela formação a partir de ligamentos e por úl timo as gotas se formaram a partir de lâminas.

A formação direta de gotas a partir de discos rotativos apresenta limitações, reporta FROST (1978), pois o fluxo máximo para a produção de gotas com $200 \mu \mathrm{m}$ de tamanho é de $0,3 \mathrm{ml} / \mathrm{seg}, 0$ qual é bastante baixo para muitas aplicações práticas. O disco "Herbi", recentemente desenvolvido, tem elevado este limite para aproximadamente $1,5 \mathrm{ml} / \mathrm{seg}$, indi cam Lake et alii, citados por FROST (1978). 
Como já foi indicado anteriormente, uma das características fundamentais de uma aspersão produzida por discos rotativos é a produção de gotas com tamanho muito uni forme. Para distinguir ou diferenciar da pulverização convencional foi criado um novo termo: aplicação de gotas uniformes (do inglês "Controlled Drop Application' e abreviado co mo CDA), o qual, de acordo com JOHNSTONE (1978b), foi proposto por JOHN FRYER da ARC Weed Research Organization em 1975, para enquadrar em uma denominação comum as aplicações de herbicidas em volumes muito baixos; especialmente com aplica dores rotativos, os quais produziam uma faixa estreita de tamanhos de gotas, ao redor de um diâmetro de $250 \mu \mathrm{m}$. Entretanto, esta terminologia tem tido limitada aceitação. Assim; JOHNSTONE (1978b) considera que o volume de aplicação na pul verização de gotas uniformes está enquadrada na classificação de baixo, muito baixo ou ultra baixo volume e, portanto, esta terminologia tambëm esta relacionada com o volume de aplicação.

O significado da terminologia aplicação de go tas uniformes é questionada pelo fato do adjetivo "controlled" não estar definido, ou seja,se está referido ao tamanho da gota ou ao volume de aplicação. Deste modo, GUNN (1978) considera.que sendo o tamanho da gota vital para a deriva da pulverização no controle de gafanhotos, o termo certo seria aplicação com gotas de tamanho uniformes.

Por outro lado, FARMERY (1978) considera que 
a técnica de gotas uniformes não está restrita a algum espeç tro de tamanho de gotas e,portanto,o equipamento de gotas uniformes não é automaticamente aquele desenhado para evitar a deriva da pulverização. Assim mesmo é lembrado que o pulverizador de gotas uniformes não está associado exclusivamen te com volumes de aplicação de 20 1/ha ou menores.

2.2. Caracteristicas da técnica de aplicação de gotas uni formes

A aplicação tradicional pode diferenciar-se da aplicação de gotas uniformes por apresentar requerimentos empíricos no uso de altos, médios e baixos volumes de aplica ção. O tamanho da gota é normalmente determinado em parte pela vazão requerida através dos bicos de pressão hidráulica. No entanto, a aplicação de gotas uniformes apresenta como cri tério primário, que o tamanho ótimo da gota é determinado pe la natureza do alvo; além disso, utiliza volumes mínimos de acordo com o tamanho da gota escolhido e que tenha um contro le eficiente (JOHNSTONE, 1978b).

O método convencional de pulverização de herbicidas, munidos de bicos hidráulicos apresenta um espectro no tamanho de gotas desde 20 a $600 \mu \mathrm{m}$ (BALS, 1971), 5 a 500 $\mu \mathrm{m}$ (STRONG, 1979): 1 a $500 \mu \mathrm{m}$ ou maiores (MICRON CORPORATION, 1981)。 
Segundo O BOLETIM INFORMATIVO HATSUTA (1982), a pesquisa em um bico convencional "Teejet" 8002 apresentou gotas com tamanhos variando desde 3 a $560 \mu \mathrm{m}$, com $80 \%$ das partículas menores que $100 \mu \mathrm{m}$ de diâmetro. Por outro lado, apenas $10 \%$ das gotículas maiores, são responsáveis por $80 \%$ da solução aplicada, sendo, portanto, a maior parte da solução pulverizada em gotas ineficientes e desnecessariamente grandes。

Para COTTON GRONER. (1980), no equipamento convencional, mais que $85 \%$ das gotas são muito pequenas, as quais evaporam ou derivam da superficie do alvo; e ao redor de $8 \%$ são muito grandes e contém $90 \%$ da solução do defensivo agrỉcola.

Baseando-se nisto é que pesquisadores como BALS (1978) consideram que a eficiência de uma máquina pulve rizadora é inversamente proporcional à variação do tamanho de gotas por ela emitida.

A preocupação constante em tornar reduzido - espectro no tamanho de gotas em uma pulverização,e assim melhorar a eficiência da mesma, deu origem a equipamentosque são chamados de aplicadores de gotas uniformes.

Os pulverizadores de gotas uniformes existentes são do tipo disco rotativo e operados à bateria, que podem ser conduzidos manualmente ou montados em tratores, e são de fácil manuseio. Baseiam-se no emprego da força centrífuga 
para gerar gotas de tamanho uniforme, em proporção inversa à velocidade de rotação (MICRON CORPORATION, 1981; BOLETIM INFORMATIVO HATSUTA, 1982)。

Na aplicação de herbicidas, pulverizações com espectro de gotas ao redor de $250 \mu \mathrm{m}$ têm sido muito pesquisa das; e este diâmetro tem sido muito utilizado nos diferentes equipamentos de gota uniforme (TAYLOR, 1981.).

Assim pulverizadores como o "Herbi", trabalhando a 2.000 r.p.m. 'produzem gotas com tamanho compreendido entre 220 e $260 \mu \mathrm{m}$ (BALS, 1975: BALS, 1978); ou como o "nicromax" que operando nas mesmas condições apresenta 90-95용 das gotas com $250 \mu \mathrm{m}$ de diâmetro (MICRON CORPORATION, 1981).

Embora a aplicação de gotas uniformes produza um espectro reduzido no tamanho de gotas, DUNN. e WALLS (1978). usando avançada tecnologia detectaram também gotas de tamanho aproximado $10 \mu \mathrm{m}$.

Entre outros equipamentos de gota uniforme, são comuns os protótipos usados pelos diferentes pesquisado- . res. Temos assim o "Microdrop" para aplicar volume de $201 /$ ha com gotas de diâmetro entre 250-300 $\mu \mathrm{m}$ (FARMERY, 1978): o pulverizador "Richmand Gibson" com gotas de 150 a. $350 \mu \mathrm{m}$. (HIND, 1978): o pulverizador "Whelbarrow" (GARNETT, 1980), e outros, como o citado por JOHNSTONE et alii (1978).

O reduzido volume de aplicação, abaixo de 40 
l/ha aliado à produção de gotas com $250 \mu$ g, as quais são dema siado grandes para serem afetados pela evaporação ou deriva, e a ótima eficiência biológica fazem com que a nova técnica de aplicação de gotas uniformes apresente vantagens econômicas e técnicas na aplicação dos herbicidas, segundo MAKEPEACE (1978), COTTON GROWER (1980), CUSSANS e TAYLOR (1978), MI CRON CORPORATION (1981), TAYLOR (1981), MATTHEWS (1978) e LONG (1978)。

Os critérios que poderiam servir de base para caracterizar a pulverização de gotas uniformes são o diâmetro mediano numérico $\left(n_{\circ} m_{\bullet} d_{\bullet}\right)$, diâmetro mediano volumétrico (v。m.d.) e o coeficiente $r$ vindo da razão v.m.d. / n.m.d. (JOHNSrIONE, 1978a). O diâmetro mediano numérico pode ser iden-: tificado como aqueie valor de diâmetro para o qual $50 \%$ em núnero das gotas são maiores e 50\% menores em tamanho. Já o diâmetro mediano volumétrico correspondente ao diâmetro que divi de a pulverização em duas partes iquais em volume, uma contendo gotas acima ou maiores e outra encerrando gotas menores ou abaixó daquele valor médio (MATTHEWS, 1975 e JOHNSTONE, 1978a).

Por outro lado, o coeficiente $r$ que expressa a dispersão da pulverização, para os equipamentos de gota uniforme, não deve ser maior que 1,4, reportam JOHNSTONE (1978a), BALS (19\%8) e JOHNSTONE et alii (1978). Nos equipamentos de gota uniforme o mais baixo valor que pode ser obti do para o coeficiente $r$ è de 1,35 (JOHNSTONE, 1978a). 
2.3. Comportamento e caracteristicas físicas das gotas em função do tamanho

Nas pulverizações, em especial naquelas em que o objetivo consiste na deposição do produto na folhagem da cultura, é essencial a presença de um pequeno deslocamento ou corrente de ar. Entretanto, nenhuma pulverização pode ser efetuada quando existem ventos fortes ou turbulências in tensas no ar, sob o risco de ter-se considerável aumento da perda de produto por deriva (SANTOS, 1976).

A quantidade de deriva em uma pulverização de pende principalmente do tamanho das gotas, da intensidade do vento e da altura de aspersão (KLINGMAN et alii, 1975). Pes quisadores como CUSSANS e TAYLOR (1978) e TAYLOR (1979) observaram que nos equipamentos de pulverização convencionais, - tamanho das gotas produzidas é variável, sendo que as meno res são muito sujeitas à deriva.

Para JOHNSTONE $(1978 \mathrm{~b})$, o tamanho da gota permanece como o fator chave durante o percurso e deposição de uma aspersão. Assim, gotas com diâmetro até $150 \mu \mathrm{m}$ têm como vantagens a obtenção de uma maior cobertura do alvo, porêm a desvantagem deste tamanho de gotas é a sua tendência à deriva (CUSSANS e TAYLOR, 1978). Assim,por exemplo,gotas com diâmetro menor que $100 \mu \mathrm{m}$ se movimentam quase igualmente em todas as direções, carregadas pela turbulência do vento; e a deposição nas partes verticais de um objeto torna-se importante (GUNN, 1978)。 
A velocidade de queda de uma gota no ar é determinada pelo balanço gravitacional e forças de viscosidade, dependendo do tamanho da gota ou, mais corretamente, de sua inércia, sendo que gotas maiores caem com maior velocidade, e diretamente sobre o alvo, ao passo que gotas menores apresentam baixa velocidade (JOHNSTONE, 1978b).

Segundo FURMIDGE (1962), a máxima retenção de una pulverização pela folhagem será obtida com um tamanho minimo de gotas, colidindo com velocidades negligiveis. No entanto, TAYLOR (1981) considera que é pouco conhecido o efeito da velocidade de impacto sobre a retenção pela folhagem.

Fatores como a temperatura e a umidade relati va afetam a evaporação das gotas. A taxa de evaporação de carregadores não aquosos, em pequenas gotículas, :movendo-se com uma corrente de ar é primariamente uma função da tempera tura do ar, porém para formulações aquosas, o déficit de saturação medido pela umidade relativa é um fator adicional que regula a evaporação (JOHNSTONE, 1978b) 。

Por exemplo,gotas de $100 \mu \mathrm{m}$ de diâmetro, cain do de uma altura de $3 \mathrm{~m}$ teriam uma "vida" de 16 selgundos (MATTHEWS. (1975)。 Assim sendo, é preciso que as gotas tenham maior tamanho, a fim de que se minimizem os efeitos da evaporação (SANTOS, 1976): e tomar cuidados especiais quando for usada água como carregador. 
Segundo HOSSEINIPOUR (1978), gotas com tamanho de $258 \mu \mathrm{m}$ perderam 10\% de seu diâmetro através da evaporação depois de uma queda de $3 \mathrm{~m}$ de altura a $40^{\circ} \mathrm{C}$ e $15 \%$ de umidade relativa. Do mesmo modo, gotas com diâmetro mediano volumétrico de $140 \mu \mathrm{m}$ depois de uma queda de 2 metros de altura mudaram para o diâmetro mediano volumétrico de $80 \mu \mathrm{m}$ ou $40 \mu \mathrm{m}$ quando submetidas às condições de $25^{\circ} \mathrm{C}$ com $75 \%$ U.R., e $40^{\circ} \mathrm{C}$ com $15 \%$ de $U_{0} R_{0}$, respectivamente.

As gotas de diâmetros compreendidos entre 150 e $400 \mu \mathrm{m}$ são classificados como de tamanho médio por cuSSANS e TAYLOR (1978), e estas parecem comportar-se relativamente estáveis em condições extremas de vento, não sendo vulneráveis à evaporação antes de atingir o alvo;e são razoavelmente eficientes na forma de aderência às folhagens.

Esta faisa de tamanhosé adequada para pulveri zações aquosas em condições de alta temperatura e baixa umidade relativa, particularmente na aplicação aêrea (JOHNSTONE。 1978b)。

Pulverizações que propiciem gotas com diâmetro maior que $400 \mu \mathrm{m}$, classificadas como gotas muito grandes, tem como desvantagem o fato de produzirem relativamente poucas gotas para um dado volume de aspersão, de tal modo que a cobertura pode ser muito pobre (CUSSANS e TAYLOR, 1978). Porém, gotas deste tamanho são muito estáveis e resistentes à deriva pelo vento, caindo diretamente no alvo 
(SANTOS, 1976); no entanto, elas são demasiadamente grandes para uma retenção eficiente pela folhagem, podendo coalescer e cair no solo.

Deste modo, gotas grandes também são evitadas, apesar de suas características de baixíssima deriva (CUSSANS e TAYLOR, 1978).

2.4. Influência do tamanho das gotas, do volume aplicado, e de aditivos, sobre a eficiência da aplicacão

A interpretação da eficiência biológica da aplicação de gotas uniformes tem sido difícil, devido a muitos fatores envolvidos. Mudanças no volume de aplicação e no tamanho das gotas poderiam ser acompanhadas por mudanças na retenção e na distribuição da aspersão, nas superfícies das plantas; como também afetar a absorção e translocação dos defensivos agrỉcolas nos tecidos das plantas, devido à varia ção na concentração dos ingredientes ativos e aditivos (MERRITT e TAYLOR, 1978)。

Trabalhos anteriores sobre a retenção tem demonstrado diferenças, as quais podem acontecer como resultado das mudanças no tamanho das gotas e no volume de aplicação. Assim, Brunskill em 1956, citado por MERRITT e TAYLOR (1978) "mostrou $q u e$ a retenção nas folhas de ervilha é maior com gotas de menor diâmetro e baixa tensão superficial. Por 
outro lado, GOTTRUP et alii (1976), reportam que a quantidade de aspersão retida sobre as folhas de Cirsium arvense $\mathrm{L}$. é um fator de suscetibilidade desta planta ao gliphosate.

Segundo MATTHEWS (1978), devido às gotas maiores caírem facilmente de algumas superfícies de folhas, os herbicidas seletivos, sem dūvida, poden ser aplicados mais eficientemente com gotas menores. De fato, Graham-Bryce,citado pelo mesmo autor, tem ilustrado teoricamente como a per da é reduzida se um alvo é atingido por mais que uma gota com baixa concentração, do que por uma gota sozinha carregan do uma dose letal.

De acordo com experimentos de HIBBITT tanto quanto ao volume total da aspersão retida, a distribuição é um fator que influencia a atividade do herbicida.

Hå muito tempo foi demonstrado por

BLACKMAN et alii (1958)。 que o nível de retenção pode ser alterado por mudanças no volume de aspersão, tamanho médio das gotas e tensão superficial, sendo que a natureza e magnitude das mudanças induzidas são dependentes das espécies de plantas pulverizadas. A adição de surfactantes, em geral, a um líquido de aspersão, tende a reduzir a tensão superficial e o ângulo de contato (FURMIDGE, 1962). Assim; os trabalhos de HIBBITT' (1969) reportam que a adição de um surfactante aumen tou bastante a retenção de pulverizações em espécies como Avena fatua L. e Linum usitatissimum L。 
Resultados obtidos por LAKE e TAYLOR

em Avena fatua L., mostram que a baixos volumes de aplicação, - tamanho da gota pode ser um fator importante que afeta a eficiência da pulverização, particularmente quando as plantas são pulverizadas na fase inicial de crescimento pela re dução da possibilidade do contato direto entre a planta e a pulverização.

Segundo TAYLOR (1981), diminuindo o volume de pulverização ou aumentando o tamanho das gotas, se reduz $\circ$ número de gotas produzidas e, portanto, a possibilidade delas atingirem o alvo. As considerações de tamanho de gotas, volume de aspersão e área de amostragem, revelam uma enorme variação no número de gotas que atingem um alvo. Por exemplo, a partir de uma pulverização com 5 l/ha e gotas de 100 $\mu \mathrm{m}, 955$ atingirão um alvo de $10 \mathrm{~cm}^{2}$, porém se este diāmetro for de $400 \mu \mathrm{m}$ somente 15 o atingirão.

A variação do número de gotas que atingem al vos de superfície menor que $0,3 \mathrm{~cm}^{2}$ é maior ${ }_{p}$ segundo reporta TAYLOR (1981)。

CLIPSHAM (1981) cita que a variabilidade no depósito da aspersão em alvos de 100 a $4 \mathrm{~cm}^{2}$ não foi afetada com bicos hidráulicos: porér, abaixo de $4 \mathrm{~cm}^{2}$ a variabilí dade se torna mais pronunciada, quando o orifício do bico ê aumentado. Com equipamentos de gotas uniformes e gotas de $350 \mu \mathrm{m}$, a variabilidade cresce notoriamente com áreas alvos 
menores que $9 \mathrm{~cm}^{2}$; e com gotas de $250 \mu \mathrm{m}$ no campo, as deposi ções foram muito variáveis, mas a recuperação da pulverização foi maior que no convencional.

As consequências biológicas desta variabilida de, não são conhecidas, porém, uma reavaliação dos resultados iniciais, indicam que a fitotoxicidade é dependente do tamanho do alvo e o volume de aplicação, o qual poderia estar relacionado ao número de gotas (TAYLOR, 1981).

Trabalhos com altos volumes de aplicação têm demonstrado que o máximo de retenção, por plantas de A. fatua, ocorre ao redor de 150 1/ha. Gotas com diâmetro entre 100 - $440 \mu \mathrm{m}$ de uma solução aquosa de barban, aplicadas em plantas jovens de A. fatua, foram igualmente bem retidas e a retenção foi linear até 150 l/ha (LAKE e TAYLOR, 1974). No entanto, quando as plantas foram pulverizadas com solução aquosa mais Agral 0,18 v/v, LAKE (1977) achou que as gotas de $100 \mu \mathrm{m}$ foram melhor retidas que as de $200-600 \mu \mathrm{m}$.

Em trabalhos posteriores MERRITT e 'TAYLOR (1978), trabalhando com esta mesma planta, encontraram que a retenção de uma solução aquosa com 0,58 de Agral foi, em geral, melhor com gotas de diâmetro entre 150 e $250 \mu \mathrm{m}$ que as de $350 \mu m_{\circ}$. Este efeito foi mais pronunciado nos maiores volu mes de aplicação, no caso de plantas com 4 folhas.

A partir destes resultados, se deduz que a retenção em relação à concentração do surfactante pode ser um 
fator importante, desde que LAKE (1977) mostrou que, usando $0,1 \%$ de Agral, as gotas maiores que $100 \mu \mathrm{m}$ foram pobremente retidas.

2.5. Algumas consideracões referentes às vantagens do aplicador de gotas uniformes.

A disponibilidade de tempo para aplicar os herbicidas em determinadas culturas é muito critico, por esta razão,o número de dias disponíveis pode ser um fator limi tante (CUSSANS e TAYLOR, 1978).

Os pulverizadores convencionais, utilizando grandes volumes de água, limitam a velocidade de aplicação e também, sob condições de muita umidade no solo, os equipamen-. tos pesados poderão causar muito dano à cultura e ao solo (BALS, 1975; TAYLOR et alii, 1976; CUSSANS e TAYLOR, 1978, NIAYES E BLANCHARD, 1978; e TAYLOR, 1979)。

A concorrência das plantas daninhas nas regiões tropicais, segundo Ashby e Pfeiffer,citados por 'MOODY (1975), são duas a três vezes maiores do que nas regiões tẹ peradas. Por outro lado, na Nigéria, um mínimo de $50 \%$ para MOODY (1975), ou 60\% para HAROLD e CHAIRMAM (1979), do tempo disponivel dos agricultores, é utilizado nas operações de limpeza das culturas com mato.

Portanto, as plantas daninhas limitam a área 
. que um homem pode cultivar e, além disso, sua remoção ocupa a maior parte do seu tempo. A utilização de herbicidas pode ser a resposta a muitos problemas das plantas daninhas, porém, é necessário contar com equipamentos adequados para,assim,obter a eficiência biológica desejada.

Como já foi indicado anteriormente, a aplicação convencional é questionada em muitos aspectos, e o desenvolvimento dos pulverizadores com tamanho de gota uniforme trazem soluções a muitos dos problemas apresentados pelos equipamentos convencionais.

As aplicações de herbicidas com equipamentos de gota uniforme, são feitas com baixos volumes de água, o que permite uma rápida pulverização, e assim estas operações podem ser feitas sob condições meteorológicas favoráveis (MAT THEWS, 1977 e TAYLOR, 1979)。 Por sua vez MAYERS et alii (1979) reportam que o novo sistema pode oferecer ao agricul tor valiosas vantagens econômicas, permitindo-lhe reduzir o volume de água na pulverização e tambèm porque melhora a oportunidade de uso dos herbicidas (COTTON GROWER, 1980; TAY LOR et alii, 1976; MATTHEWS, 1978)。 
2.6. Formulações requeridas para a aplicação com o pulverizador de gotas uniformes

Nos primeiros trabalhos de pesquisa, aplicando herbicidas com baixos volumes, BARZEE e STROUBE (1972) su geriram que as formulações pó-molhável, não seriam apropriadas para tais aplícações. Para ROBINSON (1978) a aplicação dos pó-molháveis com discos rotativos, necessita de pesquisa adicional. Us herbicidas pó-molháveis poderiam não ser aplicados a volumes menores que 20 l/ha,porque aconteceria se dimentação e freamento dos discos rotativos. Trabalhos sobre a influência das formulações são necessários (HAROLD e CHAIRMAN, 1979). Também é sugerido que o comportamento de cada composto e suas misturas, quando aplicados a baixos vo lumes de aplicação, deveriam ser mais pesquisados (BRUGE e JEAN, 1978; GENTET, 1978; CUSSANS e TAYLOR, 1978)。

Por outro lado, mudanças na formulação influenciam grandemente o comportamento das pulverizações em baixos volumes, pois podem ser afetadas a retenção, a aspersão, a molhabilidade, o grau de contato da folha com 0 ingrediente ativo,e a penetração dentro da planta (ROBINSON, 1978).Tam bém mudanças na viscosidade alteram o tamanho das gotas produzidas pela pulverização.

Algumas formulações comerciais de herbicidas, são adequadas para aplicações a baixo volume, porém,em outros casos, não estão disponíveis, e o seu uso pode ficar limi 
tado pelo tamanho das gotas e pela flora das plantas daninhas. Mudando a formulação destes herbicialas é possível que o seu comportamento melhore (ROBINSON, 1978).

As formulações sais, esteres, no caso de 2,4 -D atuam tão bem quando aplicadas em óleo como em ảgua e tem seu uso aprovado com aplicadores de gotas uniformes. o único pó molhável aprovado nestes tipos de aplicações é o propy zamida, reporta MAKEPEACE (1978) • Já para as triazinas e uréias, as suspensões concentraỏas têm sido satisfatoriamente a plicadas de tal forma que diversas companhias as produzem (HAROLD E CHAIRMAN, 1979).

2.7. Comportamento dos herbicidas aplicados em pré-emergência com equipamento convencional vs. aplicador de gotas uniformes.

A eficiência dos herbicidas pré-emergentes, quando aplicados a baixos volumes e com aplicação de gotas uniformes, tem sido pesquisada e discutida durante vários anos. Assim, BARZEE e STROUBE (1972) encontraram nas comparações feitas para os dois sistemas, que herbicidas solúveis em água e concentrados emulsiomáveis que não precisam de incorporação ao solo podem ser aplicados com resultados semelhantes aos obtidos com 187 1/ha do equipamento convencional. 
LOR (1981), têm reportado bons resultados com simazine quando aplicado por pulverizadores rotativos, manual e com volumes de aplicação tão baixos como 10 l/ha, sendo a perda da eficiência biológica do herbicida sem maior importância.

TAYLOR E MERRITT (1974) trabalhando com barban e triallate aplicádos em pré-emergência, usando aplicador de gotas uniformes e volumes de 5-20 1/ha, na cultura de cevada, verificaram que não houve perãas significativas do efei to biológico para o aparelho de gotas uniformes. MAY e AYRES (1978) chegaram às mesmas conclusões depois de pesquisar - comportamento dos herbicidas linuron, chloroprophan'e sima zine, os quais foram aplicados em solo orgânico e em doses sub-ótimas. O controle total das plantas daninhas foi similar para os dois equipamentos, embora existam indicações que a aplicação de gotas uniformes pode, as vezes, variar em seus efeitos entre espécies de plantas daninhas.

Misturas de carbetamide/dimefuron em formulação pó-molhável, foram testadas por ROBINSON (1978) na cultura da colza, onde os controles de folha-larga em doses equivalentes foram quase tão eficientes, quanto aqueles obtidos com 300 l/ha。 Porém,o controle das plantas daninhas gramineas com baixos volumes de aplicação foi mais baixo.

MC CAVISH (1973) usando os herbicidas propyzanide, atrazine e misturas de atrazine-cyanazine em plantações de conifferas com os cỏis tipos de equipamentos, obteve controles aceitáveis dependendo das espécies granineas pre- 
sentes. As formulações empregadas foram suspensão concentra da e pó-molhável.

Segundo MAKEPEACE (1978), o herbicida propyzamide é o ủnico pó-molhável aprovado para o controle de plantas daninhas em florestas e usanäo-se o aplicador de gotas uniformes. De acordo com este mesmo autor, recentes expyerimentos tèm indicado que as formulações suspensão concentrada de algumas triazinas e uréias substituidas têm sido ap̣licadas satisfatoriamente através de equipamento de gotas uniformes.

MAYERS et alii (1979) observaram uma redução no controle das plantas daninhas, o qual poderia ser devido à Laixa deriva apresentada pelas gotas produzidas pelo pulve rizador de gotas uniformes. Porém, TAYLOR (1979) através de observações durante vários anos em experimentos de campo, conclui que não há perda na eficiência quando se aplicam a volumes abaixo de $201 / \mathrm{ha}$.

Para TAYLOR (1981), não existe uma razão óbvia pela qual os herbicidas aplicados ao solo possam ser afe tados pela técnica de aplicação de gotas uniformes.

\section{BOLETIM INFORMATIVO HATSUTA (1982) reporta}

uma série de experiências realizads por diversos pesquisadores nos Estados Unidos da Anẻrica do Norte. Assim, J。 Eveland e W. Duke realizaram comparações dos herbicidas trifluralin, metribuzin, metolachlor, cyanazine, atrazine, a alachlor, liniron e outros, que foram aplicados nas culturas de 
milho è soja tanto em pré-emergência como em pré-plantio incorporado. A aplicação com volumes de 9, 14 e 28 1/ha foi tão efetiva quanto aplicações colı 187 l/ha no controle das plantas daninhas.

A aplicação da mistura de trifluralin + metri buzin en pré-plantio-incorporado, com o aplicador de gotas uniformes, apresentou o mesmo comportamento que o convencional quando utilizada na cultura da soja, e a vazão parece não ter sido afetada pelas diferentes misturas aplicadas com o mesmo volume. Nos últimos cinco anos, os aplicadores de gota uniforme têm sido testados nos Estados Unicios e Canacá e os resultados indicam que baixos volumes de aspersão podem ser utilizados igualmente nos equipamentos convencionais tan to com os pré-emergentes como os pós-energentes (WILTSE, 1983)。

Nos resultados dos últimos anos, herbicidas como alachlor, metolachlor e pendimethalin com pré-emergência e pré-plantio incorporado respectivamente, aplicados na cultura do milho, foram iguais no controle das plantas daninhas (SLACK e WITT, 1983). Na cultura da soja os resultados também foram semelhantes quando se usaram alachlor + metribuzin (SCOTT e KAPUSTA, 1983); e o controle de plântulas de capimmassambará com o herbicida metolachlor foi igual com os clois tipos de equipamentos (BARRENTINE e HURST, 1983). 
controles das plantas ảaninhas com $\circ$ aplicador de gotas uniformes, abaixo daqueles obtidos pela pulverização convencional.

Entre esses temos o de FISCHER : e TASISTRO (1930), os quais acharam que o herbicida methabenzthiazuron, quando aplicado com equipamento de gotas uniformes e volumes de 9 e 24 l/ha na cultura da cevada, teve um controle 20\% a menos que o obtido com 215 l/ha.

Sob condições de seca, herbicidas como metolachlor, alachlor e pendimenthalin aplicados com pulverizador de gotas uniformes em prēmemergência tiveram menor eficiência que o convencional (SLACK e VITT, 1983). A adição de óleo na aplicação de trifluralin em prémplantio-incorporacio, reportam BARRENIINE e HURST (1983), para o controle de plantulas de capim-massambará, não foi satisfatōrio e foi significativamente menor que o convencional.

Segundo PHILLIPS (1979), o pulverizador de go tas uniformes apresenta falhas como o entupimento devido à filtragem inadequada e desuniformidaảe das faixas de aplica ção。

2.8. Comportamento dos herbicidas aplicados em pös-emergência com o equipamento de gotas uniformes

As aplicações em pós-emergência tè̀m mostrado. resultados variáveis com alguns herbicidas, sendo o controle 
as vezes inferior à aplicação convencional ou então nitida mente superior.

No início do desenvolvimento do pulverizacior de gotas uniformes, existiu a apreensão de que 0 incremento na retenção dos herbicidas pela cultura resultaria em um pubre controle das plantas daninhas e aumentaria a possivel in júria na cultura. Pesquisas posteriores têm respondido ell,grande parte, as dúvidas apresentadas.

Uma das experiências iniciais, usando baixos volumes e com equipamentos de gotas uniformes, foi a aplicação de 2,4-D e 2,4,5-T atravẻs do "Ulva", para controlar plantas daninhas lenhosas en silvicultura. Vários anos : de uso provaram a eficiência destes herbicidas em .. aplicações com gotas uniformes. Formulações especiais de 2,4,5-T são recomendadas pela Weed Research Organization (CUSSANS e TAYLOR, 1978): e a Comissão Florestal na Inglaterra aprova o uso em florestas (HAROLD e CHAIRIIAN, 1979).

As aplicações de herbicidas hormonais,como 0 2,4-D, em culturas anuais (TAYLOR e MERRITT, 1974), o dichlorprope (TURNER e LOADER, 1978), ou O MCPA (MERRITT e TAY LOR, 1977), foram tão ativos como quando pulverizados com equipamento convencional.

Resultados semelhantes para $\circ$ 2,4,5-T são citados por COMBELLACK et alii (1978), tendo-se comportado igualmente as formulações sal ou ester, no controle de plan- 
tas herbáceas de folha-larga. Porém, os resultados sobre plantas daninhas lenhosas indicaram claramente que a técnica de gotas uniformes é viāvel para algumas espécies e não para outras. Fato semelhante é mencionado por McGARVEY e BALS (1979) com a espécie Passiflora incarnata, a qual não foi controlada satisfatoriamente pelo 2,4-D amina, pulverizado con a técnica de gotas uniformes; tendo-se,para as outras es pécies, um controle excelente: 。

Misturas de dicamba com mecoprop ou MCPA, aplicadas com os dois tipos de equipamentos, mostraram não existir maior diferença no controle das plantas daninhas de folha-larga (Ayres citado por TAYLOR, 1981). Estas mesmas misturas, aplicadas nas doses recomendadas, apresentaram 0 mesmo nivel de controle quando foram aplicadas com 45 1/ha de calda. As doses maiores da mistura, aplicadas em volumes de calda de 5 l/ha, não forañ satisfatórias, porēm, nas doses baixas o controle foi às vezes melhor com o pulverizador de gotas uniformes, como reportam AYRES e MERRITT (1978).

Condições de seca podem ter influído explica HARRIS (1978), pois a mistura de dicamía + mecoprop apresen tou controle menor em relação ao obtido com 340 l/ha.

Existe o consenso geral de que os herbicidas sistênicos podem atuar tão bem quando aplicados com baixos volumes pelo aplicador de gotas uniformes, porém os herbicicas de contato não atuam bem com volumes inferiores a 11 l/ 
ha (HAROLD e CHAIRMAN, 1979). Segundo PANS (1978), para o uso adequado dos herbicidas de contato, pulverizados com o aplicador de gotas uniformes, o tamanho das gotas deverão ser menores do que para os sistêmicos, usando-se a mesma dose e viscosidade recomendadas.

Em contraste com os herbicidas hormonais, os herbicidas de contato como o ioxynil, foram um pouco menos eficientes ao serem aplicados com equipamento de gotas uni formes. Ainda,misturas contendo um componente sistêmico como dichlorprope, foram menos eficientes quando aplicadas a baixos volumes, presumivelmente devido a que o efeito de con tato de ioxynil e bromoxynil foi parcialmente perdido (Ayres citado por TAYLOR, 1981). A mistura destes últimos herbicidas só teve efeito satisfatório com volumes de aplicação de 45 l/ha e comparáveis com aquele de 224 l/ha, porêm, com volume de 10 e $51 / \mathrm{ha}$, 0 controle foi insatisfatório, segundo AYRES E MERRITT (1978).

Para PHILLIPS et alii (1981), os resultados obtidos com misturas de bromoxynil, mecoprop e ioxynil, mostram que o nível de controle das plantas daninhas através do aplicador de gotas uniformes pode ser melhorado pelo uso de gotas com diâmetro ao redor de $170 \mu \mathrm{m}$, e volumes de calda en tre $40-60 \mathrm{l} / \mathrm{ha}$, pois com isto é possỉvel obter-se uma maior cobertura pelas gotas.

Os resultados com herbicidas para controlar plantas daninhas gramíneas variam de uma forma similar. Al- 
guns, tais como barban, têm dado controles aceitáveis quando aplicados com pulverizador de gotas uniformes, reportam LAKE e TAYLOR (1974). Porém WILSON e TAYLOR (1978) obtiveram bai xos controles de Avena fatua L. com volumes de aplicação de 5 e 10 l/ha. Já com 45 l/ha,o controle só foi debilmente in ferior ao do convencional.

O herbicidá difenzoquat não tem tido resultados satisfatórios no controle de gramíneas como A. fatua, com volumes de calda abaixo de 20 l/ha (TURNER e LOADER, 1978). Só com 40 l/ha o controle foi semelhante ou melhor que o con vencional, segundo Wilson citado por TAYLOR (1981), WILSON e TAYLOR (1978), MAYES e BLANCHARD (1978). O controle com 225 l/ha foi mais consistente que a aplicação de gotas uniformes, reporta AYRES (1978)。

Os controles baixos com volumes de aplicação abaixo de 20 1/ha podem ser devidos, segundo MAYES e BLANCHARD (1978), ao fechamento da cultura u que evitaria o contato do produto aplicado com as plantas daninhas.

2.9. Comportamento de outros herbicidas sistêmicos aplica dos com o pulverizador de gotas uniformes

o glyphosate é um dos herbicidas que demonstra a melhor eficiência da pulverização pela técnica de gotas uniformes. pesquisas reportam controles pelo menos 
iguais àqueles obtidos pela aplicação convencional, segundo BRUGE e JEAN (1978). Resultados támbém semelhantes no controle de gramineas perenes, como Agropyron repens e Cynodon dactylon, têm sido reportados por MOREL (1981), ou como no ca so de plantas daninhas anuais de folha-larga em café,citados por CRUZ et alii (1983).

Para o caso de plantas daninhas anuais, os di ferentes pesquisadores têm reportado uma atividade maior do glyphosate. Doses tão baixas como $0,06 \mathrm{~kg} / \mathrm{ha}$ controlaram sa tisfatoriamente o caruru (BOLETIM INFORMATIVO HATSUTA, 1982)。 Com doses de 0,125 kg/ha, Me GARVEY e BALS (1979) encontra ram maior eficiência sobre plantas daninhas anuais. Na cultura de café, FOLONI e PRADO FILHO (1983) com doses $50 \%$ meno res que o convencional, obtiveram controles mais eficientes, quando aplicadas com o pulverizador de gotas uniformes. PURISSIMO (1982) considera que as pesquisas de campo mostram possibilidade de redução da dose de glỳphosate aplicado com este novo equipamento, em gramineas anuais, picão-preto e carrapicho-rasteiro.

Inclusive misturas de glyphosate com outros herbicidas, quando aplicadas com pulverizador de gotas uniformes, deram melhores controles das plantas daninhas Setaria Gaberii e Ipomoea purpurea, que a aplicacão convencional, co mo reportam SLACK e WITT (1983).

No controle de plantas daninhas perenes, tam- 
bém fica evidente a maior atividade das doses mais baixas do glyphosate quando aplicadas pela técnica de gotas uniformes, como no caso do Agropyron repens, com doses de 0,56 e 1,12 $\mathrm{kg} / \mathrm{ha}$ (CHARLOTE e BURRILL, 1979; TURNER e LOADER, 1978)。

Para controlar o capim-massambará, há pouca vantagen em aplicar doses maiores que $1,12 \mathrm{~kg} / \mathrm{ha}$ com $\circ$ aplicador de gotas uniformes, reportam Mic GARVEY e BALS (1979).

Pesquisadores como BRUGE e JEAN (1978), UTULU e AKOBUNDU (1981), através de pesquisas na aplicação de glìyphosate com este novo equipamento, acharam que,inclusive, foi possivel reduzir à metade da dose e ainda obter bons controles.

Para WILTSE (1983), este herbicida tem sido mais eficiente quando aplicado pela técnica de gotas uniformes. Pesquisas nas quais o glyphosate foi aplicado com baixos e altos volumes através de bicos hidráulicos (DAVIES e TAYLOR, 1981), mostraram que o maior volume de calda apresen tou o pior controle. Experimentos subsequentes indicam que a perda de atividade do gly:phosate pode ser atribuída ao efeito do volume sobre os niveis de surfactante.

Casseley et alii, citado por TURNER e LOADER (1978), sugerem que a melhor atividade do glyphosate com bai xos volumes de aplicação pode ser devida a uma melhor retenção das gotas na superfície das folhas, maior concentração de herbicida nas gotas, como também sugere BALS (1978), e pe- 
las diferenças da superfície da folha molhada pela pulverização. E concebivel que a aspersão de gotas controladas entra em contato somente com uma pequena porção da folha e poderia ter efeito mais lento ou menos drástico sobre o metabolismo e translocação, em comparação com volumes altos de aspersão. Todavia, não é conhecido se tanto o volume de aplicação como o tamánho de gotas são importantes; porém,. o volume sem dūví da é importante. Assim, em grama-seda a translocação foi mais lenta quando se usaram altos volumes de aspersão (SALINAS, 1981)。

2.10. Comportamento de herbicidas novos aplicados pelo pulverizador de gotas uniformes

Pesquisas com herbicidas sistêmicos recentemente desenvolvidos como o Dowco 453 e fluazifop-butil,gra minicidas seletivos inclusive para perenes (ABERNATHY et alii, 1983), também mostram resultados positivos quando aplí cados com pulverizadores de gotas uniformes.

De acordo com DOLL et alii (1983) o Dowco 453 e fluazifop-butil foram muito ativos contra Agropyron repens L., nas doses de $0,38 \mathrm{~kg} / \mathrm{ha}$ e $0,25 \mathrm{~kg} / \mathrm{ha}$ respectivamente, tendo-se comportado melhor com carregadores oleosos e pulverizados com equipamento de gota uniforme. Por sua vez CRANMER e DUKE (1983) acharam resultados semelhantes usando como agente veicular óleo de soja com os herbicidas fluazi- 
fop-butil e sethoxydin, em testes com esta mesma planta dani nha. No controle de plantas daninhas anuais como Echinochloa crus-galli $L_{\circ} ;$ dose de $0,028 \mathrm{~kg} / \mathrm{ha}$ de sethoxydin apli cado em 9,34 l/ha, deram controles superiores a $80 \%$, e quando esta mesma dose foi aplicada com o equipamento convencional, o controle foi de somente $13 \%$. Os autores indicam que nas doses maiores, para este herbicida, estas diferenças não foram öbvias.

Para SLACK e WITT (1983), os herbicidas fluazi fop-butil e Dowco-453, quando apliaados nas doses recomendadas comercialmente, não mostraram diferenças no controle sobre gramineas anuais, e as doses reduzidas resultaram em con troles reduzidos para os dois tipos de equipamentos. 


\section{MATERIAIS E METODOS}

\subsection{Locais dos experimentos}

A presente pesquisa foi realizada através de experimentos com herbicidas aplicados pelo pulverizador de gotas uniformes e pelo pulverizador convencional, conduzidos sob condições de campo, e também em casa-de-vegetação. Para a condução destes experimentos foram utilizadas duas áreas experimentais situadas nos municípios de Piracicaba e Santa Bárbara D'Oeste, no Estado de são Paulo.

Os experimentos com herbicidas aplicados em pré-emergência na cuitura do milho, foram conduzidos junto ao Sítio Invernada, no Miunicípio de Santa Bárbara, e à Fazenda Areião,do Departamento de Solos, Geologia e Fertilizantes da Escola Superior de Agricultura "Luiz de Queiroz". O experimento com herijicidas pré-emergentes em soja foi conduzido na área experimental do setor de Horticultura do Departamen- 
to de Agricultura e Horticultura da Éscola Superior de Agricultura "Luiz de Queiroz". No município de Santa Bárbara, foi conduzicio o experimento com herbiciclas aplicados em pósemergência na grama-seda, o qual foi repetido em duas oportü nidades, nos anos de 1983 e 1984 .

Na casa-de-vegetação do Departamento de Agri-s cultura e Horticultura da ESALQ-USP foram conduzidos os experimentos com os herbicidas aplicados em pós-emergência na grama-seda。

O clima da região de Piracicaba - SP, é Cwa, pela classificação de KÖPPEN (SETZER, 1966), ou seja, mesotérmico úmido subtropical com inverno seco. As informações agrometeorológicas do local foram fornecidas pelo Departamen to de Física e Meteorologia da E.S.A. "Luiz de Queiroz", quais sejam: logitude $47^{\circ} 38 \cdot 00 " \mathrm{~W}$; latitude $22^{\circ} 42 \cdot 9 " \mathrm{~S}$; altí tude $540 \mathrm{~m}$; as médias diárias de temperatura, precipitação e umidade relativa do ar, durante o transcorrer dos experimentos constam nas Tabelas 46 a 56 do Apêndice.

O clima para o município de santa Bárbara D'Oeste è o mesmo que para Piracicaba, segundo SETzER (1966), pois só estão distantes $30 \mathrm{~km}$ em linha direta. Porérn,a situação geográfica és longitude $47^{\circ} 25^{\prime} 00^{\prime \prime} \mathrm{w}^{\prime}$ latitude $22^{\circ} 45^{\prime}$ $00 " \mathrm{~s}$; altitude $575 \mathrm{~m}$. As méciias diárias de temperatura e precipitação durante o transcorrer dos experimentos, constam nas Tabelas 47, 48, 49, 54, 55 e 56 do Apêndice. 
3.2. Experimentos de campo com herbicidas aplicados em prēe- emergência

3.2.1. Classificação e anālises dos solos

O experimento com herbicidas aplicados en préemergência en milho, localizado no município de Santa Bárbara D'Oeste, foi instalado em um solo Podzólico Vermelho-Amarelo, cujas características físicas e químicas encontram-se na Tabela 1 。

o outro experimento com milho, foi instalado em uma Terra Roxa Estruturada série "Luiz de Queiroz" da Fazenda "Areião" do Departamento de Solos,Geologia e Fertilizantes. As características químicas e físicas encontram-se também na Tabela 1 .

Para o experimento com soja, o solo onde foi instalado correspondeu a Terra Roxa Estruturada da série "Luiz de Queiroz", cujas características físicas e químicas são encontradas na Tabela 1 .

\subsubsection{Preparo do solo}

Para os ensaios de campo com soja e milho,da Fazenda "Ảreião", o preparo foi o normal, com uma aração e duas gradagens.

No experimento com milho,ern Santa

Bårbara D'Oeste, no ano anterior esta ārea estava ocupada com cana, 


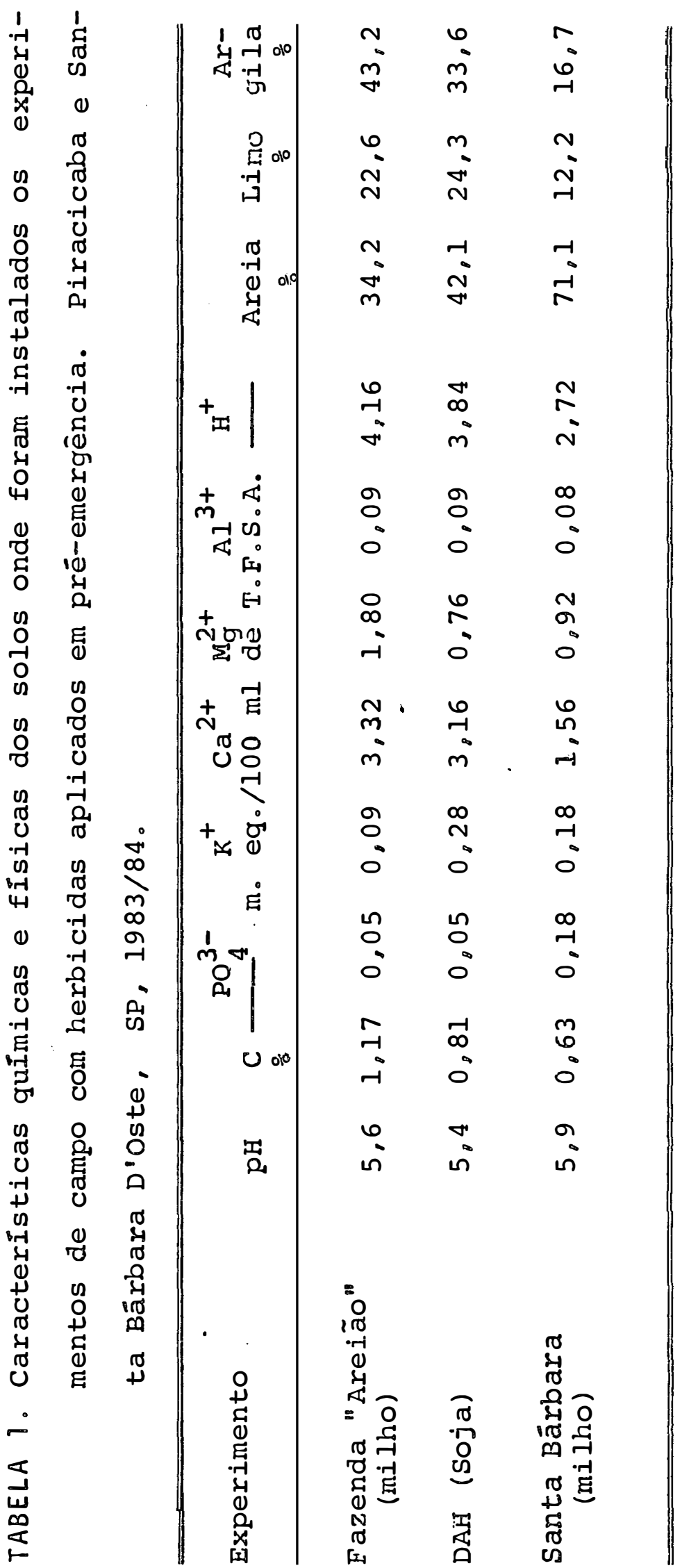


sendo o preparo realizado através de uma aração profunda para a eliminação da soqueira, e depois mais duas gradagens.

\subsubsection{Cultivares utilizados}

Os cultivares de milho plantados foram: Agroceres-301 e Agroceres-401, para Santa Bárbara D'Oeste e Fazenda Areião respectivamente. O cultivar de soja utilizado foi o Paraná.

\subsubsection{Equipamentos de aplicação}

Foi utilizado um pulverizador a pressão constante $\left(\mathrm{CO}_{2}\right)$ com barra de 1,5 metros de comprimento, com $4 \mathrm{bi}$. cos "Teejet" 8003 em leque, distânciados 50 cm um do outro, trabalhando a pressão de $2,1 \mathrm{~kg} / \mathrm{cm}^{2}$. O depósito de gás era de $3 \mathrm{~kg}$, e o depósito de calda de 3,7 l. 0 consumo de calda para os três experimentos foi de 250 l/ha, no caso da pulverização convencional.

o equipamento utilizado para a aplicação de gotas uniformes foi o pulverizador rotativo "Microherbi" cos tal, equipado com motor elétrico acionado por 8 pilhas de 1,5 volts, somando os 12 volts que giram o disco atomizador a $2.200 \mathrm{rpm}_{8}$ formando gotas com diâmetro médio de $250 \mu \mathrm{m}$. 0 depósito de calda era de 121 . 
O aparelho apresenta 4 bicos de regulagem de vazão, com as cores vermelho, amarelo, azul e laranja, permi tindo respectivamente desde uma menor para maior vazão. A es colha dos bicos foi efetuada de acordo com a velocidade e vis cosidade do defensivo utilizado. O cabeçote permaneceu a uma altura de $20 \mathrm{~cm}$ da faixa de deposição, que foi de 1,4 m de largura. A pressão foi de aproximadamente $600 \mathrm{~mm}$ de colu na de água. O volume de calda empregado foi de 32 1/ha.

\subsubsection{Delineamento experimental}

o delineamento experimental adotado para todos os experimentos de campo foi em blocos casualizados, em esquema fatorial $4 \times 2 \times 2$, com 4 repetições, ou seja 4 herbicidas, 2 doses e 2 equipamentos, totalizando 17 tratamentos incluindo uma testemunha. Para cada herbicida e equipamento de aplicação foram aplicados uma dose menor e outra maior, que são as recomendadas comercialmente. As parcelas para os experimentos com milho continham seis linhas de 7,0 $\mathrm{m}$ espaçadas de $1,0 \mathrm{~m}$ com um total de $42,0 \mathrm{~m}^{2}$.

As parcelas para o experimento com soja continham seis linhas de $6,0 \mathrm{~m}$, espaçadas de $0,5 \mathrm{~m}$, com um total de $18,0 \mathrm{~m}^{2}$.

A ârea total para cada experimento com milho foi de $2,856 \mathrm{~m}^{2} \mathrm{e}$, para a soja, de $1,224 \mathrm{~m}^{2}$. 


\subsubsection{Herbicidas utilizados}

Para os experimentos com milho utilizaram-se os seguintes herbicidas: atrazine, misturas de atrazine + metolachlor, atrazine + alachlor e atrazine + simazine. Para o experimento com soja empregaram-se os herbicidas alachlor, cyanazine, metribuzin e pendimethalin.

As principais características citadas dos her bicidas utilizados, estão baseadas no livro "Herbicide Handbook" da Weed Science Society of América (1980), assim ..como nos boletins técnicos das companhias produtoras.

\section{a. atrazine}

Formulação comercial utilizada: Gesaprim Ingrediente ativo: 2 - cloro - 4 - etilamino6-isopropilamino - s-triazina.

Características principais: A formulação comer cial utilizada foi a suspensão concentrada ("flowable") com 50용 de ingrediente ativo (atrazine)。A solubilidade em ăgua do atrazine é $33 \mathrm{ppm}$ a $27^{\circ} \mathrm{C}$, e a pressão do vapor a $20^{\circ} \mathrm{C}$ é $3 \times 10^{-7} \mathrm{~mm}$ de $\mathrm{Hg}$. E um herbicida de translocação predominante apoplástica, com algưma ação foliar, controlando plantas daninhas dicotiledôneas e monocotiledôneas, através da inibição da fotossíntese. E recomendado para aplicação em prê-emergência ou em pôs-emergência com as plantas daninhas 
pequenas. Apresenta lixiviação limitada devido à adsorção, e normalmente não é encontrado abaixo de $30 \mathrm{~cm}$ em quantidades detectáveis, mesmo após o uso contínuo no mesmo local. $\mathrm{A} \mathrm{DL}_{50}$ oral agúda, para ratos, é de $3.080 \mathrm{mg} / \mathrm{kg}$ de peso vivo.

b. arachlor

Formulação comercial utilizada: Laço CE Ingrediente ativo: 2-cloro-2 ${ }^{\prime}, 6^{\circ}$-dietil-iv

(metoximetil) acetanilida.

Características principais: a formulação comercial utilizada foi a concentrada emulsionável (CE) com 48\% de ingrediente ativo (alachlor). A solubilidade em água do alachlor é de $148 \mathrm{ppm}$ a $25^{\circ} \mathrm{C}$, e a pressão de vapor a $25^{\circ} \mathrm{C}$ é: $2,2 \times 10^{-5} \mathrm{mrn}$ de Hg. Ên herbicida de translocação predo minante apoplástica, controlando plantas daninhas dicotiledô neas e monocotiledôneas, sendo seu efeito mais acentuado sobre as ủltimas , atravês da inibição na síntese de proteínas. coma qual o crescimento fica retido. E recomendado .. para aplicação em prē-emergência e em mistura de superfície. Apre senta lixiviação reduzida pela sua adsorção aos colóides do solo e sua relativa insolubilidade em água.

A DL. 50 aguida, para ratos, è de $1.800 \mathrm{mg} / \mathrm{kg}$ de peso ...vivo. 


\section{o. cyanazine}

Formulação comercial: Bladex 50

Ingrediente ativo: 2-(4-cloro-6-etilamino-striazina-2-ilamino)-2- metil-propionitrila

Características principais: a formulação comercial empregada foi a suspensão concentrada (S.C) com 50\% de ingrediente ativo (cyanazine). A solubilidade em água do cyanazine é $171 \mathrm{ppm} \mathrm{a} 25^{\circ} \mathrm{C}$, e a pressão de vapor a $20^{\circ} \mathrm{C}$ é $1,6 \times 10^{-9} \mathrm{~mm}$ de $\mathrm{Hg}$.

E um ḩerbicida de translocação predominantemente apoplástica, controlando plantas daninhas dicotiledôneas principalmente, e monocotiledôneas através da inibição da fotossintese. E recomendado para aplicação em pré-emergência ou em pós-emergência com as plantas daninhas pequenas. Apresenta lixiviação parcialmente influenciada pela sua solubilidade em água, porém o grau de adsorção varia de acordo com a umidade e textura do solo. $\mathrm{A} \mathrm{DL}_{50}$ oral aguida, para ratos,é de $334 \mathrm{mg} / \mathrm{kg}$ de peso vivo.

\section{d. metribuzin}

Formulação comercial utilizada: Lexone Ingrediente ativo: 4-amino-6-t-butil-3- metiltio $-1,2,4-\operatorname{triazina}-5-(4 \mathrm{H})$ one 
Caracteristicas principais: a formulação comercial utilizada foi a pó-molhável (P.M.), com $70 \%$ de ingre diente ativo (metribuzin). A solubilidade em água do metribuzin é de $1220 \mathrm{ppm}$ a $20^{\circ} \mathrm{C}$, e a pressão de vapor a $20^{\circ} \mathrm{C}$ é me nor que $10^{-5} \mathrm{~mm}$ de $\mathrm{Hg}$. E um herbicida de translocação predo minante apoplástica, com alguma ação foliar, controlando plantas daninhas dicotiledôneas principalmente, e monocotile dôneas através da inibição da fotossintese. E recomendado para aplicação em pré-emergência ou em pós-emergência em cen tas culturas, quando as plantas daninhas estiverem pequenas. Apresenta lixiviação alta em solos arenosos, sendo moderadamente adsorvido em solos com alto conteúdo de argila.

$A \mathrm{DL}_{50}$ oral aguda, para ratos, $\bar{e}$ de $2.200 \mathrm{mg} /$ $\mathrm{kg}$ de peso vivo.

\section{e. pendimethalin}

Formulação comercial utilizada: Herbadox 500E Ingrediente ativo: $\mathbb{N}$-(1-etilpropil)-3-4-dimetil, 2,6-dinitrobenzenamina.

Características principais: A formulação comercial utilizada foi a concentrada emulsionável (C.E.) com $50 \%$ de ingrediente ativo (pendimethalin). A solubilidade em água do peradimethalin é 0,3 ppm a $20^{\circ} \mathrm{C}$, e a pressão de vapor a $25^{\circ} \mathrm{C}$ é $3 \times 10^{-5}$ de $\mathrm{Hg}$. Um herbicida de translocação pre dominantemente apoplástica, controlando plantas daninhas mo- 
nocotiledôneas principalmente e algumas dicotiledôneas, atra vés da inibição da divisão celular. E recomendado para apli cação em pré-plantio incorporado ou em pré-emergência. Aprẹ senta lixiviação baixa devido à adsorção forte pelos colóides do solo, e sua baixíssima solubilidade em āgua. A $\mathrm{DL}_{50}$ oral agůda para ratos é de $1.250 \mathrm{mg} / \mathrm{kg}$ de peso vivo.

\section{f. atrazine + alachlor}

Formulação comercial utilizada: Boxer

Ingrediente ativo: 2 cloro-4-etilamina,6- iso propilamino-s-triazina+2-cloro-2", 6' dietil-n (metoximetil) acetanili. da.

Características principais: a Formulação comercial utilizada foi a suspensão concentrada ('flowable')com $300 \mathrm{~g} / \mathrm{l}$ de alachlor e $180 \mathrm{~g} / \mathrm{l}$ de atrazine. As características físicas e toxicológicas destes dois herbicidas jâ foram indicados nos sub-itens a e b.

Estes dois herbicidas agen de uma forma combi nada. O alachlor é adsorvido principalmente pelo epicotilo (ou coleoptilo nas monocotiledôneas) atuando sobre ás plantas daninhias no momento da Germinação e desenvolvimento inicial. As plantas daninhas que emergirem absorvem . atrazine via radicular matando-as quando emergidas. Nas ... espécies suscetíveis o alachlor inibe a divisão e elongação celular e, consequentemente, o crescimento. 
O- atrazine atua como inibidor da fotossintese. O efeito mais acentuado do alachlor sobre gramineas, e do atrazine sobre as folhas-largas, assegura um amplo espectro de controle.

\section{g. atrazine + simazine}

Formulação comercial utilizada: Triamess 50 FW Ingrediente ativo: (atrazine)-2-cloro-4-(etila mino)-6-(isopropilamino)-S-triazi $\mathrm{na}+$ (simazine) 2-cloro-4,6- bis(etilamino)-s-triazina.

Caractèrísticas principais: a formulação comercial utilizada foi a suspensão concentrada (Flowable) com $250 \mathrm{~g} / \mathrm{l}$ de atrazine e $250 \mathrm{~g} / \mathrm{l}$ de simazine. A solubilidade em ägua a $20^{\circ} \mathrm{C}$ do simazine é $5 \mathrm{ppm}$, sendo a pressão de vapor a $20^{\circ} \mathrm{C}, 6,1 \times 10^{-9} \mathrm{~mm}$ de $\mathrm{Hg}$.

Ambos os herbicidas têm translocação apoplāstica edepois de absorvidos pelo sistema radicular são levados até a folha onde inibem a fotossíntese. A mistura é recomendada para aplicação em prē-emergência para controle de plantas daninhas dicotiledôneas e monocotiledôneas. Apresenta lixiviação limitada devido à aảsorção e baixa solubili dade, especialmente do simazine.

A $D_{50}$ oral aguda,para ratos, do simazine ë $5.000 \mathrm{mg} / \mathrm{kg}$ de peso vivo. 
h. atrazine + metolachlor

Formulação comercial utilizada: Prinextra Ingrediente ativo: 2-cloro-4-(etilamino)-6isopropilamino)-S-triazina+2-etil-6-(metilN-l-metil-metoxietil)-cloroacetanilida.

Caracteristicas principais: A formulação comercial utilizada foi a suspensão concentrada ("Flowable") com $300 \mathrm{~g} / 1$ de metolachlor $+200 \mathrm{~g} / 1$ de atrazine. A solubilidade em água do metolachlor a $27^{\circ} \mathrm{C}, \bar{e} 530 \mathrm{ppm}$ e a pressão de vapor, a $20^{\circ} \mathrm{C}$ é de 1 , $3 \times 10^{-5} \mathrm{~mm}$ de $\mathrm{Hg}$. Os componentes ativos do Primextra atuam sobre as plantas daninhas sensiveis segundo as propriedades do grupo químico a que per tencem, através da inibição da germinação, no caso do metolachlor,e da inibição da fotossíntese, no caso do atrazine. Normalmente é aplicado em pré-emergência controlando plantas daninhas mono e dicotiledôneas anuais. A lixiviação é considerada média no solo pelas características físico-quími cas dos seus componentes.

$A \mathrm{LD}_{50}$ oral, em ratos, para metolachlor é 2.780 $\mathrm{mg} / \mathrm{kg} \cdot \mathrm{de}$ peso vivo.

3.2.7. Tratamentos

Os tratamentos resultantes das misturas entre herbicidas, doses e equipamentos, tanto para o milho como pa 
ra a soja encontram-se nas Tabelas $2 \in 3$.

\subsubsection{Semeadura}

O experimento com milho, em Santa Bárbara, in $\underline{\underline{s}}$ talado numa plastação comercial, foi semeado a tração animal, em 26.10.83. Para o milho da Fazenda Areião e a soja, a semeadura foi realizada com plantadeiras tracionadas mecanicamente em 28.10 .83 e 13.12 .83 , respectivamente. o espaça mento do milho na Fazenda Areião foi de 1,0 m entre-linhas e com densidade de 8-9 sementes por metro. Em Santa Bárbara D'Oeste o espaçamento entre-linhas foi igual e com 7-8 semen tes por metro de sulco. Foram utilizadas 50 sementes de soja por metro as quais foram tratadas previamente com inoculante, na dose de $300 \mathrm{~g} / 100 \mathrm{~kg}$ de sementes.

\section{2 .9 . Adubação}

A adubação da soja foi feita na semeadura, na dose de 0-80-30 kg/ha de NPK, respectivamente.

Para o milho em Santa Bárbara D Oeste, a dose de adubação foi de 20-60-30 kg/ha de NPK, sendo a metade aplicada na semeadura a a outra metade em cobertura.

Para o experimento na Fazenda Areião, a dose de adubação foi de 15-60-30 de NPK. na semeadura, e $45 \mathrm{~kg} / \mathrm{ha}$ de $\mathrm{N}$ na cobertura na prefloração. 


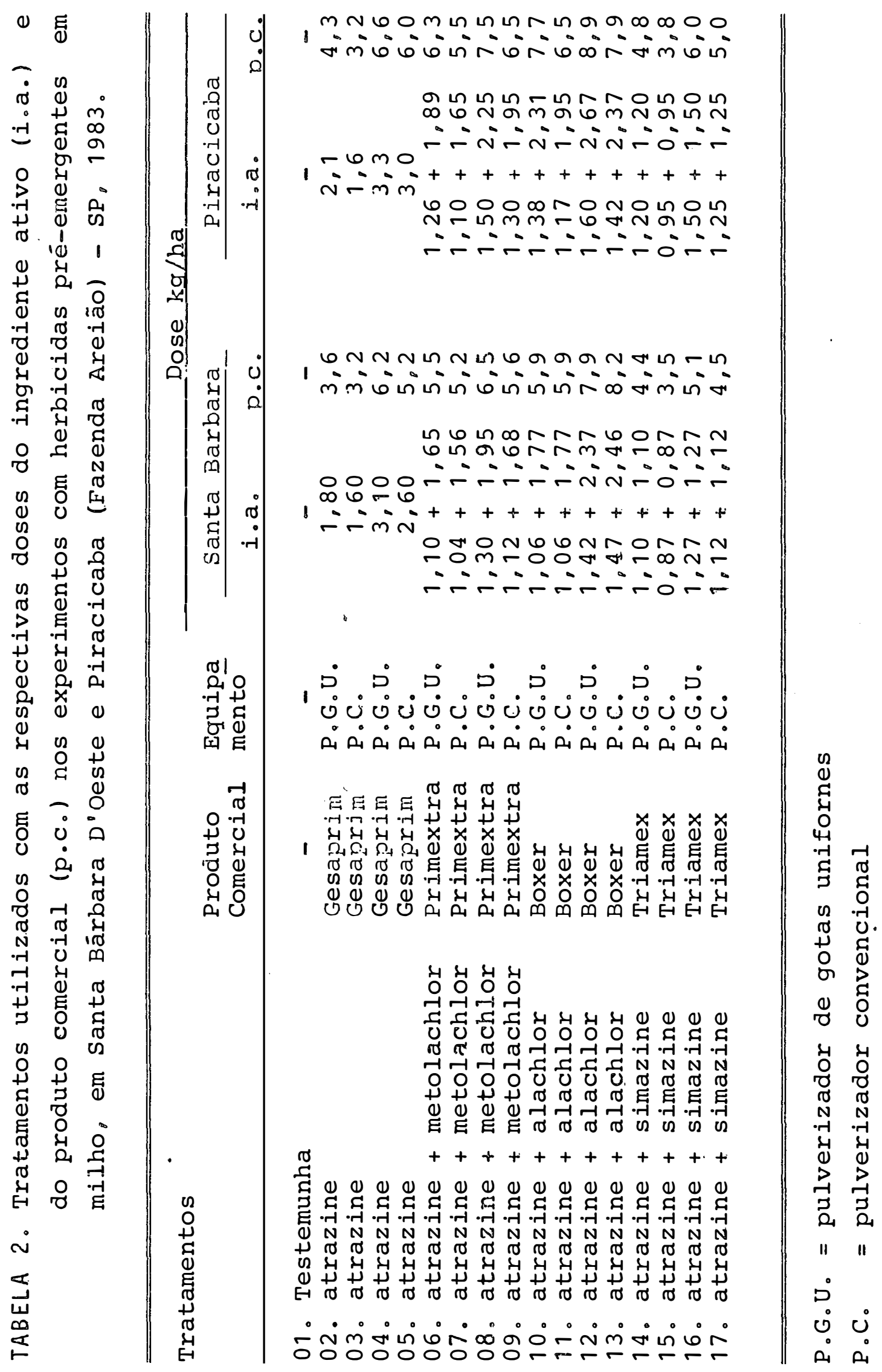


TABELA 3. Tratamentos utilizados com as respectivas doses do ingrediente ativo (i.a.) e do produto comercial (p.c.) no experimento com herbicidas aplicados em pré-emergencia em soja. ESALQ, 1983-84.

\begin{tabular}{lllcc}
\hline Tratamentos & Produto & Equipa & \multicolumn{2}{c}{ Dose kg/ha } \\
\cline { 4 - 5 } 01. Testemunha & Comercial & mento & i.a. & p.C. \\
02. alachlor & & & & \\
03. alachlor & Laço & P.G.U. & 2,35 & 4,9 \\
04. alachlor & Laço & P.C. & 2,68 & 5,6 \\
05. alachlor & Laço & P.G.U. & 4,12 & 8,6 \\
06. cyanazine & Laço & P.C. & 3,84 & 8,0 \\
07. cyanazine & Bladex & P.G.U. & 1,60 & 3,1 \\
08. cyanazine & Bladex & P.C. & 1,95 & 3,9 \\
09. cyanazine & Bladex & P.G.U. & 2,10 & 4,2 \\
10. metribuzin & Bladex & P.C. & 2,30 & 4,6 \\
11. metribuzin & Lexone & P.G.U. & 0,35 & 0,5 \\
12. metribuzin & Lexone & P.C. & 0,42 & 0,6 \\
13. metribuzin & Lexone & P.G.U. & 0,60 & 0,8 \\
14. pendimethalin & Lexone & P.C. & 0,70 & 1,0 \\
15. pendimethalin & Herbadox & P.G.U. & 1,45 & 2,9 \\
16. pendimethalin & Herbadox & P.C. & 1,55 & 3,1 \\
17. pendimethalin & Herbadox & P.C. & 2,30 & 4,6 \\
\hline \hline
\end{tabular}

P.G.U. = pulverizador de gotas uniformes.

P.C. = pulverizador convencional. 
3.2.10. Aplicação dos tratamentos e condições climatológicas

a. Experimento com herbicidas aplicados em pré-emergência em mitho em Santa Bärbara D'Oeste: a aplicação foi feita no dia 28.10.83, ou seja 3 dias após a semeadu ra. No momento da aplicação o solo apresentava-se seco na superfície e úmido à profundidade de $2-5 \mathrm{~cm}$ g corn poucos torrões: o céu apresentava-se claro e sem vento. Dados de temperatura do solo, do ar e da umidade relativa durante a aplí cação são mostrados na Tabela 59 do Apêndice.

b. Experimento com herbicidas aplicados em pré-emergência em milho na Fazenda Areitão: a aplicação foi feita no dia 01.11.83, ou seja, 4 dias após a semeadura. Durante a aplicação, 'o solo encontrava-se úmido, a presença de torrões era pouca e o cêu estava parcialmente encoberto e a velocidade do vento era $\pm 7 \mathrm{~km} / \mathrm{h}$. Os dados de temperatura do solo, do ar e da umidade relativa durante a aplicação estão contidos na Tabela 59 do Apêndice.

C. Experimento eom herbicidas aplicados em prë-emergencia em soja: a aplicação foi feita no dia 17.12. 83, ou seja 5 dias após a semeadura. No momento da aplicação dos herbicidas, o solo estava muito úmido com muitos pou cos torrões; o céu apresentava-se encoberto e a velocidade do vento era de $\pm 5 \mathrm{~km} / \mathrm{h}$. Os dados de temperatura do solo, do ar e da umidade relativa durante a aplicação estão conti- 
dos na Tabela 59 do Apêndice.

3.2.11. Condicões climäticas durante o ciclo das cul turas

Os dados climäticos, durante o transcorrer dos experimentos de campo, estão contidos nas Tabelas 51 , $52,53,54,55,56$ e 57 do Apēndice.

Esses dados foram obtidos junto do Departamen to de Fisica e Meteorologia da ESALQ, para os experimentos conduzidos em Piracicaba. Para o experimento com milho em Santa Bārbara D'Oeste, foram obtidos junto ao observatório meteorológico da Usina Santa Bárbara.

\subsubsection{Avaliação dos experimentos}

As avaliações, pära cada um dos três experimentos até aqui descritos, seguiram na mesma ordem as datas de coleta de dados, assim como os critérios empregados para as avaliações visuais e levantamentasmatofloristicos.

Aos 15 dias depois da aplicação dos tratamentos foram registrados mediante avaliacão visual, o controle das plantas daninhas, usando a escala da Asociación Latinoamericana de Malezas (ALAM), que se encontra na Tabela 4. Para a avaliação de injūria à cultura, usou-se a escala de 0 
-100 , onde 0 é nenhuma injüria e 100 corresponde à morte to tal das plantas. Também foi avaliada a população inicial da cultura, mediante a contagem das plantas emergidas nas duas linhas centrais da parcela aplicada.

TABELA 4. Escala de avaliação visual para o controle de plan tas daninhas, adotada pela Asociación Latinoamerica na de Malezas (ALAM)*。

Indice

Controle das plantas daninhas

\begin{tabular}{|c|c|c|}
\hline 0 & 40 & nulo a fraco \\
\hline 41. & 60 & regular \\
\hline 61 . & 70 & suficiente \\
\hline 71 . & 80 & bom \\
\hline 81 . & 90 & muito bom \\
\hline 91. & 100 & excelente \\
\hline
\end{tabular}

* Fonte: Revista ALAM 1(1): 35-38, 1974 .

Aos 30 e 60 dias após o tratamento, dependendo das condições climáticas, pequenas mudanças eram realizadas na época dessas avaliações; o controle das plantas daninhas foi avaliado visualmente, ao mesmo tempo foram feitas contagens das diferentes espécies presentes nos experimentos. Deste modo, foi possivvel determinar a porcentagem de 
controle para certas espécies de plantas daninhas, ou somente entre os grupos de folha-larga e de folha-estreita.

Para realizar as contagens, nos experimentos, em milho, utilizaram-se quadrados de $0,5 \times 0,5 \mathrm{~m}$, e na soja de 0,2 $20,5 \mathrm{~m}$ lançados ao acaso nas entrelinhas de cada par cela aplicada.

\section{2 .13 . Colheita}

Foram colhidas duas linhas centrais da parce la aplicada, nas quais avaliou-se o nủmero de plantas e núme ro de espigas. A áreà colhida foi de $2,0 \times 6,0 \mathrm{~m}$, isto em razão de ter deixado meio metro a cada extremo da parcela.

Depois da pesagem dos grãos e determinação da porcentagem de umidade, os rendimentos por parcela foram con vertidos em $\mathrm{kg} / \mathrm{ha}$, e ajustados a $13 \%$ de umidade.

A colheita para o milho em Santa Bárbara D' Oeste foi realizada em 14.03 .84 , e na Fazenda Areião em 02 . 04.84 。

O experimento com herbicidas pré-emergentes em soja não foi levado até a colheita devido à longa estiagem que ocorreu durante o seu ciclo, o qual é mostrado pelos dados de precipitação nas Tabelas 54,55 e 56 do Apêndice. 0 período de seca coincidiu com a época de floração e enchimen 
to das vagens, o qual reduziu drasticamente os rendimentos. Portanto, esse experimento foi encerrado apōs a última ava. 1 iação

\subsubsection{Anāiose estatística}

Os dados obtidos foram submetidos à análise estatística empregando-se o teste $F$, e para a comparação das médias, utilizou-se o teste de Tukey, calculando-se a diferença mínima significativa ao nível de $5 \%$ de probabilidade (PIMENTEL GOMES, 1976), usando o esquema fatorial modificado, apresentado na Tabela 5.

3.3. Experimentos de campo com herbicidas aplicados em pós-emergência em grama-seda (Cynodon dactylon Pers。)

Foi escolhida a grama-seda por ser uma das plantas daninhas que se constitui em sério problema para a cana-de-açúcar (MARCONDES et $\alpha l_{i} i, 1980$ ) e citros (CATTANEO e SOARES, 1982) sendo o mato predominante, onde o uso de grades e implementos mecânicos é constante, sendo o controle químico uma das alternativas de melhor sucesso. 
TABELA 5. Esquema das anālises da variância, para todos os dados obtidos, nos experimentos com herbicidas prẹ emergentes.

Causas de variação

Graus de liberdade

Testemunha vs. Fatorial

Herbicidas ( $\mathrm{H}$ )

Doses (D)

Equipamentos (E)

interação H x D

Interação $\mathrm{H} \times \mathrm{E}$

Interação D x E

Interação $\mathrm{H} \times \mathrm{D}$ \& $\mathrm{E}$

Tratamentos

Blocos

Resíduo

\subsubsection{Classificação e anālises de solos}

O experimento com herbicidas aplicados em pós -emergência em grama-seda foi conduzido na Usina Santa Bár bara, do Município de Santa Bārbara D'Oeste, cujas caracteristicas clináticas e geográficas foram indicadas no item 
3.1. Durante o ano de 1983, o experimento foi instalado em um solo Latossolo Vermelho-Escuro Distrófico, cujas características físicas e quimicas estão na Tabela 6 . No ano de 1984 foi repetido o mesmo experimento, porém em outra área, cujo solo foi um Latossolo Vermelho-Amarelo Distrófico, com as caracteristicas físicas e quimicas encontradas na Tabela 6 .

\subsubsection{Escolha do local e preparo do solo}

Em âreas de renovação do canavial, e com altas infestações de grama-seda, a soqueira è eliminada median te uma aração profunda durante os meses de novembro-dezembro, ficando esta área assim por um tempo minimo de 2 meses. Após este periodo no qual a grama-seda rebrota intensamente, è uma prática normal desta usina aplicar o herbicida glyphosa te para controlar ou diminuir as infestações.

Assim, durante os anos de 1983 e 1984 foram es colhidas áreas altamente infestadas e por conseguinte, com uma máxima uniformidade na cobertura com esta planta daninha。 


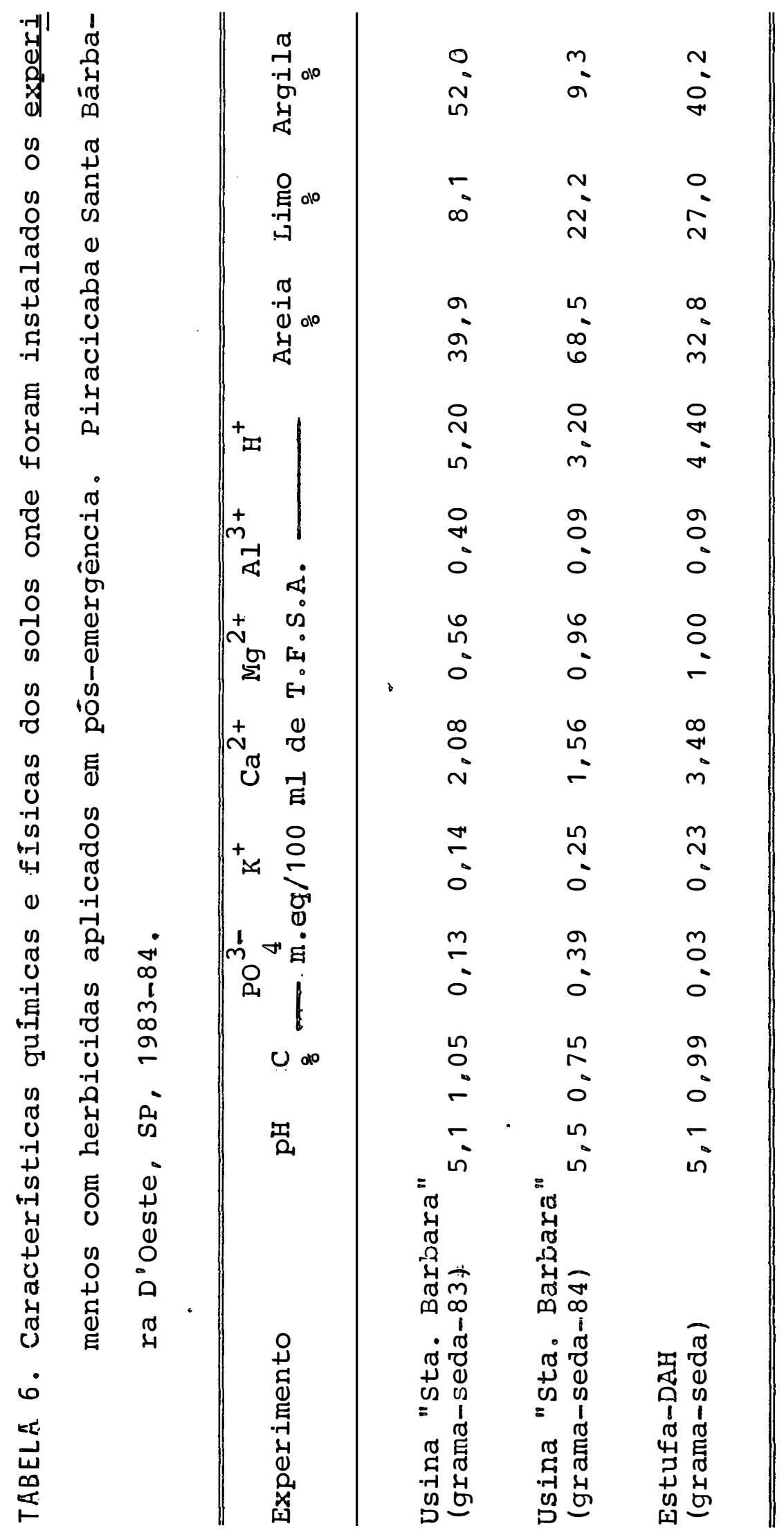


3.3.3. Herbicidas utilizados

Foram utilizados os herbicidas glyphosate, fluazifop-butil, Dowco 453 e dalapon, cujas principais carac terísticas, aqui relatadas, estão baseadas no livro "Herbicide Handbook", da Weed Science Society of America (1980), assim como nos boletins técnicos das companhias produtoras. Os herbicidas utilizados nos experimentos aplicados em pós-emergência foram:

a. dalapon

Formulação comercial: Secafix 85 e Dowpon 74 magnesiano.

Ingrediente ativo: ácido 2,2-idicloropropionico。

Características principais: a formulação comercial utilizada

foi o pömsolúvel (P.S.) com $85 \%$ de ingrediente ativo (dalapon). A solubilidade em água do dalapon é de $50,2 \times 10^{4} \mathrm{ppm}$.

E um herbicida de translocação predominantemente apo-simplástica, de ação específica sobre as gramíneas anuais e perenes, sendo absorvido pelas plantas, essencialmen te, via foliar. Eum herbicida que atua inibindo a formação do ácido pantotênico, aminoácido responsável pela formação da vitamina $B$, indispensável ao crescimento e desenvolvimento das plantas. Normalmente é recomendado para aplicação em 
pós-emergência, e quando aplicado no solo é rapidamente lixí viado da camada superficial. $A D_{50}$ oral, para ratos, é de $9.330 \mathrm{mg} / \mathrm{kg}$ de peso vivo.

b. Doweo $453 \mathrm{ME} \begin{aligned} & \text { (nome proposto: haloxyfop- } \\ & \text { metil) }\end{aligned}$ Formulação comercial utilizada: Ainda não dig ponível.

Ingrediente ativo: Metil $2-[4$ (3-cloro-5- tri fluorometil-2-piridinoxy ) fenoxi-j propanoato.

Características principais: Este é um produto que ainda está em fase de pesquisa, cujo nome ainda está em côdigo, alēm de outras informações adicionais não estarem disponíveis. A formulação empregada foi a concentrada emulsionável com $240 \mathrm{~g} / 1$ de ingrediente ativo. Apresenta alta atividade no controle de gramíneas anuais e perenes quando aplicado por via foliar. Em doses maiores, também pode ser aplicado em pré-emergência. Este produto não tem atividade sobre as plantas daninhas de folha larga, e nem sobre cipera ceas。

A $\mathrm{DL}_{50}$ oral agúda, para ratos, é de $2.178 \mathrm{mg} / \mathrm{kg}$ de peso viæo.

c. fluazifop-butil

Formulação comercial utilizada: Fusilade. 
Ingrediente ativo: Butil 2-4-(5-trifluorometil-2-piridiloxi) Fenoxi propionato.

Características principais: A formulação comercial utilizada foi a concentrada emulsionāvel (C.E.) com 25\% de ingrediente ativo (Fluazifop-butil). um herbicida de translocação apo-simplástica, altamente ativo, 'seletivo para controle de gramíneas anuais e perenes das culturas de folha-larga. E um herbicida que se acumula nos pontos de crescimento das plantas, afetando os tecidos meristemáticos dos nódulos e das gemas. Estudos de laboratōrio sugerem que estè herbicida interfere na produção de ATP na planta, sendo normalmente recomendado para aplicação em pōs-energência, pô rém em,doses maiores apresenta atividade em pré-emergência quando aplicado aó solo.

$\mathrm{A} \mathrm{DL}_{50}$ oral agúda, para ratos, é de $3.328 \mathrm{mg} /$ kg de peso vivo.

d. gryphosate

Formulação comercial utilizada: Roundup Ingrediente ativo: N - (fosfonometil) glicina Características principais: A formulação comercial utilizada foi a solução concentrada (S.C.), contendo $480 \mathrm{~g} / 1$ do ingrediente ativo (glyphosate). E um herbicida de translocação apo-simplāstica controlando plantas daninhas 
monocotiledôneas e dicotiledôneas, como também plantas perenes, devido à translocação eficiente aos órgãos de propagação vegetativa situados no solo. E um herbicida que atua inibindo a biossintese de aminoácidos aromáticos. Normalmente é recomendado para aplicação em pós-emergência, devido à for te adsorção que sofre pelos colóides do solo. A lixiviação é muito baixa no solo. A $\mathrm{DL}_{50}$ aral aguda, para ratos, é de $4.320 \mathrm{mg} / \mathrm{kg}$ de peso vivo.

3.3.4. Adjuvantes utilizados

Foram utilizados: Nonil fenoxi poli etilenoxi etanol (Agral 90); octil fenoxi polietoxi etanol (Extravon) e óleo mineral (Triona B) junto aos herbicidas fluazifop-butil, dalapon e Dowco-453, respectivamente.

3.3.5. Tratamentos

Os tratamentos resultantes das combinações en tre herbicidas, doses e equipamentos, encontram-se na Tabela 7.

3.3.6. Equipamentos de aplicação Os mesmos que foran descritos no item 3.2.4. 


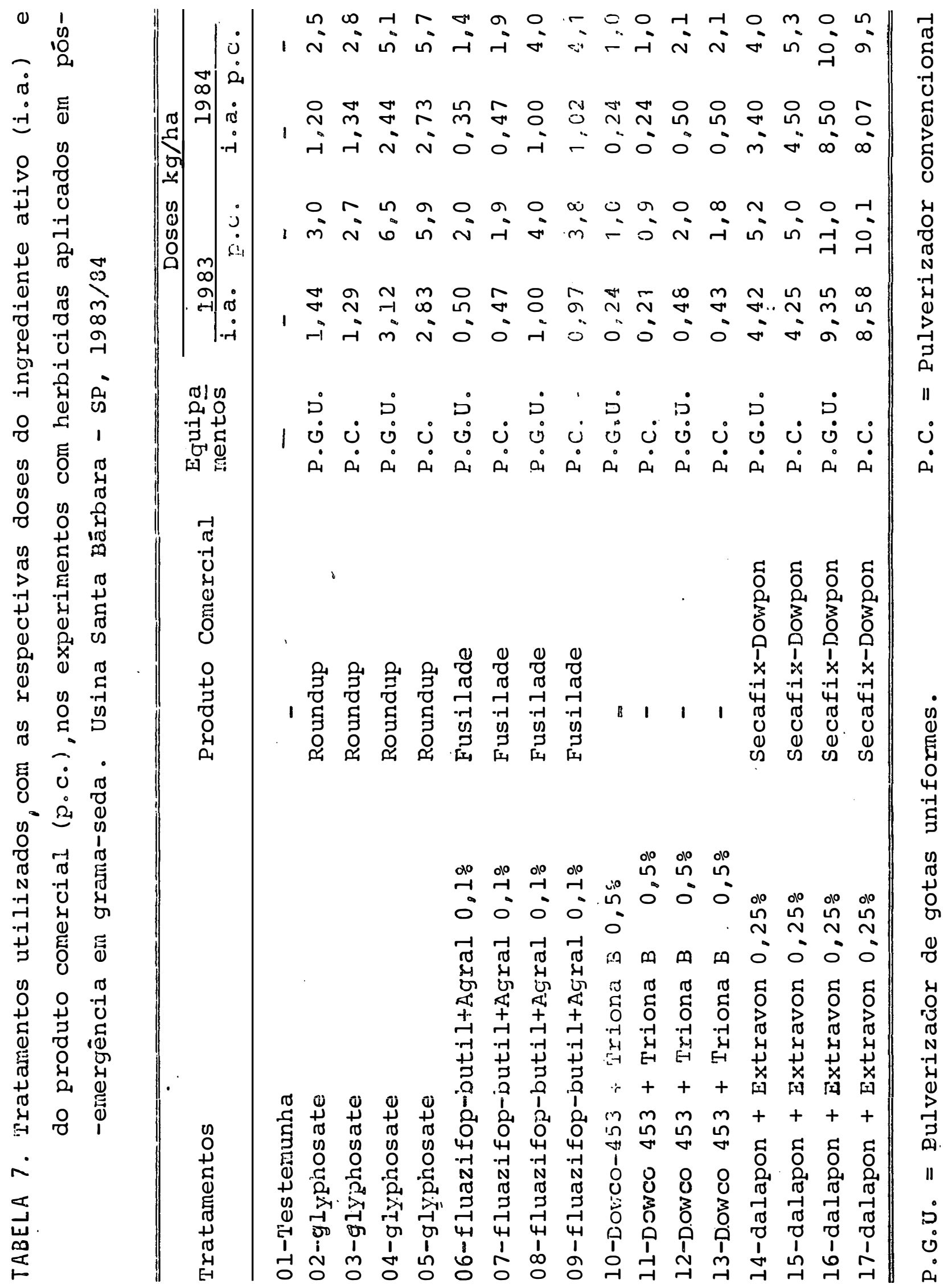


3.3.7. Delineamento experimental

O delineamento experimental adotado foi elu blocós ao acaso eln fatorial $4 \times 2 \times 2$ com 4 repetições, ou seja, 4 herbicidas, 2 doses e 2 equipamentos, perfazendo 17 tratamentos incluindo uma testemunha. No ano de $1983 \circ$ deli neamento só teve 3 repetições, a área das parcelas foi. de $5,0 \times 8,0=40,0 \mathrm{~m}^{2}$, sendo a área total do experimento 2.040 $\mathrm{m}^{2}$. A parcela aplicada para o equipamento convencional foi de $4,0 \times 8,0 \mathrm{~m}^{2}=32,0 \mathrm{~m}^{2}$ e para $\circ$ pulverizador de gotas uni formes foi de $4,2 \times 8,0=33,6 \mathrm{~m}^{2}$. No ano de $1984 \circ$ delinea mento apresentou 4 repetições, com a área das parcelas de $5,0 \times 7,0=25,0 \mathrm{~m}^{2}$ ! sendo a área total do experimento $2.380 .0 \mathrm{ma}^{2}$. A parcela aplicada para o equipamento convencio nal, foi de $4,0 \times 7,0=28,0 \mathrm{~m}^{2}$ e para $\circ$ pulverizador de gotas uniformes de $4,2 \times 7,0=29,4 \mathrm{~m}^{2}$.

\subsubsection{Aplicação dos tratamentos}

Quando a grama-seda se encontrava na preflora ção, ou seja,quando comçavam a aparecer as primeiras inflorescências, foram feitas as aplicações dos tratamentos. A planta daninha cobria o solo em aproximadamente $90 \%$ e tinha uma altura de $\pm 15 \mathrm{~cm}$. ivo ano de 1983 a aplicação foi feita em 28/01/83, e no ano seguinte em 10.01.84. 


\subsubsection{Condições climāticas na aplicação}

No momento da aplicação, no ano de 1983, o so lo estava úmido, e durante as primeiras horas da manha havia orvalho, o céu estava parcialmente encoberto, e a velocidade do vento entre $5-10 \mathrm{~km} / \mathrm{h}$. Os dados de temperatura do ar e do solo durante á aplicação estão contidos na Tabela 58 do Apêndice.

ivo experimento do ano de 1984, o solo estava úmido, a folhagem sem orvalho, com céu parcialmente encoberto e velocidade do vento entre $5-8 \mathrm{~km} / \mathrm{h}$. Os dados de temperatura do ar e do solo durante a aplicação estão contidos na Tabela 58 do Apêndice.

3.3.10. Condições ci limáticas durante o transcurso do experimento

As tabelas $47,48,49,54,55$ e 56 do Apêndice trazem os dados de precipitação e temperatura registrados durante a evolução dos experimentos nos dois anos.

\subsubsection{Avà iàção dos experimentos}

Foram feitas avaliações visuais do controle, usando a escala da Associacion Latinoamericana de Malezas (ALAM), e a cobertura da grama-seda, aos 10,30 e 40 dias 
após o tratamento, no experimento do ano 1983. Para o experimento do ano 1984, as avaliações foram feitas aos 20, 30 e 60 dias após os tratamentos.

Aos 30 e 60 dias depois do tratamento foram feitas amostragens para determinação da biomassa verde e bio massa seca da grama-s̈eda. Foi col.hida a parte aérea da grama-seda contida em quadrados de $0,5 \times 0,5 \mathrm{~m}$, e lançados ao acaso no centro da parcela aplicada. Para o experimento do ano de 1983 não foi possível fazer esta avaliação aos 60 dias.

\subsubsection{Anālise estatistica}

Os dados das avaliações visuais, assim como pe sos de biomassa verde e biomassa seca, foram submetidos à anālise de variância, cujo esquema é o mesmo que para os experimentos com herbicidas pré-emergência, e apresentado na Tabela 5.

\subsection{Experimentos en casa de vegetação}

Foram plantados em 23.12.82 estolões de grama-seda em vasos plásticos, com capacidade de $950 \mathrm{ml}$ e furados no fundo, contendo solo. o nümero de estolões por vaso foi 6, no experimento conduzido em 1982-1983. 
Jâ para os experimentos realizados em 1983-84 o nümero de estolões por vaso foi 9; e a data de plantio foi 25-26.10.83. A irrigação dos vasos foi feita diariamente, a partir da data de plantio.

\subsubsection{Solos utilizados}

As características físicas e químicas do solo utilizado nos experimentos en casa-de-vegetação encontram-se na ri'abela 6 .

\subsubsection{Herbicidas utilizados}

Foram os mesmos que para os experimentos com herbicidas aplicados em pós-emergência no campo, os quais fo ram descritos no item 3.3.3.

\subsubsection{Equipamentos de aplicação}

Foram utilizados os mesmos equipanentos descritos no ítern 3.2.4. no experimento instalado em 1983-84. Para o experimento conduzido em 1982-83, o pulverizador de gotas uniformes usado foi o "Micron Herbi" da Micron Sprayers, que possui um tanque para 2,51 de calda e produz uma faixa de aplicação de 1,2 $\mathrm{m}$ de largura. O disco rotativo ë acionado por um notor elétrico que usa pilhas de lan- 
terna, e a $2.000 \mathrm{rpm}$ produz gotas de tamanho médio de 250 $\mu \mathrm{m}$. A calda foi colocada no disco rotativo, sob pressão de uma coluna de água de 800 rum. 0 volume de aplicação foi 32 l/ha。

\subsubsection{Delineamento experimental}

o delineamento experimental adotado foi em blocos inteiramente ao acaso, em esquema fatorial de $4 \times 2 \times$ 2 × 3 com 3 repetições 8 ou seja, 4 herbicidas, 2 doses, 2 equipamentos e 3 épocas de corte. Os cortes foram feitos a uma altura de $1,0 \mathrm{~cm}$ do solo, as 12,48 e 192 horas depois da aplicação. Foi incluída uma testenunha no experimento.

\subsubsection{Tratamentos}

Os tratamentos utilizados nos experimentos em casa-de-vegetação encontram-se na Tabela 8 , sendo de início os mesmos que para os experimentos de campo. 


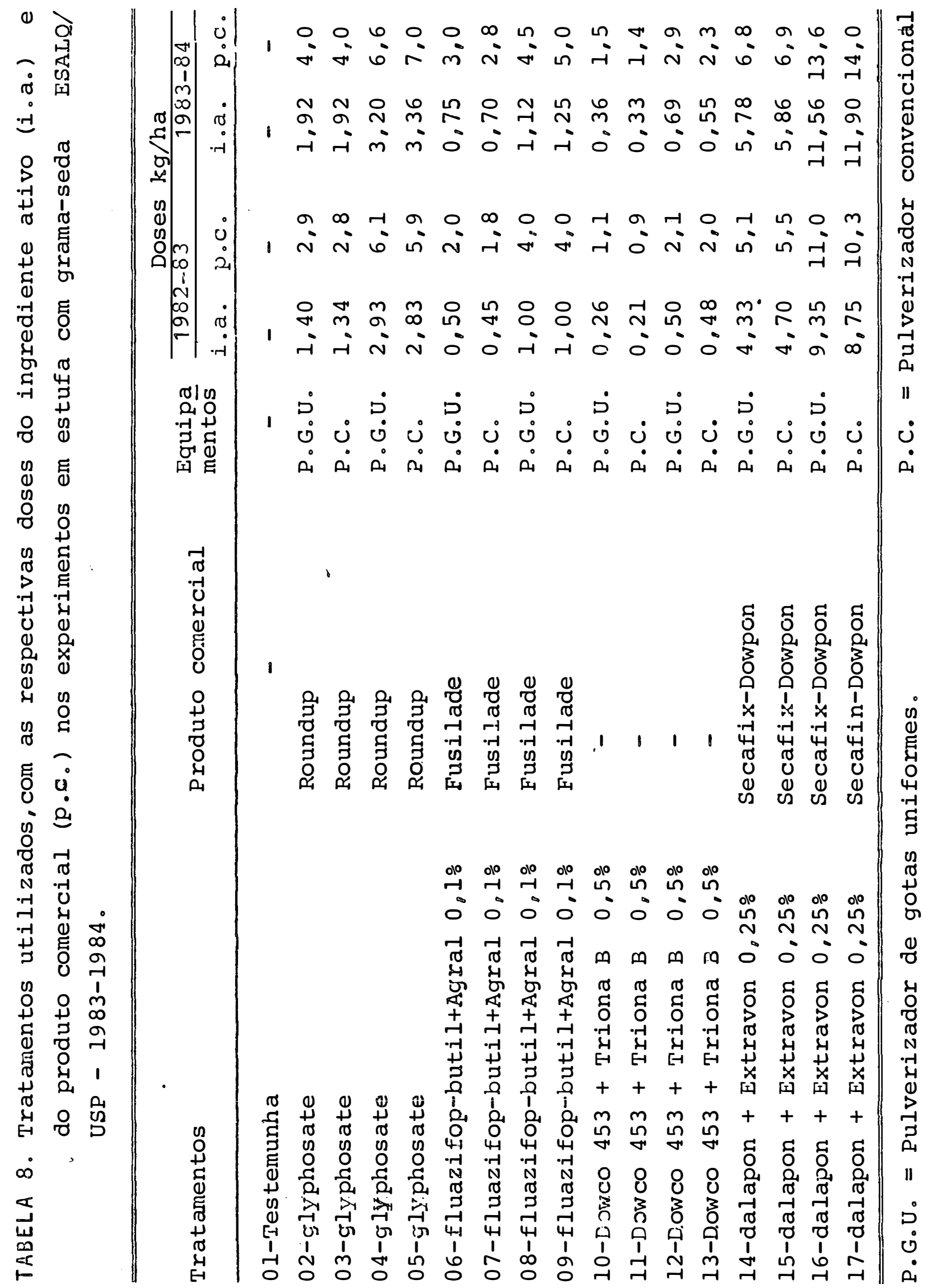


3.4.6. Adubação e condução das plantas de grama-seda Os experimentos eln vasos não foram adubados. Para uniformizar a altura e idade dos colmos da grama-seda, antes da aplicação, foram feitas podas na folhagem, isto com uma anteceâência de mais ou menos 1 mês. As infestações de trips que aconteceram na grama-seda, foram controladas com pulverizações de diazinon a $0,5 \%$

\subsubsection{Aplicação dos tratamentos}

a. Experimento de vasos em 1982-83: a aplicação foi realizada no dia 21.03 .83 , ou seja,87 dias apōs o plantio, quando a grama-seda tinha uma altura em torno de $20,0 \mathrm{~cm}$. INo começo da aplicação a temperatura, tanto dentro como fora da casa-de-vegetação, era de $18^{\circ} \mathrm{C}, \mathrm{e}$ a umidade rela tiva de $80 \%$. A aplicação foi iniciada às $6 \mathrm{~h}$ e $15 \mathrm{~m}$ e termi nou às $8 \mathrm{~h}$ e $20 \mathrm{~m}$. Ao final da aplicação, a temperatura ambiente fora da casa-de-vegetação era de $25^{\circ} \mathrm{C}$ e a umidade relativa de $72 \%$, e dentro era de $30^{\circ} \mathrm{C}$ e $74 \%$ de umidade relativa. Os dados de temperatura e umidade relativa durante a aplicação estão registrados na Tabela 60 do apêndice.

b. Experimento de vasos em 1983-84, a aplicação foi realizada no dia 16.12 .83 ou seja 52 dias após o plantio.

A grama-seda tinha uma altura em torno de $20,0 \mathrm{~cm}$. Os dados de temperatura e umidade relativa durante 
a aplicação estão registrados na Tabela 60 do apêndice.

No começo da aplicação a temperatura ambiente era de $26,5^{\circ} \mathrm{C}$ e a umidade relativa de $70 \%$. A aplicação foi iniciada às $17 \mathrm{~h}$ e $50 \mathrm{~m}$ e terminou às $19 \mathrm{~h}$ e $15 \mathrm{~m}$, quando a temperatura era de $24^{\circ} \mathrm{C}$ e a umiade relativa de $30 \%$

3.4.8. Condiçöes climāticas durante o transcurso dos experimentos

As tabelas $46,47,48,49,50,53,54,55,56$ e 57 do Apêndice trazem os dados de precipitação, temperatura e umidade relativa registrados durante a evolução dos experimentos nos dois anos.

\subsection{Avaliação dos experimentos}

Todos os experimentos em casa-de-vegetação foram avaliados através da biomassa verde produzida após os tratamentos.

Assim,o experimento em 1982-83 foi colhido aos 70 dias apōs os tratamentos. Os rebrotes de cada vaso foram cortados e pesados imediatamente.

O experimento de 1983-84 foi colhido aos 80 dias após os tratamentos. Os rebrotes de cada vaso foram cortados rente ao solo e pesados imediatamente. 
3.4.10. Anālise estatistica

Os dados de biomassa verde produzidos em cada um dos experimentos em casa-de-vegetação, e descritos anteriormente, não foram analisados de acordo com o delineamento estatistico com o qual foram implantados, devido às dificuldades na execução da anālise de variância. Por isțo, cada herbicida.foi analisado separaciamente adotando-se 0 delineamento em blocos inteiramente casualizados, em esquema fatorial de $2 \times 2 \times 3$ com 3 repetições, ou seja, 2 doses, 2 equipamentos e 3 épocas de corte.

Quando necessário, realizaram-se as comparações das médias pelo teste de I'ukey. o esquema de anālise àa variância encontra -se na Tabela 9. 
TABELA 9. Esquema da análise de variância, dos dados de biomassa verde nos experimentos com grama-seda em casa-de-vegetação. Piracicaba。SP。 1982-83-84 .

Causas de 'variação

Graus de liberdade

Testemunha vs fatorial

Doses (D)

1

Equipamentos (E)

1

Cortes (C)

2

Interação $\mathrm{D} \times \mathrm{E}$

1

Interação $D \times C$

Interação $\mathrm{E} \times \mathrm{C}$

Interação $D \times E \times C$

2

Tratamentos

Blocos

Residuo 
4. RESULTADOS E DISCUSSAO

4.1. Comportamentos dos herbicidas aplicados em pré-emergēncia, no controle das plantas daninhas, através do equipamento convencional e do pulverizador de gotas uniformes

4.1.1. Experimentos na cultura do milho Pelos dados de precipitação das Tabelas 51, 52 e 53 do Apêndice, observamse que a umidade do solo foi adequada para os dois experimentos, em particular depois da aplicação dos herbicidas, pois as precipitações ocorridas nos dias seguintes foram em quantidades suficientes para as segurar um bom desempenho dos herbicidas no controle das plantas daninhas.

As avaliações da pörcentagem de injúrià e os 
dados da população inicial da cultura aos 15 dias após aplicação dos tratamentos, não evidenciaram diferenças signi ficativas através do teste $F$ no experimento conduzido na Fa zenda Areião. Como se pode observar na Tabela 10, a testemu nha sem aplicação de herbicida foi estatissticamente igual aos demais tratamentos. Já para o experimento realizado em Santa Bárbara, num solo de textura média, as porcentagens de injüria resultaram estatisticamente significativas pelo tes te $F$. Se bem que a injúria,foi quase desprezivel, esta dife riu significativamente entre os diferentes herbicidas e em especial da testemunha.

As avaliações da população inicial da cultura e a porcentagem de injúria em nenhum,dos experimentos evidenciaram diferenças significativas pelo teste $F$, quando os herbicidas foram aplicados pelo pulverizador de gotas unifor mes ou pelo equipamento convencional.

Não existe na literatura consultada, referências a problemas de fitotoxicidade influenciadas pelo pulveri zador de gotas uniformes na cultura do milho. Assim, as pes quisas com herbicidas aplicados em pré-emergência,como alachlor, atrazine, metolachlor e simazine, reportados pelo BOLETIM INFORMATIVO HATSUTA (1982), SLACK e WITT (1983) e WILTSE (1983), não mencionam efeitosfitotóxicos à cultura do mi lho, e nem relacionados com o tipo de equipamento.

Esta falta de referências se deve a que nos 


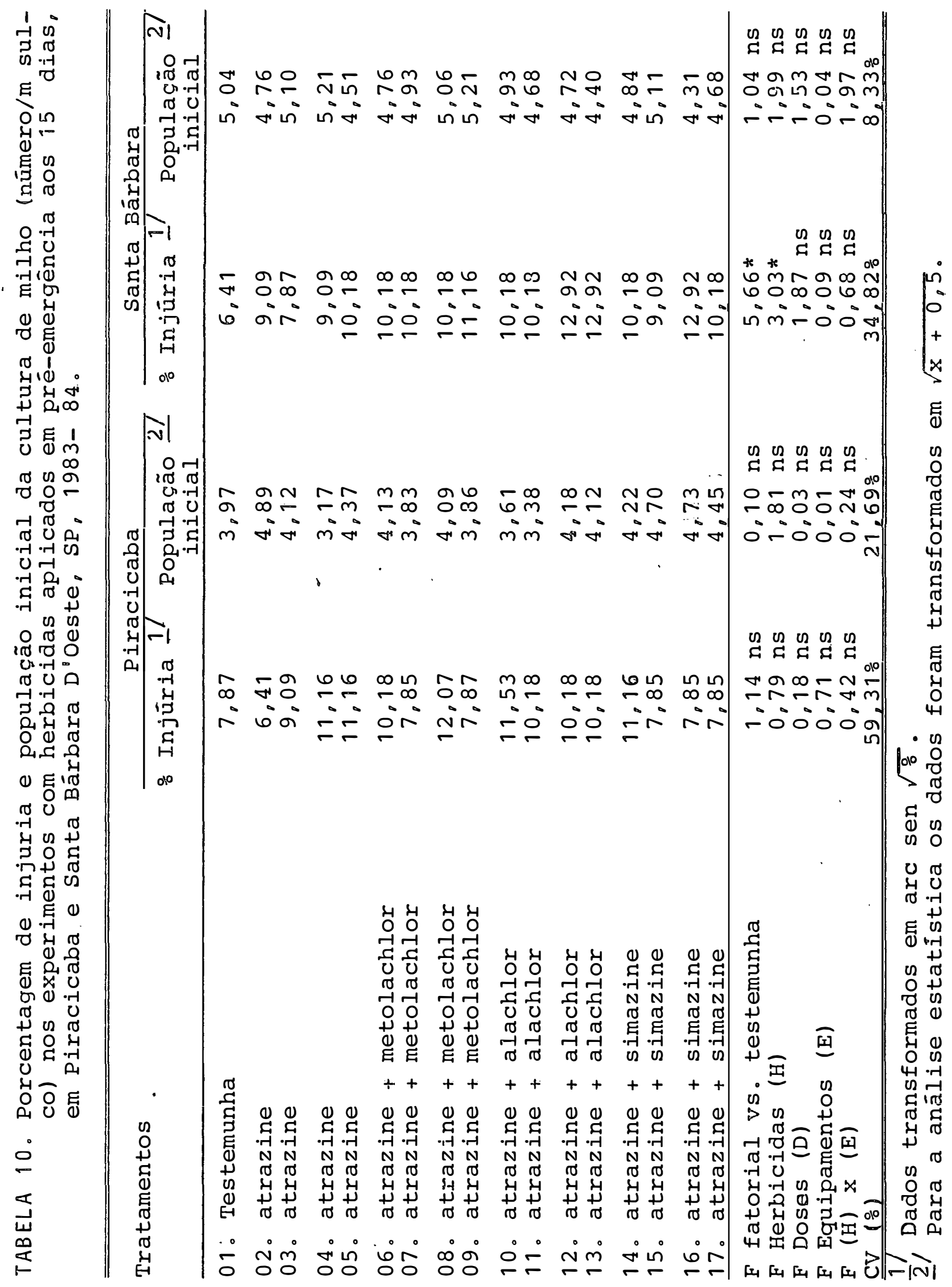


experimentos realizados, devido ao baixo nivel de injūria a influência do tipo de equipamento sobre a fitotoxicidade não tem sido muito considerada, com os herbicidas aplicados em pré-emergência. No experimento conduzido em Santa Bárbara , as principais plantas daninhas que ocorreram na área, assim como sua porcentagem dentro da população foram; guanuma-bran ca (Sida cordifolia L。) 49, caruru (Amaranthus spp) 13, guanxuma (Sida spp) 14\%, capim pé-de-galinha (Eleusine indica (L。) Gaertn.) 8,3응 poaia (Richardia brasiliensis Gomez) 3,6\% e capim-colchão (Digitaria sanguinalis (L.) Scop) 2,4\% 。

As principais plantas daninhas e sua composição, para o experimento conduzido na Fazenda Areião, em Pira cicaba, foram: capim-colchão (Digitaria sanguinalis (I.) Scop) 43,6\%; corda-de-viola (Ipomoea spp) 29,6\%, anileira (Indigofera hirsuta L。) 15,7\%, guanxuma (Sida spp) 6\%, poaia (Richardia brasiliensis Gomez) 1,8\%, capim-colonião (Panicum maximum Jacq) 1,2\%, capim-marmelada (Brachiaria plantaginea (Link) Hitch.) 0,6\%, capim-pé-de-galinha (Eleusine indica (L。) Gaertn。) e picão-preto (Bidens pilosa L。) 0,6\%。

A incidência de plantas daninhas nos experimentos foi baixa. Assim, em Santa Bárbara D'Oeste, aos 35 dias após a aplicação dos herbicidas, a testemunha apresenta va 28 plantas $/ \mathrm{m}^{2}$ 。 Na Fazenda Areião, em Piracicaba, a densi dade foi maior $e$, nesta mesma época, foi de 52,9 plantas/ $\mathrm{m}^{2}$ (Tabelas 11 e 12)。 
.78.

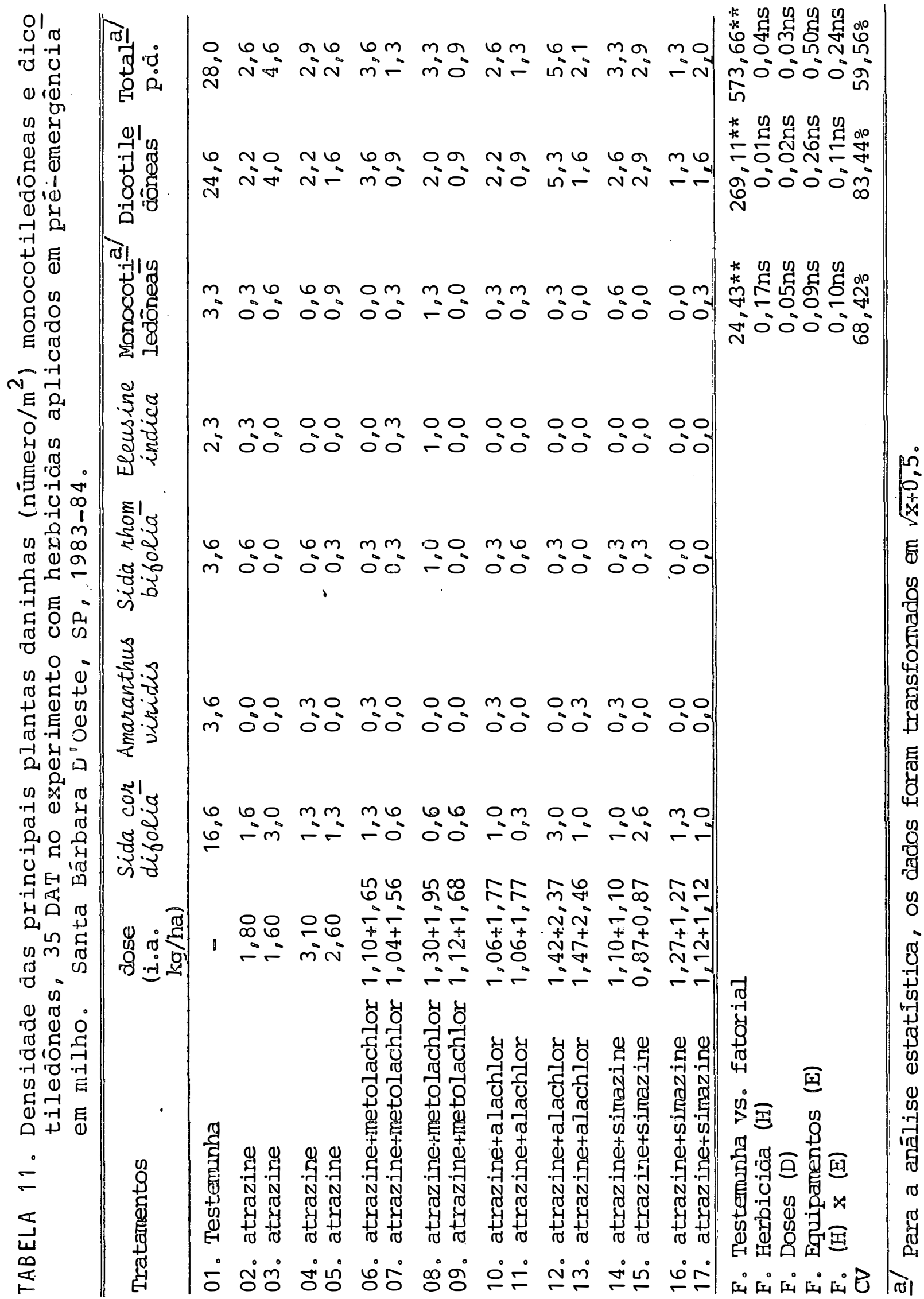


.79.

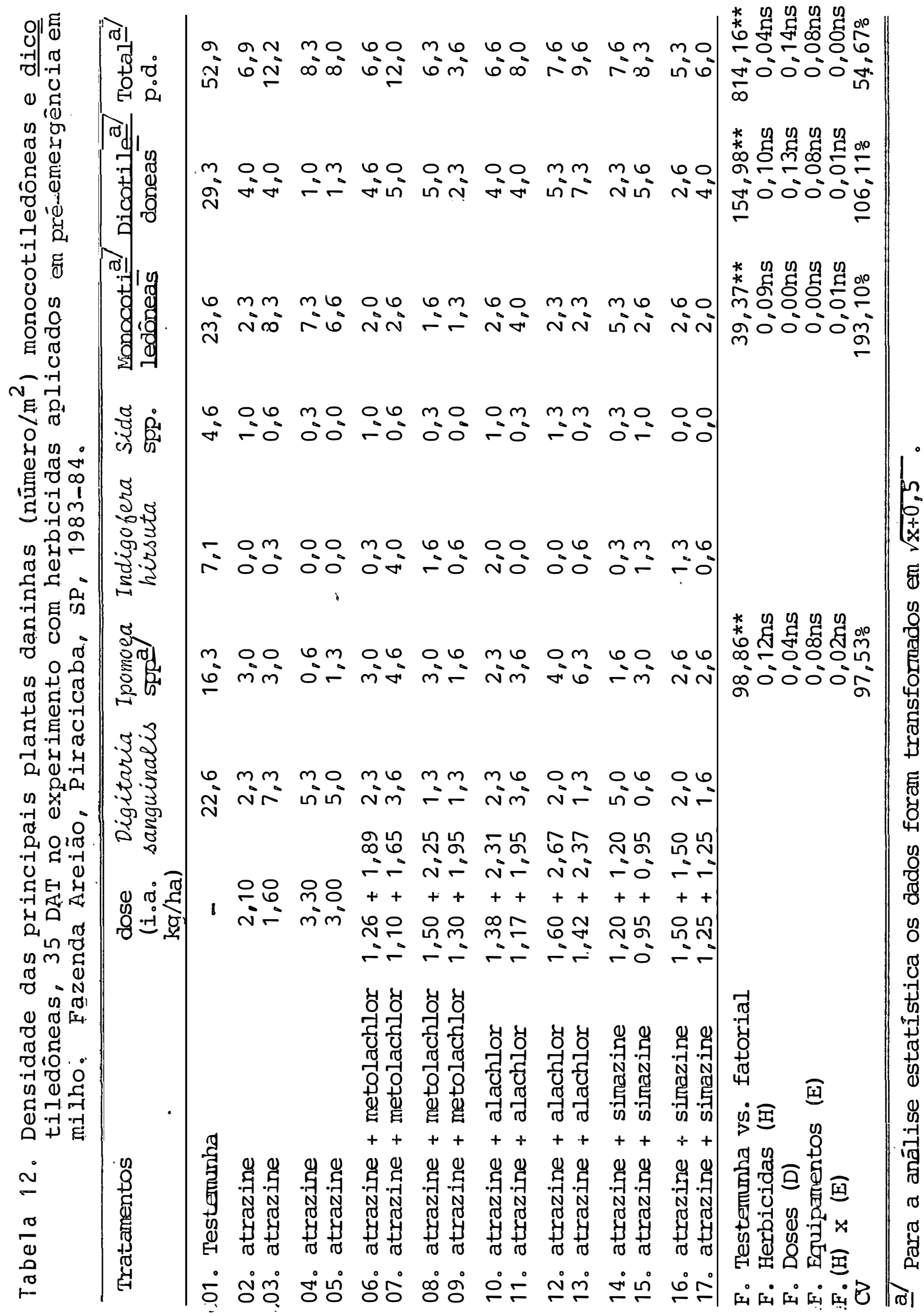


As avaliaçöes do controle das plantas daninhas realizadas por meio de contagens, para total de plantas daninhas e separaças em monocotiledôneas e dicotiledôneas , aos 35 e 70 dias após a aplicação dos herbicidas, não mostra ram diferenças significativas pelo teste $F$ para herbicidas, doses, e equipamentos, tanto no experimento em Santa Bärbara como no da Fazenda Areião, em Piracicaba.

As Tabelas 11, 12, 13 e 14 mostram que pelo teste $F$, só a testemunha difere significativamente dos tratamentos. No experimento em Piracicaba, aos 70 dias apōs a aplicação, o efeito das doses resultou significativo.

Uma explicação para o fato de não existir diferenças significativas para herbicidas e doses, seria a efi ciência semelhante das misturas para controlar as plantas da ninhas presentes nos experimentos, sendo as doses menores su ficientes para controlar as baixas populações de plantas daninhas incidentes nas duas áreas experimentais.

As avaliações visuais de controle das plantas daninhas monocotiledôneas e dicotiledôneas, aos 15, 35 e 70 dias após a aplicação dos herbicidas (Tabela 15), para o experimento em Santa Bárbara, e quandn feitas as respectivas anālises estatisticas, não mostraram diferenças significativas pelo teste $F$, para herbicidas, doses ou equipamentos.

Excetua-se a avaliação do controle das plantas daninhas dicotiledoneas aos 35 dias, cujo $F$ foi signifi- 


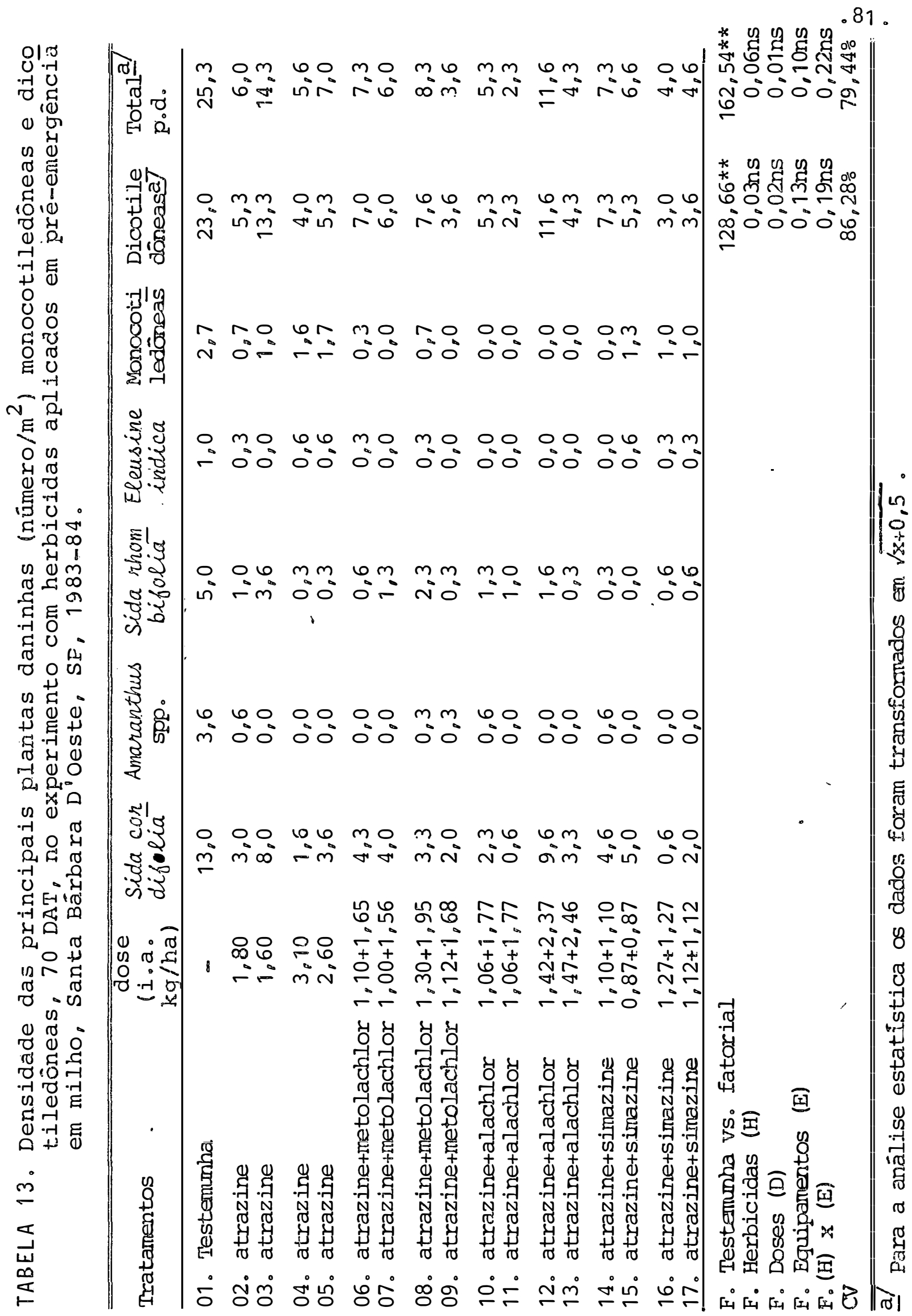




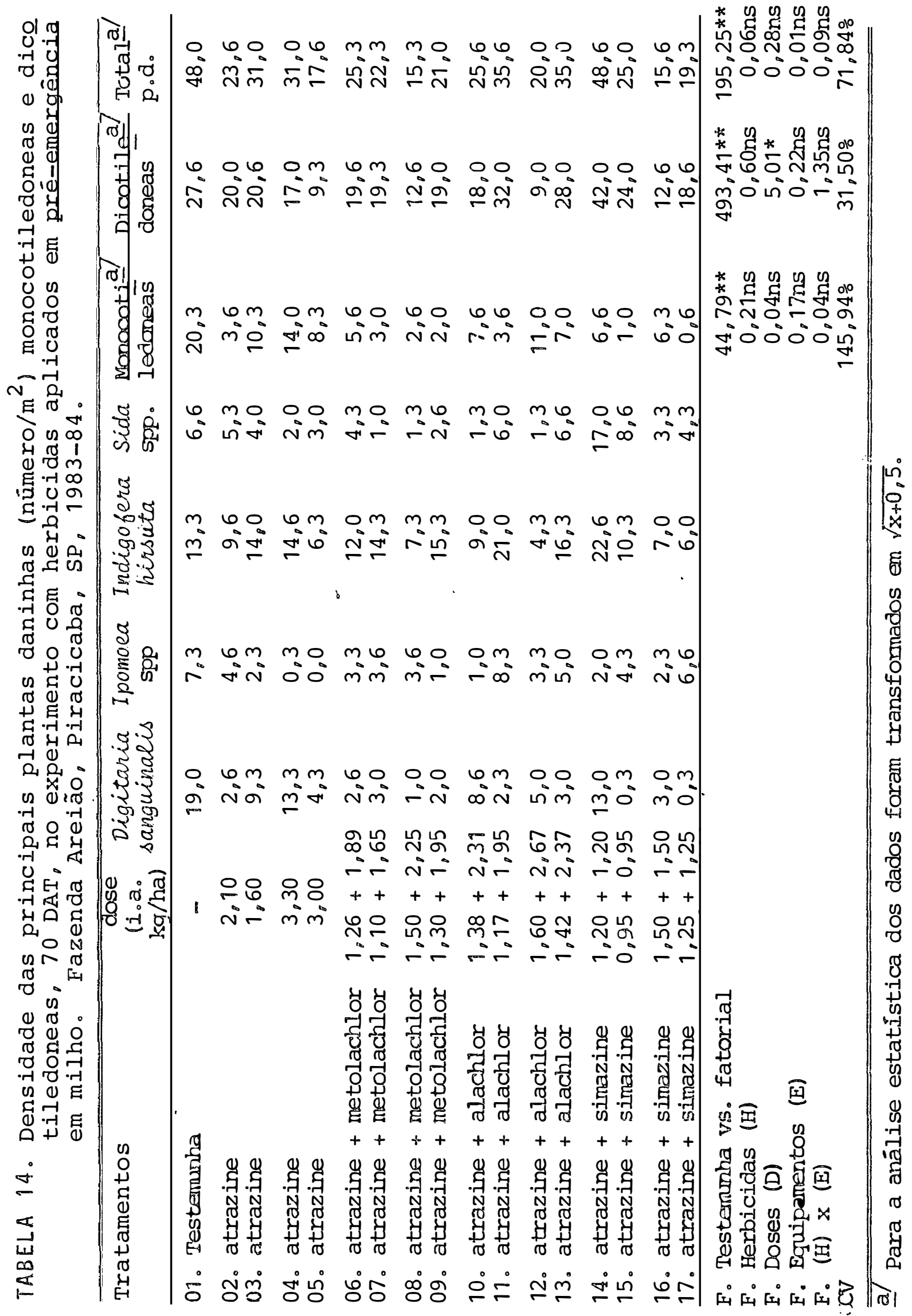




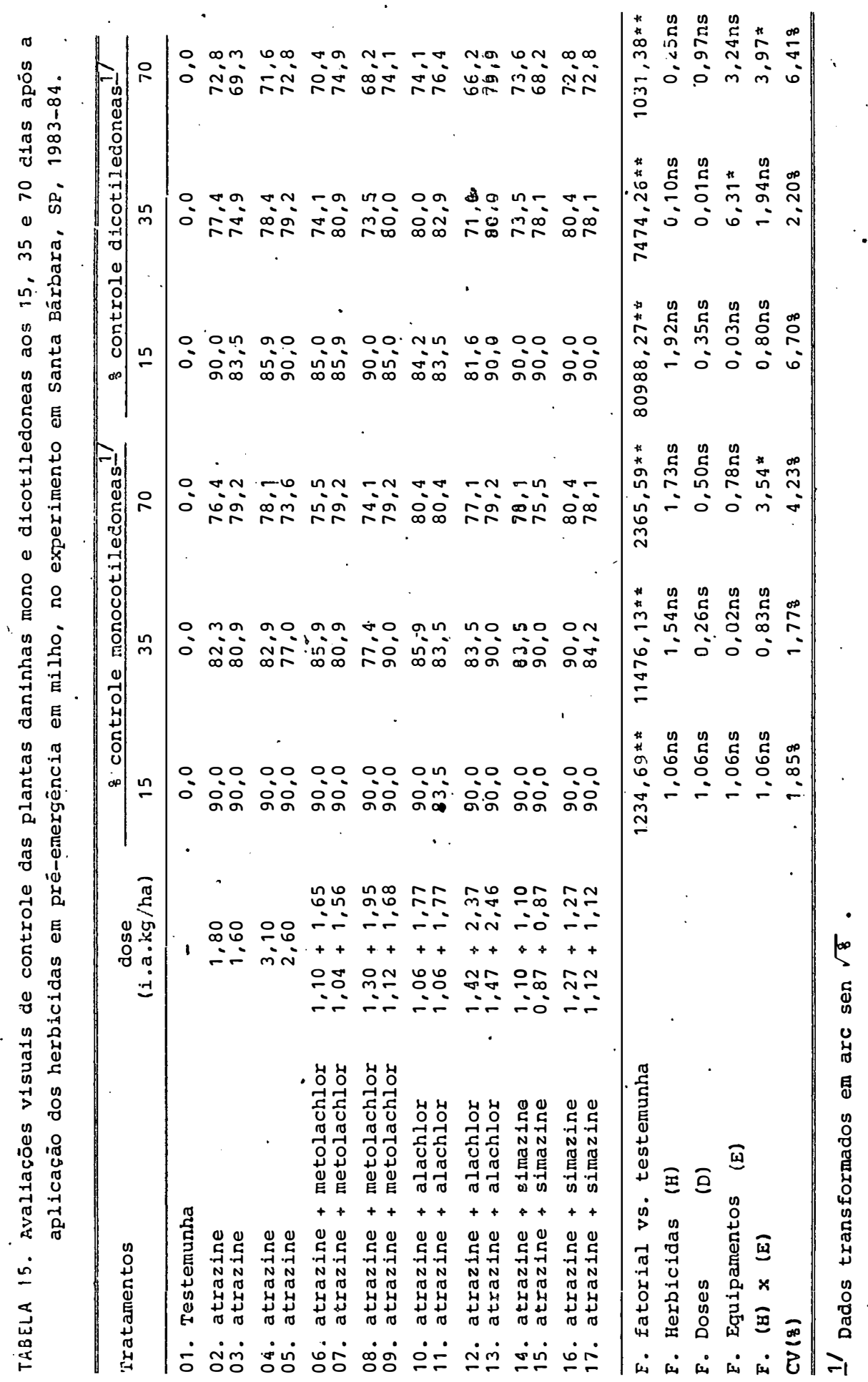


cativo para equipamentos de aplicação. Já na avaliação aos 70 dias, somente a interação herbicida $x$ equipamento foi sig nificativa。 o desdobramento da análise da variância para equipamentos dentro dos diferentes herbicidas mostrou, através do teste $F$, haver diferenças significativas entre equipamentos, com os herbicidas metolachlor + atrazine e alachlor + atrazine; porém, só nas doses maiores, como se obser va na Tabela 16. Este mesmo fato é observado na avaliação aos 70 dias, sendo que o controle visual das dicotiledôneas, nas doses maiores foi menor quando aplicado pelo pulverizador de gotas uniformes, como consta na Tabela 15.

TABELA 16. Teste $F$ e niveis de significância para equipamentos dentro dos diferentes herbicidas, na avaliação visual de controle de dicotiledôneas aos 35 e 70 dias após a aplicação. Experimento com milho, Santa Bárbara, SP。1983-84.

\begin{tabular}{lcc}
\hline \hline Causas de Variação & \multicolumn{2}{c}{$\mathrm{F}$} \\
\cline { 2 - 3 } & \multicolumn{1}{c}{35} & 70 \\
\hline Equipamentos dentro atrazine & $0,14 \mathrm{~ns}$ & $0,11 \mathrm{~ns}$ \\
Equipamentos dentro metalachlor + atrazine & $6,40^{*}$ & $* 6,38^{*}$ \\
Equipamentos dentro alachlor + atrazine & $5,26^{*}$ & $7,11^{*}$ \\
Equipamențos dentro simazine + atrazine & $0,33 \mathrm{~ns}$ & $1,55 \mathrm{~ns}$ \\
Equipamentos dentro doses menores & $2,18 \mathrm{~ns}$ & $0,04 \mathrm{~ns}$ \\
Equipamentos dentro doses maiores & $4,30^{*}$ & $7,61 * *$ \\
\hline
\end{tabular}


Este controle menor para as doses maiores po deria ser explicado por uma pobre distribuição da pulverização, pois as mudanças na viscosidade da calda alterariam a largura da faixa de aplicação, ou o tamanho das gotas, como indica ROBINSON (1978).

Por outro lado, no experimento de MAY e AYRES (1978), os reduzidos controles da planta daninha Chenopodium album, uma folha-larga, com os herbicidas simazine e chloroprophan, quando pulverizados com o equipamento de gotas uniformes, apoiam, em parte,os resultados aquí obtidos, porém no presente experimento os menores controles só ocorreram nas doses maiores, diferindo estatisticamente daqueles semelhantes e aplicadas pelo pulverizador convencional.

A partir destes resultados fica evidente a im portância de testar o comportamento e eficiência biológica de cada composto, assim como suas misturas, quando aplicados com pulverizador de gotas uniformes, sugestões que são apresentadas pelos pesquisadores BRUGE e JEAN (1978), GENTET (1978) e CUSSANS e TAYLOR (1978).

Para o experimento na Fazenda Areião, com uma flora de plantas daninhas diferente, e já indicada anteriormente, as avaliações visuais de controle de plantas daninhas monocotiledôneas e dicotiledôneas, aos 15, 35 e 70 dias após a aplicação dos herbicidas, não mostraram diferenças signifi cativas pelo teste $F$, para equipamentos, doses e herbicidas 
(Tabela 17). Só o controle de monocotiledôneas resultou sig nificativo para herbicidas, nas avaliações visuais aos 35 e 70 dias após a aplicação. Nas três datas de avaliações, e pa ra os dois grupos de plantas daninhas, os controles consegui dos pelos diferentes tratamentos, foram altamente significativos e diferentes da testemunha.

Sendo o capimmcolchão (Digitaria sanguinalis) a espécie predominante neste experimento, era de se esperar o melhor controle de monocotiledôneas obtido pelas misturas de atrazine + metolachlor ou alachlor, devido ao efeito grap minicida destes dois ủltimos herbicidas, o qual pode sei observado na Tabela 18, A análise de variância da porcentagem de controle do capim-colchão (Tabela 18) mostra diferenças altamente significativas pelo teste $F$ para doses e fatorial vs. testemunha; já para herbicidas e equipamentos o nível de significância pelo teste $F$ foi de 5 영 de probabilidade.No des dobramento da análise de variância para equipamentos dentro dos diferentes herbicidas, usando o teste $F$, observa-so que há ldiferenças significativas entre equipamentos, dentro 'das misturas de atrazine + metolachlor e alachlor; mas estas diferenças só são significativas nas doses maiores,como pode-se observar na Tabela 19. 


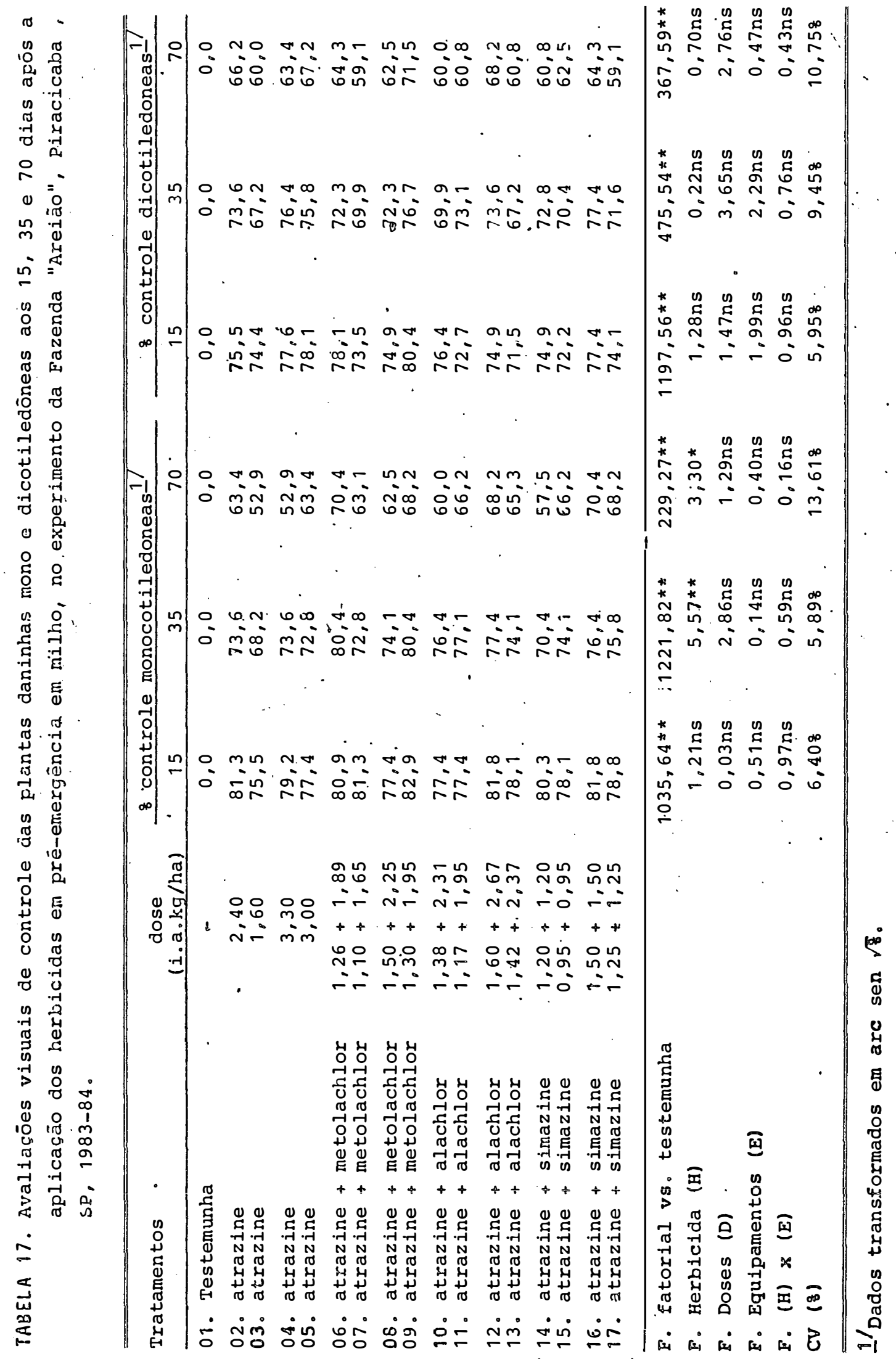


Tabela 18. Porcentagem de controle do capim-colchão e do total de plantas daninhas, pelos diferentes herbici das aplicados em pré-emergência 35 dias após a aplicação no experimento em milho.

Fazenda "Areião". Piracicaba, SP, 1983-84.

01. Testemunha

02. atrazine

03. atrazine

04 . atrazine

05. atrazine

06 . atrazine t metolachlor

07. atrazine + metolachlor

08. atrazine + metolachlor

09. atrazine + metolachlor

10. atrazine + alachlor

11. atrazine + alachlor

12. atrazine + alachlor

13. atrazine + alachlor

14. atrazine + simazine

15. atrazine + simazine

16. atrazine + simazine

17. atrazine + simazine

$\begin{array}{lll}- & 22,6 * & 52,9 * \\ 2,10 & 62,1 & 70,3 \\ 1,60 & 62,1 & 66,6 \\ 3,30 & 71,9 & 68,4 \\ 3,00 & 69,1 & 70,6\end{array}$

$1,26+1,89 \quad 76,7$

69,1

$1,10+1,65 \quad 60,7$

57,4

$1,50+2,25$

83,8

72,6

$1,30+1,95 \quad 77,0$

72,8

$1,38+2,31$

73,5

65,9

$1,17+1,95$

62,7

70,1

$1,60+2,67$

80,3

72,9

$1,42+2,37$

74,8

64,0

$1,20+1,20$

61,6

65,9

$0,95+0,95$

73,8

65,8

$1,50+1,50$

80,6

71,6

$1,25+1,25$

70,0

F。 testemunha vs. fatorial

$250,88 * *$

$332,21 * *$

F。 Herbicidas $(\mathrm{H})$

$3,20 *$

$0 \% 01 \mathrm{~ns}$

F。 Doses (D)

$23,39 * *$

4,41 *

E. Equipamentos (E)

4,55 *

$1,71 \mathrm{~ns}$

F。 (H) \& (E)

$2,05 \mathrm{~ns}$

$0,33 \mathrm{~ns}$

CV

$10,01 \%$

$11,31 \%$

al os valores médios do capim-colchão e total de plantas dani nas estão transformados em arc sen $\sqrt{ }$ 活. 
TABELA 19. Teste $F$ e níveis de significância para equipamentos dentro dos diferentes herbicidas, na porcenta gem de controle do capim-colchão. Experimento em milho. Piracicaba。SP, 1983-84。

Causas de variação

F

Equipamentos dentro atrazine

$0,30 \mathrm{~ns}$

Equipamentos dentro metolachlor + atrazine

5,38 *

Equipamentos dentro alachlor + atrazine

4,49 *

Equipamentos dentro atrazine + simazine

$0,52 \mathrm{~ns}$

Equipamentos dentro doses menores

$0,98 \mathrm{~ns}$

Equipamentos dentro doses maiores

$4,09 *$

Pela Tabela 18 verifica-se que os controles do capim-colchão obtidos pelas misturas de atrazine.+ metolachlor ou alachlor foram maiores quando pulverizados pelo aplicador de gotas uniformes, talvez devido as doses relativamente maiores que foram aplicadas com este pulverizador.

Os dados de rendimento, população da cultura e nûmero de espigas de milho no momento da colheita dos expe rimentos nas duas localidades, encontram-se na Tabela 20. As análises estatísticas para os três parâmetros mencionados não resultaram significativas pelo teste $F$, seja para herbicidas, doses e equipamentos. Os rendimentos da testemunha, quando comparados com os rendimentos dos demais tratamentos, 


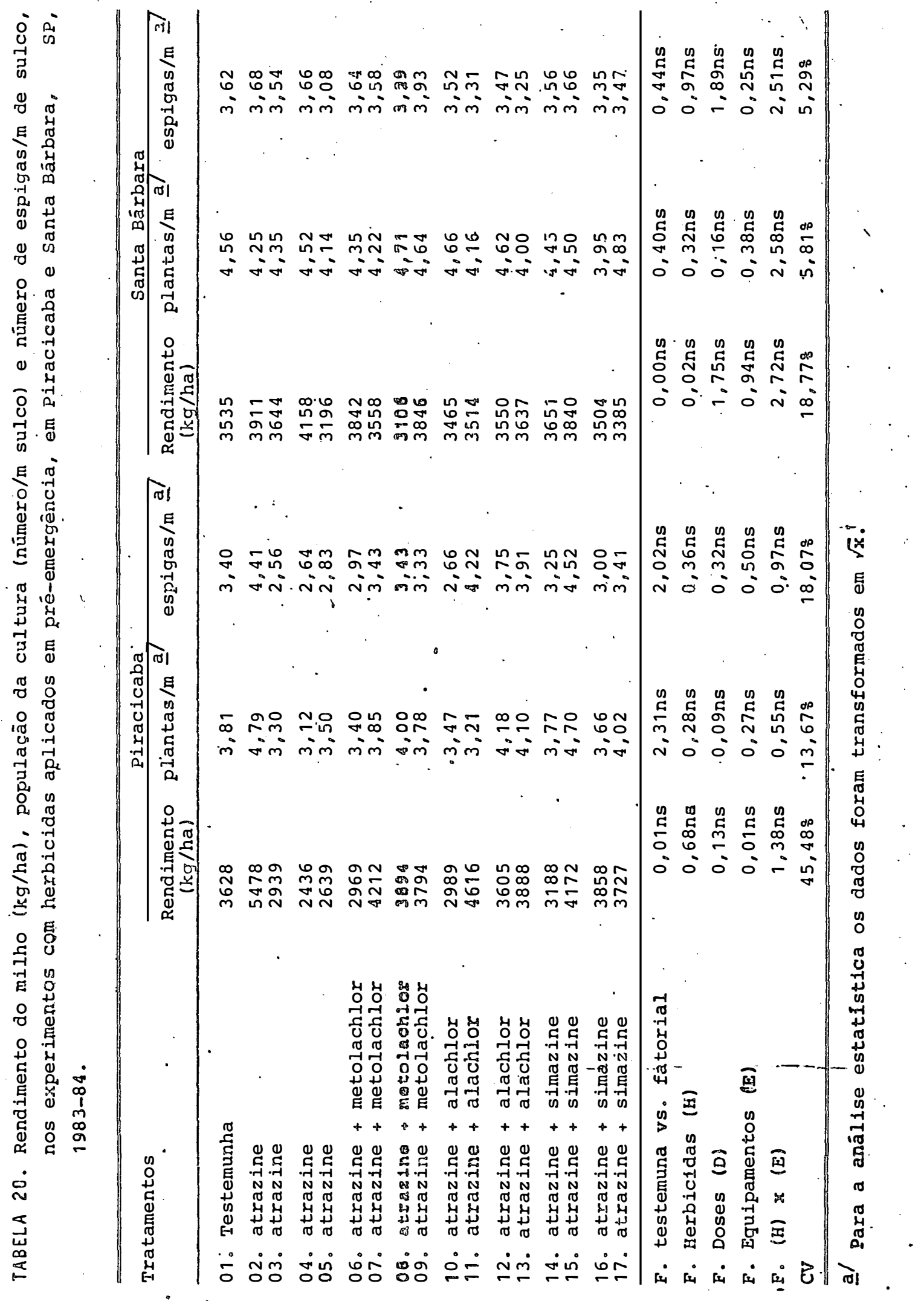


não resultaram estatisticamente diferentes, o que demonstra que as populações de plantas daninhas nos dois experimentos não foram tão importantes a ponto de influir nos rendimentos da cultura. Por outro lado, a não existência de diferenças significativas entre herbicidas, doses e equipamento, è uma indicação indireta dos controles semelhantes das plantas daninhas presentes em cada experimento.

Pelos resultados até aqui expostos, e nas con dições em que foram realizados os experimentos com : milho, não hả diferenças na eficiência dos herbicidas aplicados em pré-emergência pelo pulverizador de gotas uniformes, em rela ção ao equipamento convencional, resultados iguais a aqueles obtidos por BARZEE e STROUBE (1972), TAYLOR e MERRITT:(1974), BOLETIM INFORMATIVO HATSUTA (1982), SLACK e WITT (1983) ou a aqueles obtidos por MAY e AYRES (1978) em solos orgânicos。

O controle das plantas daninhas gramineas pre sentes nas duas āreas experimentais, foi igual. para os dois equipamentos de aplicação, não se repetindo os controles deficientes obtidos por ROBINSON (1978) e MC CAVISH (1978) com certas espécies de gramíneas, quando as aplicações de atrazi ne e misturas de atrazine + cyanazine foram feitas com o puI verizador de gotas uniformes.

Por outro lado, as formulações suspensão concentrada dos herbicidas atrazine e suas misturas com alachlor, metolachlor e simazine, utilizados nos dois experimen 
tos, são consideradas adequadas para a apḷicação com equipamento de gotas uniformes, como reportam MAKEPEACE (1978) e HAROLD e CHAIRMAN (1979), constituindo-se em outro fato de muito importância para ajudar a explicar a não existência de diferenças nos controles entre os dois equipamentos.

Os fatos negativos apontados por PHILLIPES (1979), referentes a falhas na faixa de aplicação, tạ bém foram observados com o pulverizador de gotas uniformes. Pelas observações realizadas, uma das causas deste acon-tecimento, são as rajadas de ar que deslocam ligeiramente a faixa padrão de aplicação, com o que ficam pequenas āreas sem aplicar e onde as plantas daninhas germinam e o controle total pode ser diminuido.

\subsubsection{Experimento na curtura da soja}

As condições climáticas no momento da aplicação dos herbicidas pré-emergentes na cultura da soja, foram de certo modo adversos inara a cultura.

Assim, o solo estava muito úmido e a cultura começando a germinar, pois as precipitações ocorridas depois da semeadura não permitiram fazer a aplicação dos tratamentos imediatamente após ao plantio, como se pode observar na Tabe la 53 do Apêndice. Devido às condições de solo muito úmido, houve dificuldade na aplicação, especialmente com o pulveriza 
dor convencional. Fatores como solo muito úmido e textura mëdia fizeram com que o nível de injúria fosse alto e a popu lação inicial diminuida, particularmente para os herbicidas cyanazine e pendimethalin nas suas doses maiores.

Por esta razão, a avaliação visual de porcentagem de injúria e a população inicial da cultura, aos 20 dias apōs a aplicação dos herbicidas, apresentados na Tabela 21, mostraram altas porcentagens de injúria e diminuição da população inicial äa cultura. A análise da variância e o teste $F$ indicam existir diferenças altamente significativas entre herbicidas e doses, porēm não há significância para os equipamentos.

Muito embora os problemas descritos, assim co mo nos experimentos com milho, não houve diferença entre os dois equipamentos, ou seja, convencional e pulverizador de go tas uniformes, portanto as considerações feitas para aqueles experimentos, consideram-se tambēm validos para o experimen-to com soja.

A densidade das plantas daninhas aos 40 dias apôs a-aplicação dos herbicidas, foi de $138,7 \mathrm{plantas} / \mathrm{m}^{2}$ na testemunha (Tabela 22)。

A composição matoflorística e porcentual, incidente na área experimental foi: capim-colchão (Digitaria sanguinalis (L。) Scop.) $27,4 \%$, beldroega (Portulaca oleracea I.) 24,7\%, guansuma (Sida spp.) 16,2\%, malva-estrela (wissa- 
Tabela 21. Porcentagem de injuria e população inicial da cul tura da soja (número/m de sulco) no experimento com herbicidas aplicados em pré-emergência, aos 20 dias após a aplicação dos tratamentos. Piraci caba, SP, 1983-84.

\begin{tabular}{|c|c|c|c|}
\hline Tratamentos & $\begin{array}{c}\text { Q̄oses } \\
(i . a . \mathrm{kg} / \mathrm{ha})\end{array}$ & $\underset{\frac{\circ}{\sigma}}{\text { Injuaria }} 17$ & $\begin{array}{l}\text { População inicial } \\
\text { plantas } / \mathrm{m} \underline{2}\end{array}$ \\
\hline 01. Testemunha & - & 0,0 & 21,5 \\
\hline 02. alachlor & 2,35 & 2,5 & 20,2 \\
\hline 03. alachlor & 2,68 & 2,5 & 21,4 \\
\hline 04. alachlor & 4,12 & 3,7 & 19,2 \\
\hline 05. alachlor & 3,84 & 2,5 & 22,9 \\
\hline 06. cynazine & 1,60 & 40,0 & 11,4 \\
\hline 07. cynazine & 1,95 & 55,0 & 7,6 \\
\hline 08. cynazine & 2,10 & 73,7 & 3,5 \\
\hline 09.'cynazine & 2,30 & 81,2 & 5,5 \\
\hline 10. metribuzin & 0,35 & 2,5 & 20,6 \\
\hline 11. metribuzin & 0,42 & 2,5 & 22,7 \\
\hline 12. metribuzin & 0,60 & 2,5 & 22,1 \\
\hline 13. metribuzin & 0,70 & 2,5 & 26,5 \\
\hline 14. pendimethalin & 1,45 & 0,0 & 23,7 \\
\hline 15. pnedimethalin & 1,55 & 10,0 & 21,7 \\
\hline 16. pendimethalin & 2,10 & 57,5 & 15,1 \\
\hline 17. pendimethalin & 2,30 & 55,0 & 15,0 \\
\hline \multicolumn{2}{|c|}{ F. testemunha vs. fatorial } & $28,47 * *$ & ns \\
\hline \multicolumn{2}{|c|}{ F. Herbicidas (\&) } & $109,69 * *$ & $51,66 * *$ \\
\hline \multicolumn{2}{|l|}{ F. Doses (D) } & $50,82 * *$ & $5,95 *:$ \\
\hline \multicolumn{2}{|l|}{ F. Equipamentos (E) } & $2,68 \mathrm{~ns}$ & $0,90 \mathrm{~ns}$ \\
\hline \multicolumn{2}{|l|}{$F 。(H) \&(E)$} & $1,96 \mathrm{~ns}$ & $1,26 \mathrm{~ns}$ \\
\hline \multicolumn{2}{|l|}{$\operatorname{CV}\left(\frac{8}{8}\right)$} & 38,63 & 22,57 \\
\hline
\end{tabular}

17 Para a análise estatistica os dados foram transformados em arc sen $\sqrt{ }$ 客。

2/ Para a análise estatística os dados foram transformados em $\sqrt{x}$. 


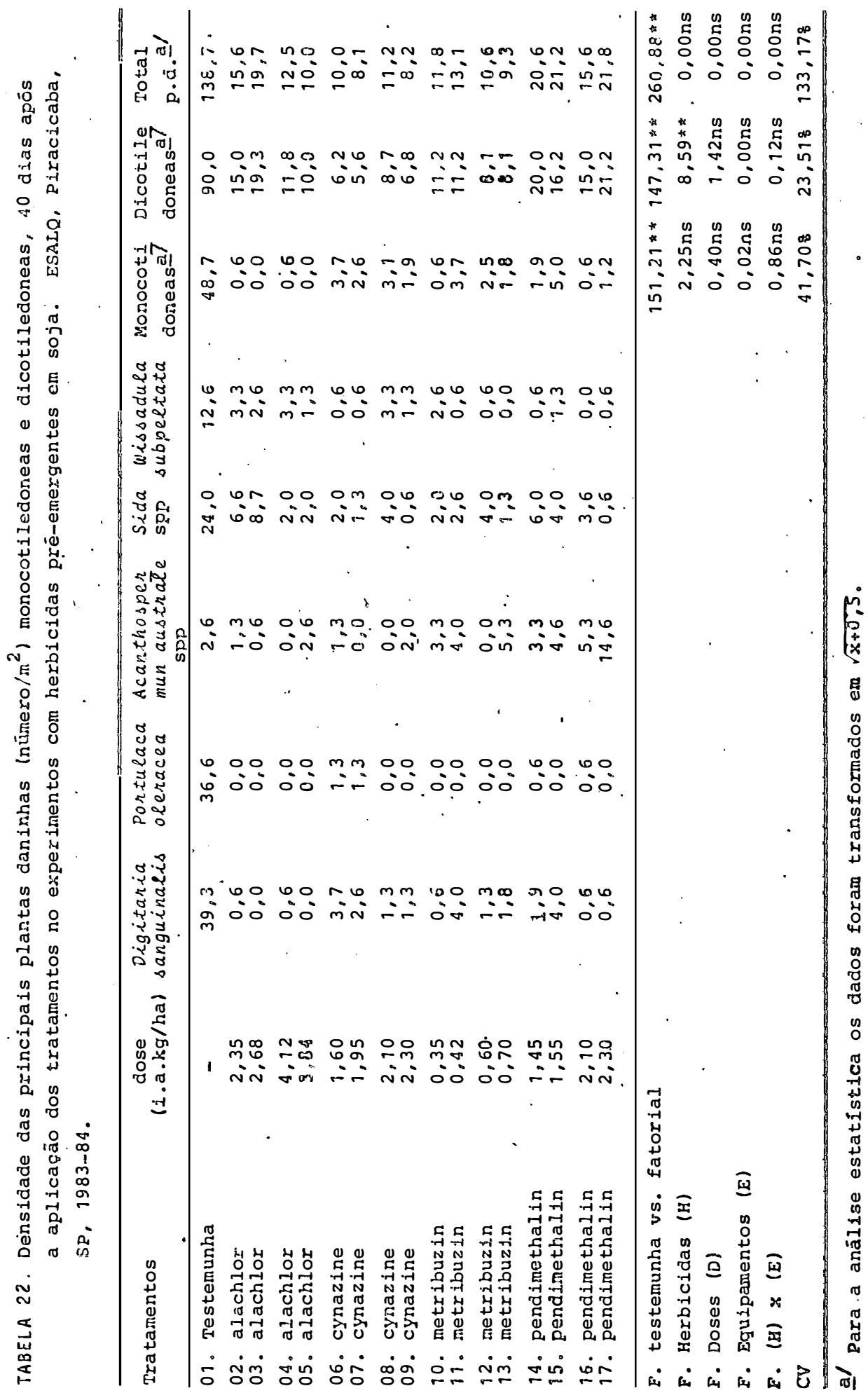


dula subpeltata (Kuntze) Fries) 8,5\%, fedegoso (Cassia tora L.) 4,9\%, caruru (Amaranthus spp.) 4,5\%, corda-de-viola (Ipo mea acuminata Roem. et Sch.) 2,2\%, capim-pé-de-galinha (Ele u sine indica (L.) Gaertn) 3,1\%, apaga-fogo (Alternanthera bicoidea (L。) R०Br.) 1,3\% e carrapichinho (Acanthospermun australe (Loef.) O. Kuntzee) 1,38.

As contagens das plantas daninhas remanescentes em cada tratamento, diferenciaaas em monocotiledôneas e dicotiledôneas e o total das mesmas aos 40 e 70 dias após a aplicação dos herbicidas, foram analisadas estatisticamente, e por meio do teste $F$ verifica-se que não há diferenças estatisticas significativas para herbicidas, doses e equipamentos (Tabelas 22 e 23), exceção às contagens de dicotiledôneas aos 40 dias e total de plantas daninhas aos 70 dias, que mostraram diferenças significativas para herbicidas pelo teste $\mathrm{F}$ 。

Em todas as anālises estatísticas só a testemunha diferiu significativamente de todos os tratamentos.

Nas avaliações visuais de controle das plantas daninhas monocotiledoneas e dicotiledōneas, aos 20,40 e 70 dias após a aplicação dos herbicidas, tampouco evidencia-rarit-se diferenças no controle das plantas daninhas para os dois equipamentos de aplicação. Assim, na Tabela 24, encontram-se os resultados da análise da variância para as dife-rentes avaliações e constatou-se através do teste $F$, que há 


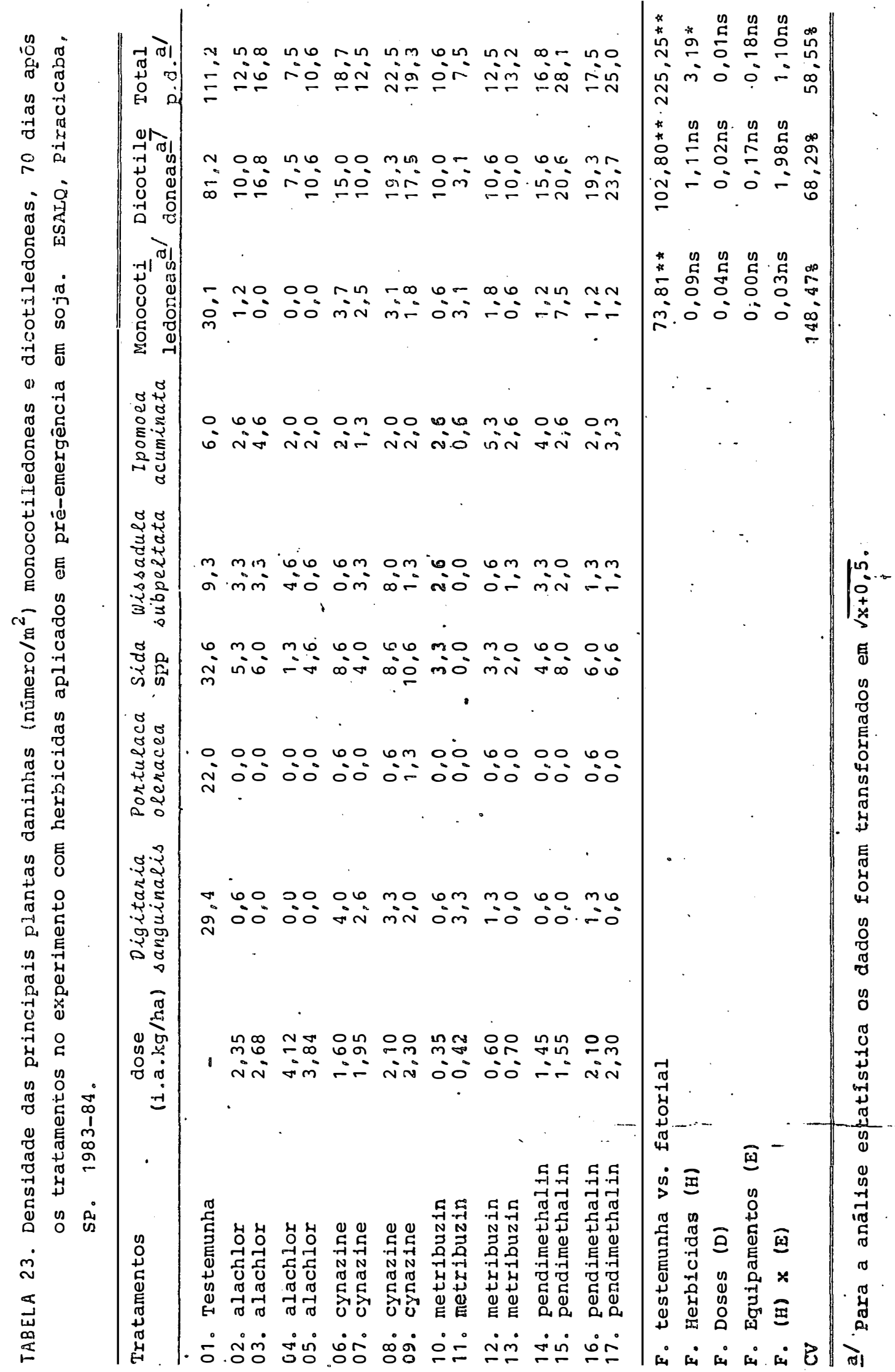




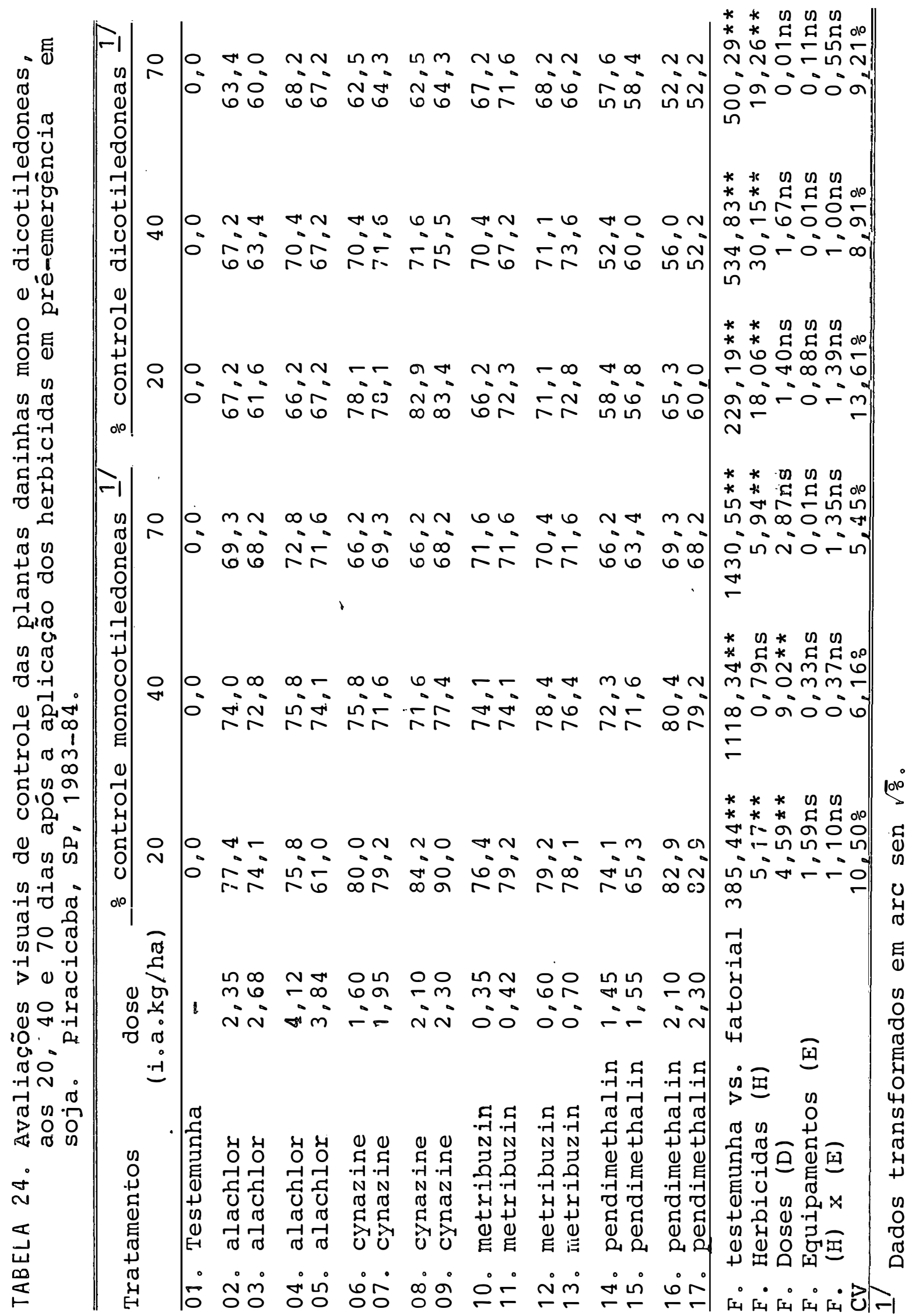


diferença significativa somente para o controle entre herbicidas e o conjunto de tratamentos com a testemunha.

Na avaliação da porcentagem de controle para monocotiledôneas aos 20 e 40 dias apỏs a aplicação, o teste F também resulta significativo para as doses.

Como já foi antecipado em llateriais e Métodos, o experimento com herbicidas pré-emergentes em soja,não foi conduzido até a colheita, por motivos de seca ocorrida nos meses de fevereiro e começo de março (Tabelas 55 e 56 do Apêndice), e que coincidiu com o estágio de enchimento das vagens afetando os rendimentos.

\section{Assim como nos experimentos com herbicidas} aplicados em pré-emergêncià em milho, não houve diferenças no controle das plantas daninhas entre os dois equipamentos. Resultados semelhantes foram obtidos por BOLETIM INFORMATIVO HATSUTA (1982) utilizando os mesmos herbicidas e cultura, ou aqueles citados por SCOTT e KAPUSTA (1983) usando os herbici das alachlor + metribuzin também na cultura da soja.

Dos quatro herbicidas empregados, três são formulações líquidas (alachlor, metolachlor e cynazine), e o metribuzin que é pó-molhável. Segundo BARzEE e STROUBE (1972) e ROBINSON (1978), esta última formulação não seria apropriada para as aplicações com o pulverizador de gotas uni formes, porém no presente experimento, não houve problemas na aplicação, possivelmente pela boa soiubilidade do metribu 
zin em água, e de outro lado as doses aplicadas resultaram também em baixás concentrações do herbicida na calda.

Pela semelhança dos resultados da pesquisa em outros países com aqueles da presente pesquisa, não existe uma razão óbvia para que os herbicidas aplicados ao solo sejam afetados, quando aplicados com pulverizadores de gota uniforme (TAYLOR, 1981), e de acordo com WILTSE (1983) este novo equipamento pode ser utilizado com resultados semelhantes aos pulverizadores convencionais.

4.2. Comportamento dos herbicidas aplicados em pós-emeirgência no controle da grama-seda, com os equipamentos convencional e de gotas uniformes

\subsubsection{Experimentos de campo}

O experimento conduzido no ano de 1983 apresentou condições extremas de precipitação e umidade ambiental, antes e depois da aplicação dos herbicidas, condições estas muito favoráveis para o desenvolvimento da grama-seda e desfavoráveis para o normal funcionamento dos herbicidas. Nas Tabelas 47,48 e 49 do Apêndice estão of dados climáticos da época em que se conduziu o experimento.

Já no experimento realizado durante o ano de 1984, a precipitação ocorrida antes da aplicação dos tratamentos, foi normal e adequada para o desenvolvimento inicial 
da grama-seda. Porém, depois da aplicação dos herbicidas, ou seja, nos meses de fevereiro e março, a precipitação foi muito escassa, como se pode observar nas Tabelas 54,55 e 56 do Apêndice.

As avaliações visuais de cobertura aos 30 e 40 dias após a aplicação dos herbicidas, no experimento conduzido em 1983, mostraram diferenças altamente :significativas para equipamentos (Tabela 25). Um posterior desdobramen to da análise de variância, indicado na Tabela 26, mostrou que estas diferenças somente foram significativas para equipamentos dentro das doses menores dos herbicidas fluazifopbutil e Dowco 453, observando-se na Tabela 25 uma cobertura maior da grama-seda para estes herbicidas quando aplicados pelo pulverizador de gotas uniformes.

Ainda que existisse a mesma tendência no experimento de 1984, quer dizer, uma cobertura ligeiramente maior com os mesmos herbicidas e @quipamentos, isto não foi significativo pelo teste $F$ durante as aváliações aos 20,35 e 60 dias após a aplicação dos tratamentos (Tabela 27).

As avaliações visuais de controle da grama-seda, em nenhuma das avaliações e nenhum dos anos, foram es tatisticamente significativas para equipamentos. Somente as interações herbicidas $x$ equipamentos foram significativas nas avaliações aos 10 e 40, 20 e 35 dias após a aplicação dos herbicidas nos anos de 1983 e 1984, respectivamente, resulta 


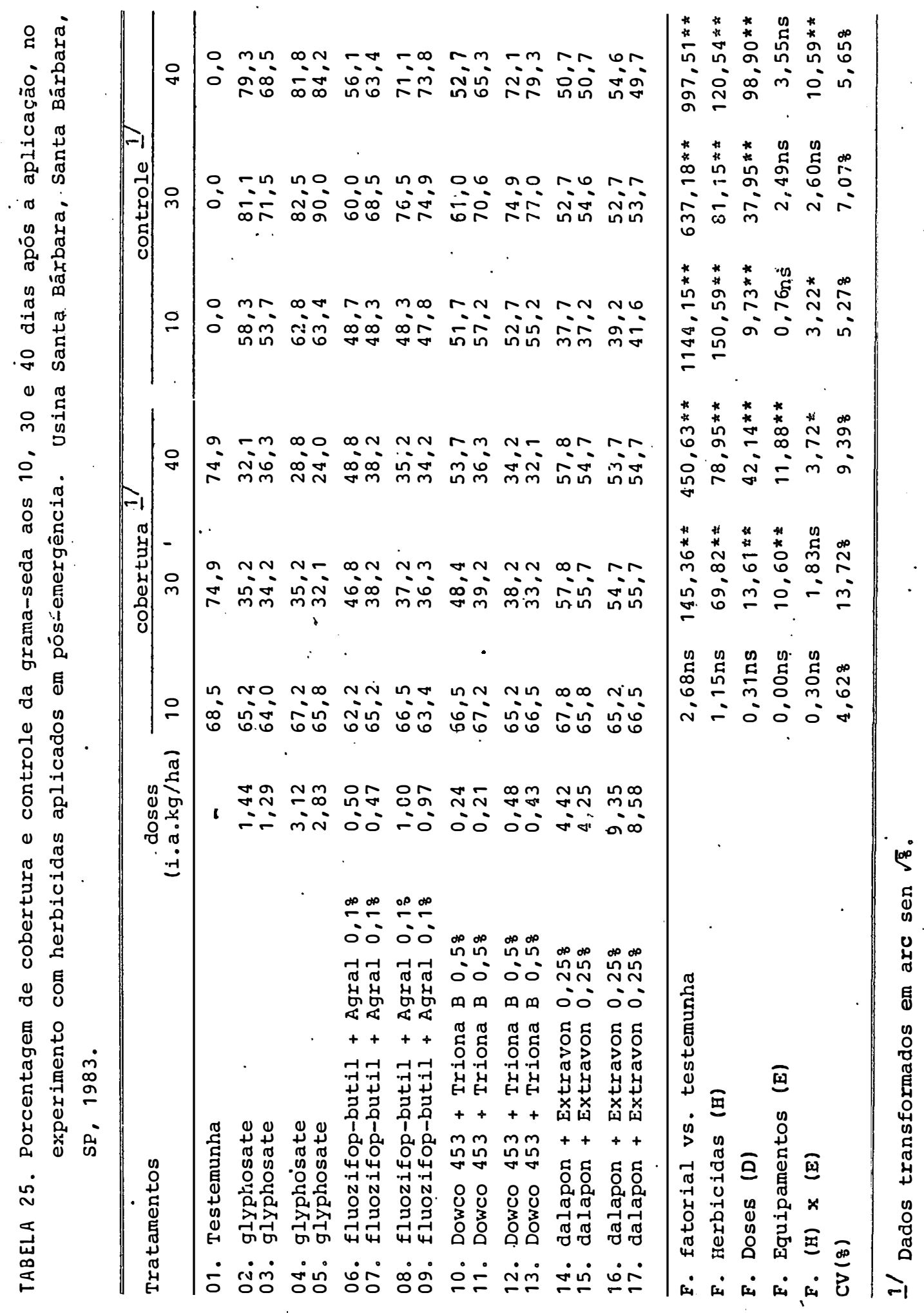


TABELA 26. Teste $F$ e niveis de significância para equipamentos dentro dos diferentes herbicidas, na avaliação visual de cobertura, no experimento com herbi cidas aplicados em pós-emergência em grama-seda. Santa Bárbara, SP, 1983.

Causas de variação

\begin{tabular}{cccc}
$\mathrm{F}$ & & \\
\hline 30 & $\mathrm{DAT}$ & 40 & $\mathrm{DAT}$
\end{tabular}

Equipamentos dentro glyphosate

$0,75 \mathrm{~ns} \quad 0,00 \mathrm{~ns}$

Equipamentos dentro fluazifop-butil

$4,71 * 6,04 *$

Equipamentos dentro Dowco 453

$10,60 * * \quad 16,97 * *$

Equipamentos dentro dàlapon

$0,40 \mathrm{~ns} \quad 0,05 \mathrm{~ns}$

Equipamentos dentro doses menores

$11,40 * \dot{x} \quad 14,82 * *$

Equipamentos dentro doses maiores

$1,50 \mathrm{~ns} \quad 1,05 \mathrm{~ns}$ 


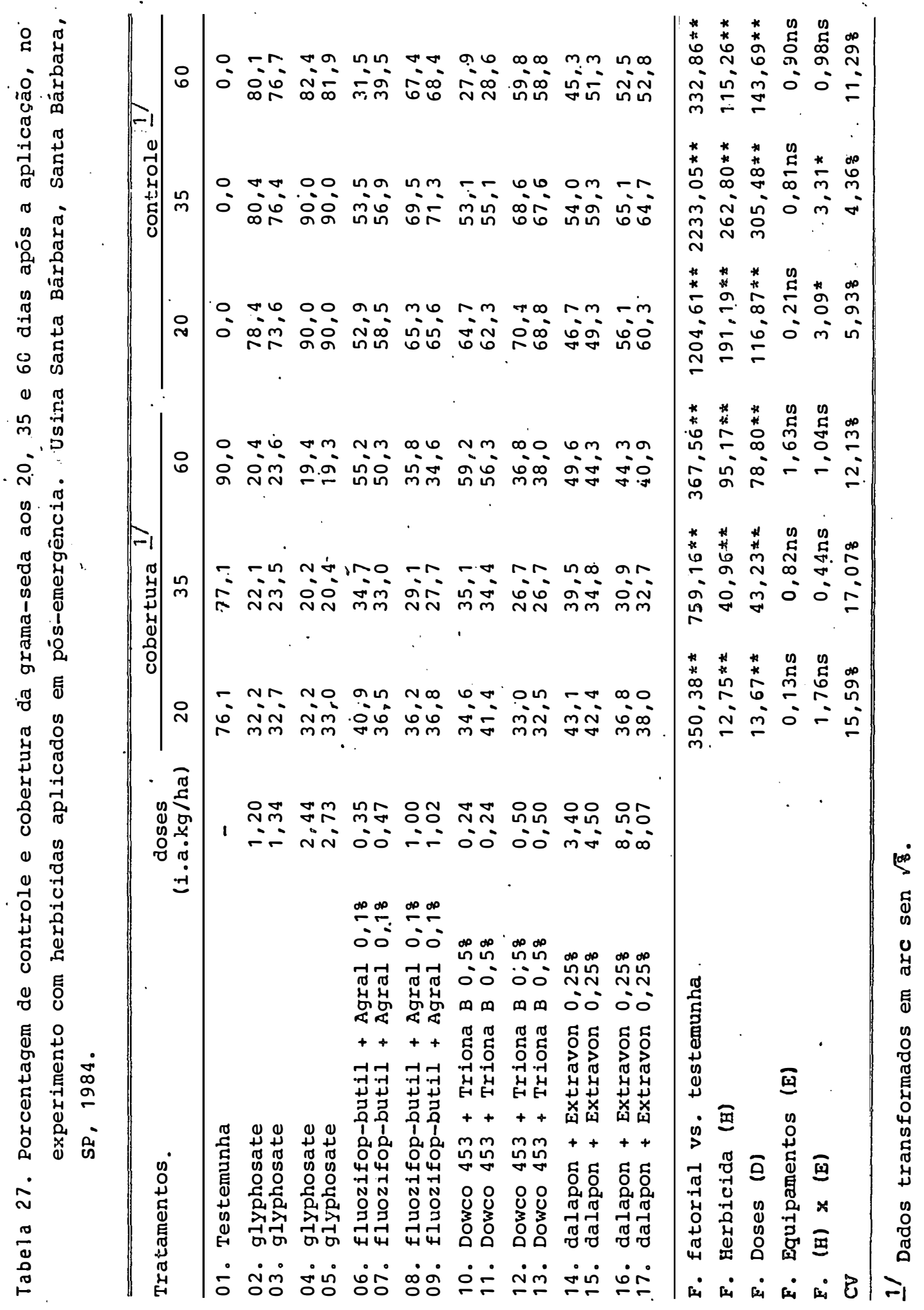


TABELA 28. Teste $F$ e niveis de significancia para equipamentos dentro dos diferentes herbicidas, na avaliação visual de controle, no experimento com herbicidas aplicados em pós-emergência em grama-seda . Santa Bárbara, SP. 1983.

Causas de variação

\begin{tabular}{lll}
\multicolumn{3}{c}{$\mathrm{F}$} \\
\hline $10 \mathrm{DAT}$ & 40 & $\mathrm{DAT}$ \\
\hline
\end{tabular}

Equipamentos dentro glyphosate

$1,96 \mathrm{~ns} \quad 4,68 *$

Equipamentos dentro fluazifopmbutil

$0,11 \mathrm{~ns} \quad 4,96 \mathrm{~ns}$

Equipamentos dentro Dowco-453

$7 ; 88 * 24,22$ **

Equipamentos dentro dalāpon

$0,46 \mathrm{~ns} \quad 1,47 \mathrm{~ns}$

Equipamentos dentro doses menores

$0,00 \mathrm{~ns} \quad 2,27 \mathrm{~ns}$

Equipamentos dentro doses maiores

$1,52 \mathrm{~ns} \quad 1,34 \mathrm{~ns}$ 
dos estes que se encontram nas Tabelas 25 e 27 .

Os desdobramentos da análise de variância rea lizados para os dois experimentos mostraram que nas avaliações feitas aos 10 e 40 dias após a aplicação, no experimento de 1983, o herbicida Dowco 453 obteve controles estatisti camente diferentes, sendo estes menores quando aplidados através do pulverizador de gotas uniformes (Tabela 28).

O herbicida fluazifop-butil também apresentou controles menores e estatisticamente diferentes, porém só na avaliação aos 40 dìas, quando aplicado pelo pulverizador de gotas uniformes (Tabela 28). Já o herbicida glyphosate obteve controles estàtisticamente superiores quando aplicado com o novo equipamento, nas avaliações aos 40 dias após a aplicação no ano de 1983 (Tabela 28) e aos 35 dias após a aplicação no ano de 1984 (Tabela 29).

No experimento do ano de 1984,os herbicidas fluazifop-butil, Dowco-453 e dalapon não mostraram diferenças significativas para equipamentos.

Por meio do teste Tukey para herbicidas dentro de equipamentos, no ano de 1983, mostrados na Tabela 30, os controles da grama-seda foram sempre maiores com o glypho sate; e menores com 0 dalapon. Aplicado com 0 equipamento conviencional o Dowco 453 teveisom desempenho, sen do estatisticamente iqual ao controle do glyphosate; no entanto,com o aplicador de gotas uniformes os herbicidas Dow- 
co-453 e fluozifop-butil apresentaram controles semelhantes, sendo estes intermediários entre o glyphosate e o dalapon.

TABELA 29. Teste $\mathrm{F}$ e niveis de significância para equipamentos dentro dos diferentes herbicidas, nas avaliações de controle visual aos 20 e 35 dias após a aplicação dos herbicidas. Santa Bárbara, SP, 1984 。

Causas de variação $\mathrm{F}$

$20 \mathrm{DAT}$ 35 DAT

Equipamentos dentro g'lyphosate $2,40 \mathrm{~ns} \quad 4,25$ *

Equipamentos dentro fluazifop-butil $2,54 \mathrm{~ns} \quad 3,39 \mathrm{~ns}$

Equipamentos dentro Dowco-453 $0,98 \mathrm{~ns} \quad 0,08 \mathrm{~ns}$

Equipamentos dentro dalapon $3,54 \mathrm{~ns} \quad 3,08 \mathrm{~ns}$

Equipamentos dentro doses menores $0,00 \mathrm{~ns} \quad 2,68 \mathrm{~ns}$

Equipamentos dentro doses maiores $0,39 \mathrm{~ns} \quad 0,12 \mathrm{~ns}$ 
TABELA 30. Teste de Tukey para herbicidas dentro de equipamentos. Avaliações visuais de controle no experi mento com herbicidas aplicados em pós-emergência, em gramamseda. Santa Bárbara, SP, 1983.

\begin{tabular}{|c|c|c|c|c|}
\hline \multirow{2}{*}{ Herbicidas } & \multicolumn{2}{|c|}{$10 \mathrm{DAT}$} & \multicolumn{2}{|c|}{$40 \mathrm{DAT}$} \\
\hline & $\begin{array}{l}\text { Conven } \\
\text { ciona } \overline{1}\end{array}$ & $\mathrm{CDA}$ & $\begin{array}{l}\text { Conven } \\
\text { cional }\end{array}$ & $\mathrm{CDA}$ \\
\hline glyphosate & 58,61 a & $60,63 a$ & 76,46 a & $80,85 a$ \\
\hline fluazifop-butil & $48,11 \mathrm{~b}$ & $48,60 \mathrm{~b}$ & $68,81 \mathrm{~b}$ & $64,28 \mathrm{~b}$ \\
\hline Dowco-453 & $56,32 a$ & $52,26 \mathrm{~b}$ & $72,54 \mathrm{ab}$ & $62,55 \mathrm{~b}$ \\
\hline dalapon & $39,45 \mathrm{c}$ & $38,47 \mathrm{c}$ & $50,29 \mathrm{c}$ & $52,75 \mathrm{c}$ \\
\hline DMS ' & 3,915 & 3,915 & 5,507 & 5,507 \\
\hline
\end{tabular}

Os resultados do experimento conduzido em 1984, diferem um pouco dos resultados citados para o ano anterior. Pode-se verificar pelo teste Tukey da Tabela 31, que somente na avaliação aos 20 dias depois da aplicação os herbicidas fluazifop-butil e Dowco-453 apresentaram controles intermediários entre glyphosate e dalapon. Já para a avaliação aos 35 dias após a aplicação, só o glyphosate dife riu estatisticamente dos outros três herbicidas. 
TABELA $3 \uparrow$. Teste de Tukey para herbicidas dentro de equipamentos. Avaliações visuais de controle da grama-seda aos 20 e 35 dias após a aplicação dos herbí cidass. Santa Bárbara, SP, 1984 .

\begin{tabular}{|c|c|c|c|c|}
\hline \multirow{2}{*}{ Herbicidas } & \multicolumn{2}{|c|}{$20 \mathrm{DAT}$} & \multicolumn{2}{|c|}{$35 \mathrm{DAT}$} \\
\hline & $\begin{array}{l}\text { Conven } \\
\text { cional }\end{array}$ & $\mathrm{CDA}$ & $\begin{array}{l}\text { Conven } \\
\text { cional }\end{array}$ & $\mathrm{CDA}$ \\
\hline glyphosate & $81,78 a$ & $84,64 a$ & $82,55 a$ & 85,40 a \\
\hline fluazifop-butil & $62,26 \mathrm{~b}$ & $59,32 \mathrm{c}$ & $64,19 b$ & $61,65 \mathrm{~b}$ \\
\hline Dowco-453 & $65,77 \mathrm{~b}$ & $67,61 \mathrm{~b}$ & $61,43 \mathrm{~b}$ & $61,04 \mathrm{~b}$ \\
\hline dalapon & $54,93 \mathrm{c}$ & $51,46 \mathrm{~d}$ & $62,05 \mathrm{~b}$ & $59,64 \mathrm{~b}$ \\
\hline DMS ' & ' 4,916 & 4,916 & 3,680 & 3,680 \\
\hline
\end{tabular}

As avaliações da biomassa verde e seca da grama-seda aos 60 dias depois da aplicação, foram realizadas somente no experimento de 1984. Para o experimento do ano de 1983, a área experimental não ficou disponível até aquela data, razão pela qual estas avaliações foram feitas somente aos 40 dias.

As análises estatísticas e o teste $F$ para biomassa verde e seca da grama-seda aos 40 dias, no experimento de 1983, mostraram que há diferenças significativas pa ra equipamentos somente com a biomassa seca (Tabela 32), e diferenças significativas para a interação herbicida $\mathrm{x}$ equi- 
.110

TABELA 32. Biomassa verde e seca da grama-seda $\left(\mathrm{g} / \mathrm{m}^{2}\right)$ aos 40 dias após a aplicação dos herbicidas aplicados em pós-emergência em grama-seda. Usina Santa Bárbara, SP, 1983.

\begin{tabular}{|c|c|c|c|}
\hline Tratamentos & $\begin{array}{c}\text { doses } \\
(i . a . \mathrm{kg} / \mathrm{ha})\end{array}$ & $\begin{array}{c}\text { Biomassa } \\
\text { verde }\end{array}$ & $\begin{array}{l}\text { Biomassa } \\
\text { seca }\end{array}$ \\
\hline 01. Testemunha & - & 999,4 & 433,8 \\
\hline 02. glyphosate & 1,44 & 200,9 & 109,1 \\
\hline 03. glyphosate & 1,29 & 203,3 & 98,4 \\
\hline 04. glyphosate & 3,12 & 149,4 & 89,3 \\
\hline 05. glyphosate & 2,83 & 139,3 & 78,4 \\
\hline 06. fluazifop-butil + Agral $0,1 \%$ & 0,50 & 385,1 & 162,9 \\
\hline 07. fluazifop-butil + Agral 0,1\% & 0,47 & 388,1 & 117,2 \\
\hline 08. fluazifop-butil + Agral $0,1 \%$ & 1,00 & 279,8 & 117,6 \\
\hline 09. fluazifop-butil + Agral 0,18 & 0,97 & 262,2 & 110,5 \\
\hline 10. Doweo 453 + Triona B 0,58 & 0,24 & 517,9 & 205,7 \\
\hline 11. Dowco 453 + Triona B 0,58 & 0,21 & 297,4 & 126,6 \\
\hline 12. Dowco 453 + Triona B 0,58 & 0,48 & 372,1 & 158,3 \\
\hline 13. Dowco 453 + Triona B $0,5 \%$ & 0,43 & 251,1 & 112,9 \\
\hline 14. dalapon + Extravon 0,25\% & 4,42 & 567,7 & 218,3 \\
\hline 15. dalapon + Extravon 0,25\% & 4,25 & 664,8 & 255,0 \\
\hline 16. dalapon + Extravon $0,25 \%$ & 9,35 & 667,8 & 265,4 \\
\hline 17. dalapon + Extravon 0,25\% & 8,58 & 692,8 & 258,8 \\
\hline F. testemunha vs。 fatorial & & $72,06 * *$ & $60,33 *$ \\
\hline F。Herbicidas (H) & & $32,48 * *$ & $47,62 *$ \\
\hline F. Doses (D) & & $1,45 \mathrm{~ns}$ & $1,76 \mathrm{~ns}$ \\
\hline F。 Equipamentos (E) & & $1,15 \mathrm{~ns}$ & $4,78 *$ \\
\hline F. (H) $\times$ (E) & & $1,85 \mathrm{~ns}$ & $2,81 *$ \\
\hline $\mathrm{CV}$ & & $30,20 \%$ & 26,53 \\
\hline
\end{tabular}


pamento, no caso da biomassa seca da grama-seda. O desdobra mento da análise da variância para este fator, demonstrou que somente para o herbicida Dowco-453 estas diferenças são significativas (Tabela 33).

Verifica-se na Tabela 32 que a biomassa seca da grama-seảa foi maior naqueles tratamentos com o herbicida Dowco-453 e com o pulverizador de gotas uniformes, quándo se compara este mesmo herbicida pulverizado com o : equipamento convencional。

Através do teste Tukey para bijomassa seca, indicado na Tabela 34, verifica-se que o herbicida glyphosate foi o que produziu' menos que os demais hericidas, ainda que nas comparações dentro do equipamento convencional, não diferindo estatisticamente dos herbicidas fluazifop-butil e DowCO-453.

Já com o equipamento de gotas uniformes somen te o fluazifop-butil não diferiu estatisticamente do herbicida glyphosate. O Dowco 453 e o dalapon, embora diferentes estatisticamente, apresentaram as maiores produções de matéria seca.

No experimento conduzido em 1984, as avaliações de biomassa verde e seca da grama-seda, aos 30 dias, re sultaram não significativos pelo teste $F$, para equipamentos: porềm as interações herbicidas $\mathrm{x}$ equipamentos foram significativas. Estes mesmos parâmetros, avaliados e analisados es 
TABELA 33. Teste $F$ e niveis de significância para equipamentos dentro dos diferentes herbicidas, biomassa se da da grama-seda, no experimento com herbicidas a plicaảos em pós-emergência em grama-seda. Santa Bārbara, SP, 1983.

Causas de variação F

biomassa seca

Equipamentos dentro glyphosate $0,31 \mathrm{~ns}$

Equipamentos dentro fluazifop-butil

$1,85 \mathrm{~ns}$

Equipamentos dentro Dowco-453

10,44 * *

Equipamentos dentro dalapon

$0,60 \mathrm{~ns}$

Equipamentos dentro doses menores

$3,31 \mathrm{~ns}$

Equipamentos dentro doses maiores

$1,61 \mathrm{~ns}$

TABELA 34. Teste de Tukey para herbicidas dentro os dois equipamentos da biomassa seca em grama-seda; no ex perimento com herbicidas pós-emergentes em grama-seda. Santa Bárbara, SP, 1983.

\begin{tabular}{lcc}
\hline Herbicidas & \multicolumn{2}{c}{ Matéria seca } \\
\cline { 2 - 3 } glyphosate & Convencional & CDA \\
\hline fluazifop-butil & $88,43 . \mathrm{b}$ & $99,24 \mathrm{c}$ \\
Dowco-453 & $113,85 \mathrm{~b}$ & $140,26 \mathrm{bc}$ \\
dalapon & $119,76 \mathrm{~b}$ & $182,48 \mathrm{~b}$ \\
& $256,93 \mathrm{a}$ & $241,93 \mathrm{a}$ \\
\hline DISS & & 51,722
\end{tabular}


tatisticamente aos 60 dias após a aplicação, tampouco resultaram signficativos para equipamentos ou para a interação herbicida x equipamento, como consta na Tabela 35.

o desdobramento da análise da variância para equipamentos dentro de herbicidas para os dois parâmetros avaliados aos 30 dias, mostraram que para o herbicida fluazi fop-butil há diferenças significativas entre equipamentos (Tabela 36), havendo menor produção de biomassa verde e bio massa seca na grama-seda quando pulverizado com o equipamento convencional,ó que também pode ser observado na Tabela 35.

O mesmo desdobramento da análise de variância (Tabèla 36), também mostrou que para o herbicida dalapon hou ve diferenças significativas na avaliação de biomassa verde, sendo este parâmetro menor quando pulverizado pelo equipamen to convencional. Muito embora o teste $F$ para equipamentos dentro de doses não acuse significancias, há indicações de que as diferenças observadas entre os equipamentos, com os herbicidas fluazifop-butil e dalapon, sejam devidas,em parte, às diferenças nas doses aplicadas.

Pelo teste Tukey da Tabela 37 , a produção de biomassa verde e seca pela grama-seda, foi sempre menor. com o herbicida glyphosate, particularmente quando pulverizado com o aplicador de gotas uniformes, se bem que não diferiu estatisticamente. Para os herbicidas fluazifop-butil e Dowco-453 estas produções foram estatisticamente iguais quando 


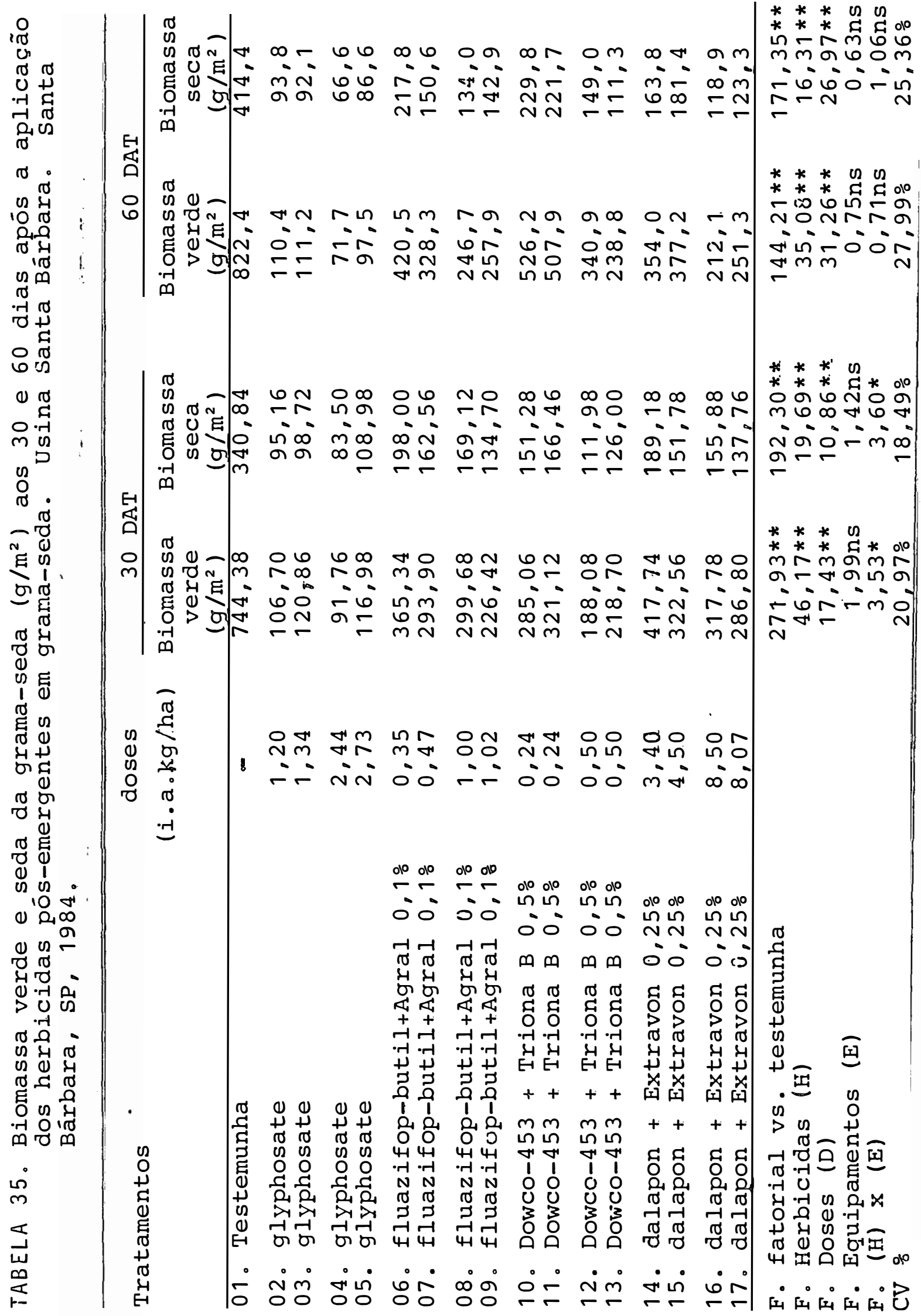


TABELA 36. Teste $F$ e niveis de significancia para equipamentos dentro dos diferentes herbicidas, nas avaliações de biomassa verde e seca em grama-seda, 30 dias após a aplicação dos herbicidas. Santa Bár ra, SP, 1984.

\begin{tabular}{llc}
\hline Causas de variação & \multicolumn{2}{c}{$\mathrm{F}$} \\
\cline { 2 - 3 } & $\begin{array}{c}\text { biomassa } \\
\text { verde }\end{array}$ & $\begin{array}{c}\text { biomassa } \\
\text { seca }\end{array}$ \\
\hline Equipamentos dentro glyphosate & $0,45 \mathrm{~ns}$ & $1,06 \mathrm{~ns}$ \\
Equipamentos dentro fluazifop-butil & $6,15^{*}$ & $6,18^{*}$ \\
Equipamentos dentro Dowco-453 & $1,30 \mathrm{~ns}$ & $1,08 \mathrm{~ns}$ \\
Equipamentos dentro dalapon & $4,67^{*}$ & $3,90 \mathrm{~ns}$ \\
Equipamentos dentro doses menores & $1,98 \mathrm{~ns}$ & $1,85 \mathrm{~ns}$ \\
Equipamentos dentro doses maiores & $0,34 \mathrm{~ns}$ & $0,10 \mathrm{~ns}$ \\
\hline
\end{tabular}

TABELA 37. Teste de Tukey para herbicidas dentro os dois equipamentos. Avaliações de biomassa verde e seca da grama-seda, aos 30 dias após a aplicação dos herbicidas. Santá Bárbara, SP, 1984.

\begin{tabular}{|c|c|c|c|c|}
\hline \multirow{2}{*}{ Herbicidas } & \multicolumn{2}{|c|}{ biomassa verde } & \multicolumn{2}{|c|}{ biomassa seca } \\
\hline & $\begin{array}{l}\text { Conven } \\
\text { cional }\end{array}$ & $\mathrm{CDA}$ & $\begin{array}{l}\text { Conven } \\
\text { cional }\end{array}$ & $\mathrm{CDA}$ \\
\hline glyphosate & $118,92 \mathrm{~b}$ & $99,21 \mathrm{c}$ & $103,85 \mathrm{~b}$ & $89,33 c$ \\
\hline fluazifop-butil & $260,16 a$ & $332,52 a$ & 148,64 a & $183,56 \mathrm{a}$ \\
\hline Dowco -453 & $269,92 a$ & $236,57 \mathrm{~b}$ & 146,12 a & $131,64 \mathrm{~b}$ \\
\hline dalapon & $304,68 \mathrm{a}$ & 367,76 a & $144,77 a$ & $172,53 \mathrm{a}$ \\
\hline DMS & 77,734 & 77,734 & 37,443 & 37,443 \\
\hline
\end{tabular}


aplicados com o pulverizador convencional, no entanto, este comportamentu mudou um pouco com o equipamento de gotas uniformes. As aplicações de Dowco 453 com o equipamento de gotas uniformes, reduziram a produção de biomassa verde e seca em quantidades levemente menores em relação a aquelas obtidas com o pulverizacior convencional, porèm, como mostrado na Tabela 36, estas diferenças entre equipamentos não resultaram significativas.

Como foi indicado em parágrafos iniciais, os dois anos nos quais foram conduzidos os experimentos apresentaram condições climáticas muito diferentes. Assim em 1983 a precipitação foi excessiva, a umidade relativa alta e a temperatura normal. Já para o ano de 1984 no periodo de condução do experimento, a precipitação foi escassa, a umidā de relativa baixage por outro lado,foi um ano que se caracte rizou por altas temperaturas, dados estes que constam nas Tabelas 54, 55 e 56 do Apêncide.

No mesmo dia dæ aplicação dos herbicidas no experimento em 1983, houve uma precipitação de 3,2 mm a qual aconteceu aproximadamente 7 horas após a aplicação dos herbi cidas (Tabela 47. do Apêndice). Se bem que este fato possa ter influenciado negativamente a todos os tratamentos 8 pelas avaliações de cobertura, controle e biomassa seca da grama -seda evidenciou-se que os herbicidas fluazifop-butil, e em grau maior o Dowco-453, quando aplicados pelo pulverizador de gotas uniformes, foram mais prejudicados no seu desempe- 
nho. Se bem que isto somente foi significativo para o herbi cida Dowco-453 em todas as avaliações, já para o fluazifop-butil nas avaliações de biomassa seca houve diferenças, mas sem significancia estatistica. Para o Dowico-453, as diferenças foram estatisticamente difurentes nas duas doses.

\section{Para explicar este fato, inexiste na literatu} ra consultada qualquer referência indicando maior suscetibilidade a lavagem pela chuva, dos herbicidas aplicados com o pulverizador de gotas uniformes; pois deve ter aconteciāo uma lavagem maior para us herbicidas fluazifop-butil e Dowco -453, quando aplicados por este equipamento. A não existência de diferenças significativas para doses dentro dos diferentes herbicidas, na avaliação de biomassa verde e seca (Tâ bela 32), é um fato que apoia a incidência negativa da chuva sobre os diferentes herbicidas, pois, se bem que existem produções menores com as doses maiores, estas não foram estatís ticamente diferentes daquelas obtidas com as doses menores.

No experimento realizado em 1984, quando não houve chuva depois da aplicação, existiram diferenças significativas para as doses dos diferentes herbicidas.

Por outro lado, ocorreu uma grande produção de biomassa verủe e consequentemente, a camada de grama-seda foi mais espessa no momento da aplicação dos herbicidas, para $\circ$ ano de 1983. Este fato pode também ter contribuído para o menor desempenho do pulverizador de gotas uniformes ao se aplicar os mencionados herbicidas. 
Assim, MAYES e BLANCHARD (1978) atribuem os controles menores obtidos pelo novo equipamento a problemas de adensamento que evitariam a pulverização atingir todas as plantas daninhas com a pulverização. Por outro lado, a tama nho das g'utas produzidas pelo pulverizador de gotas uniformes apresentam deposição horizontal predominante, de acordo com JOHNSTONE $(1978 \mathrm{~b})$, sendo que as gotas com tamanho menor que $100 \mu \mathrm{m}$ e que apresentam deposição vertical (GUNN, 1978), estão praticamente ausentes. Esta reduzida suscetibilidade à deriva como indicam MAYERS et alii (1979) pode ser uma causa para a obtenção de um controle menor, como aqueles obser vados com os herbicidas fluazifop-butil e Dowco-453.

Jả para a pulverização convencional, o amplo espectro de gotas por ela produzida (BALS, 1971; STRONG, 1979; COTTON GROWER, 1980; MICRON CORPORATION, 1981; BOLETIM INFORMATIVO HATSUTA, 1982) faria com que a cobertura horizon tal e vertical da folhagem da grama-seda fosse satisfatória, diminuindo o efeito da lavagem pela chuva e,portanto,permitindo um melhor controle desta planta daninha nas mencionadas condições.

Fatores como retenção, aspersão e molhabilidade, grau de contato da folha com o ingrediente ativo, penetração dentro da planta, são afetados pela formulação do her bicida (ROBINSON, 1978) e poderia ter acontecido que alguns destes fatores, nos herbicidas fluazifop-butil e Dowco-453, fossem afetados pela chuva e equipamentos, resultando em bai 
xos controles da grama-seda para estes herbicidas.

No experimento do ano de 1984, favorável para o bom desempenho dos herbicidas, as diferenças observadas en tre equipamentos e herbicidas foram explicadas em parte pelas diferenças nas doses aplicadas. De um modo geral, o desempenho dos herbicidas foi semelhante para os dois equipamentos。

O uso de carregadores oleosos para aplicar os herbicidas fluazifop-butil e Dowco-453, como neportam DOLL et alii (1983) e CRANMER e DUKE (1983), resultaram em melhores controles da graminea perene Agropyron repens, quando pulvèrizados com o pulverizador de gotas uniformes. No presente experimento, os herbicidas foram aplicados em solução aquosa e os resultados mostraram que não há diferenças entre os dois equipamentos. Isto concorda com SLACK e WITT (1983) já que os herbicidas fluazifop-butil e Dowco-453, quando apli cados nas doses recomendadas comercialmente, não mostraram diferencas significativas no controle, e as doses reduzidas também resultaram em controles reduzidos para os dois tipos de equipamentos.

Os resultados com o dalapon, mostraram que es te herbicida não foì, influenciado pelo tipo de equipamento e,sim,pela dose de aplicação como foi indicado anteriormente.

A pulverização com equipamento convencional ou gotas uniformes do herbicida glyphosate resultaram em 
controles estatisticamente iguais, seja com as doses menores ou as maiores. Embora tenha sido observado sempre, nas doses menores, um melhor desempenho do pulverizador de gotas uniformes, seja no controle ou nas avaliações de biomassa, verde e seca da grama-seda, concordando assim com os resulta dos de BRUGE e JEAN (1978), MOREL (1981) e ViLLTSE (1983), e $\underline{\underline{s}}$ tas não foram estatisticamente significativas, salvo em uma ocasião.

Os melhores controles deste herbicida, quando aplicados com o pulverizador de gotas uniformes, sobre a graminea perene Agropyron repens, citados por CHARLCTTE : e BURRILL (1979) e TURNER e LOADER (1978), foram obtidos com doses de 0,56 e 1,12 kg i.a./ha, doses estas menores que as empregadas em qualquer dos experimentos conduzidos.

Segundo MC GARVEY e BALS (1979), para controlar o capim-massambará,hā poüca vantagem em aplicar doses maiores que $1,12 \mathrm{~kg}$ i.a./ha de glyphosate, com $\circ$ pulverizador de gotas uniformes. A partir dos resultados obtidos, e comparando-os com os da literatura consultada, nas doses tes tadas seria pouco provável serem obtidas diferenças estatísticas nos controles da grama-seda. Por outro lado, também é provável que as condições climáticas ótimas durante o experi mento de 1984, fizeram com que a dose menor de glyphosate e pulverizada com equipamento convencional, também atingisse altos niveis de controle. 


\subsubsection{Experimentos em casa-de-vegetação}

Os dois experimentos conduzidos em casa-de-ve getação tinham como objetivo apoiar os experimentos de campo: a tentar uma explicação para os melhores controles de alguns herbicidas quando aplicados pelo pulverizador de gotas uniformes 。

As condições de temperatura : e luminosidade dentro da casa-de-vegetação não foram controladas, portanto, ficaram infiluenciadas pelas condições climáticas externas.

O primeiro experimento aplicado em 21. 03.83, transcorreu nọs meses de março, abril e maio, caracte rizados pela alta umidade relativa e temperaturas em declínio, Eomo pode-se observar nas Tabelas 49 e 50 do Apêndice. Para o experimento conduzido durante 1983-84, a aplicação foi realizada em 16.12.83, transcorrendo nos meses de dezembro, janeiro, fevereiro e março, com condições climáticas de alta luminosidaāe e temperatura, dados estes encontrados nas Tabe las $53,54,55$ e 56 do Apêndice.

No experimento conduzido em 1982-83, os dados da biomassa verde da grama-seda, analisados estatisticamente, revelaram que há diferenças estatisticamente significativas entre os dois equipamentos de pulverização, para os herbicidas glyphosate, Dowco-453 e fluazifopimbutil, porém,não foi observado com oitherbicida dalapon (Tabelas 38 e 39). o teste $F$ para doses e cortes também resultam altamente significa 


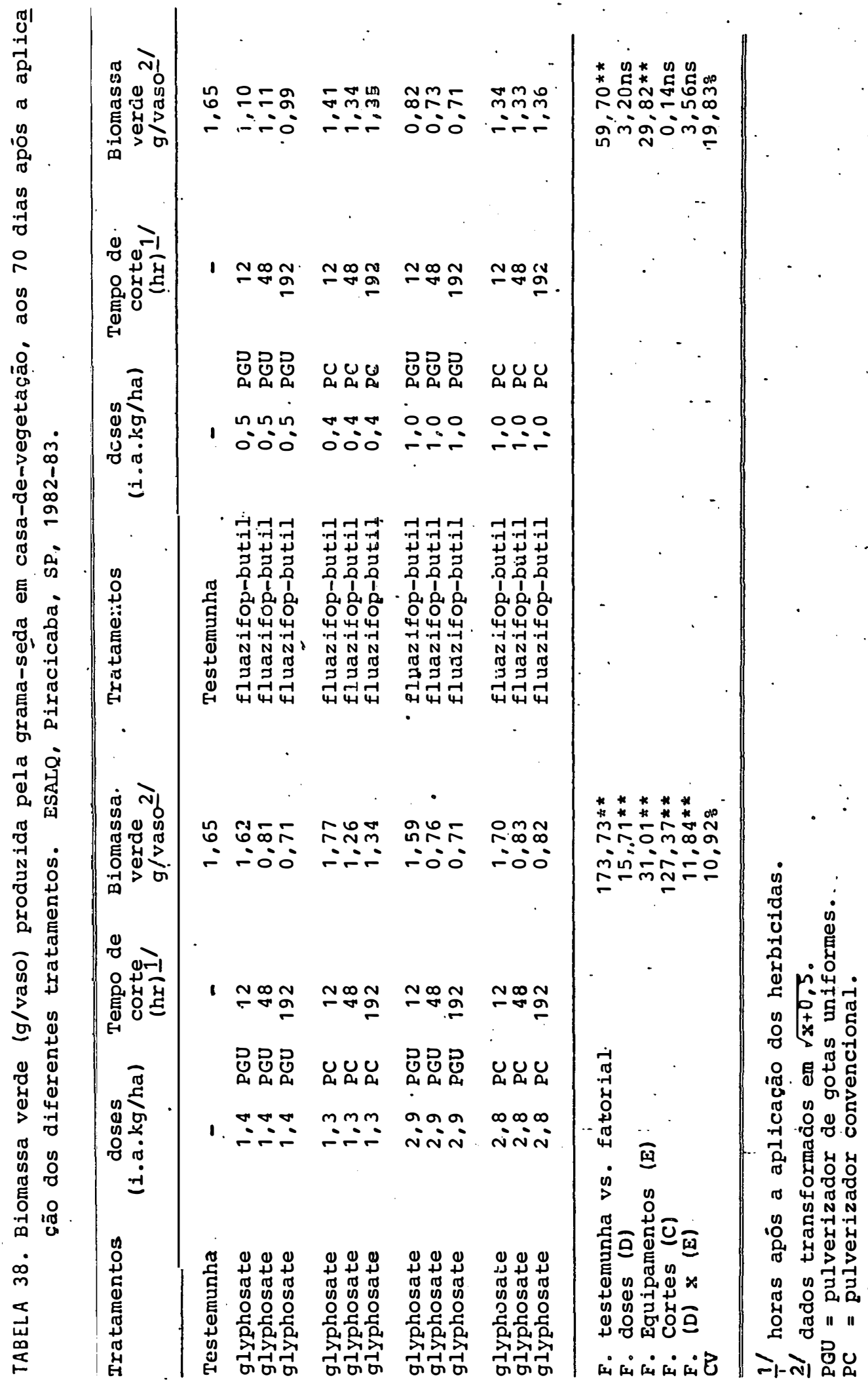




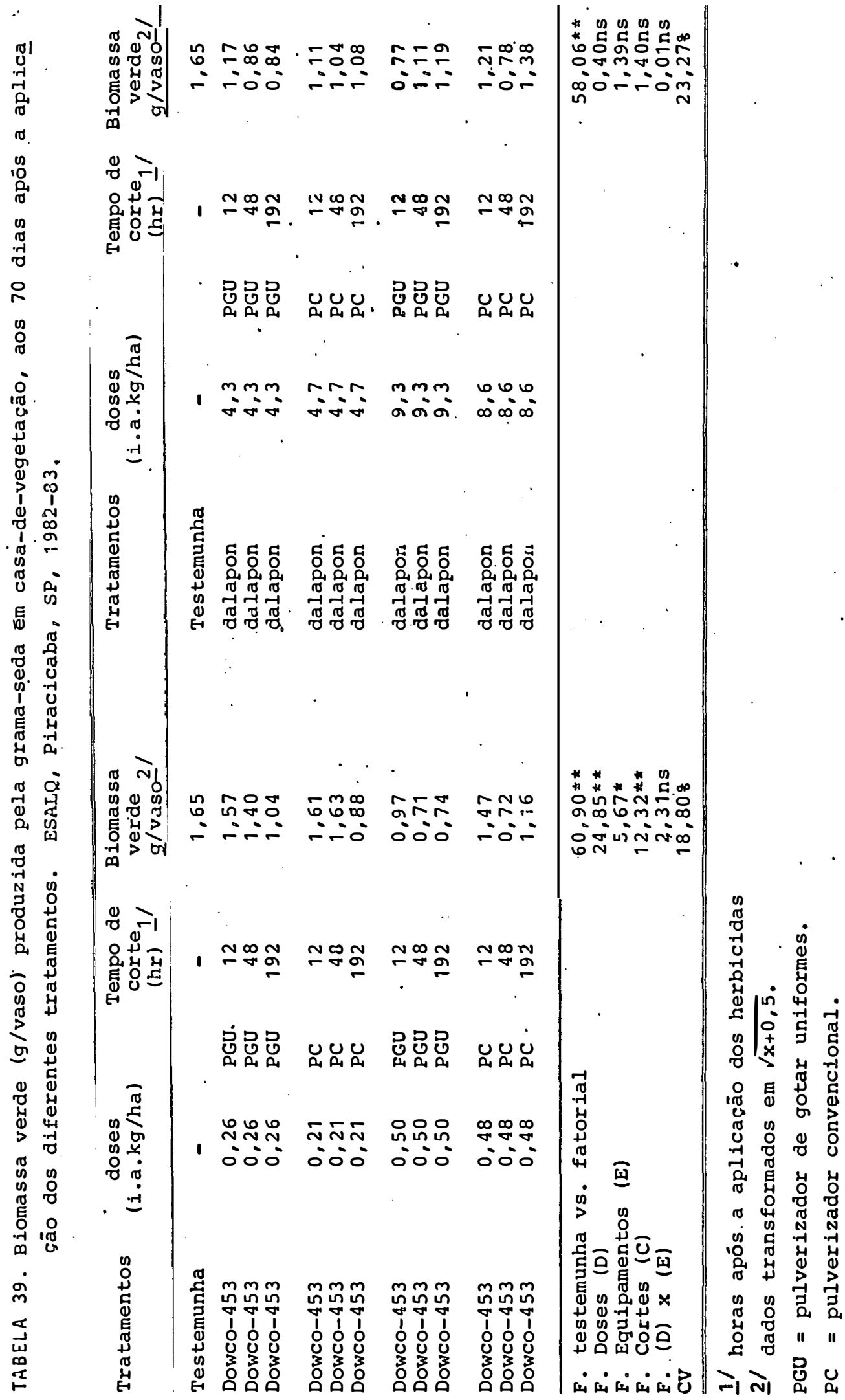




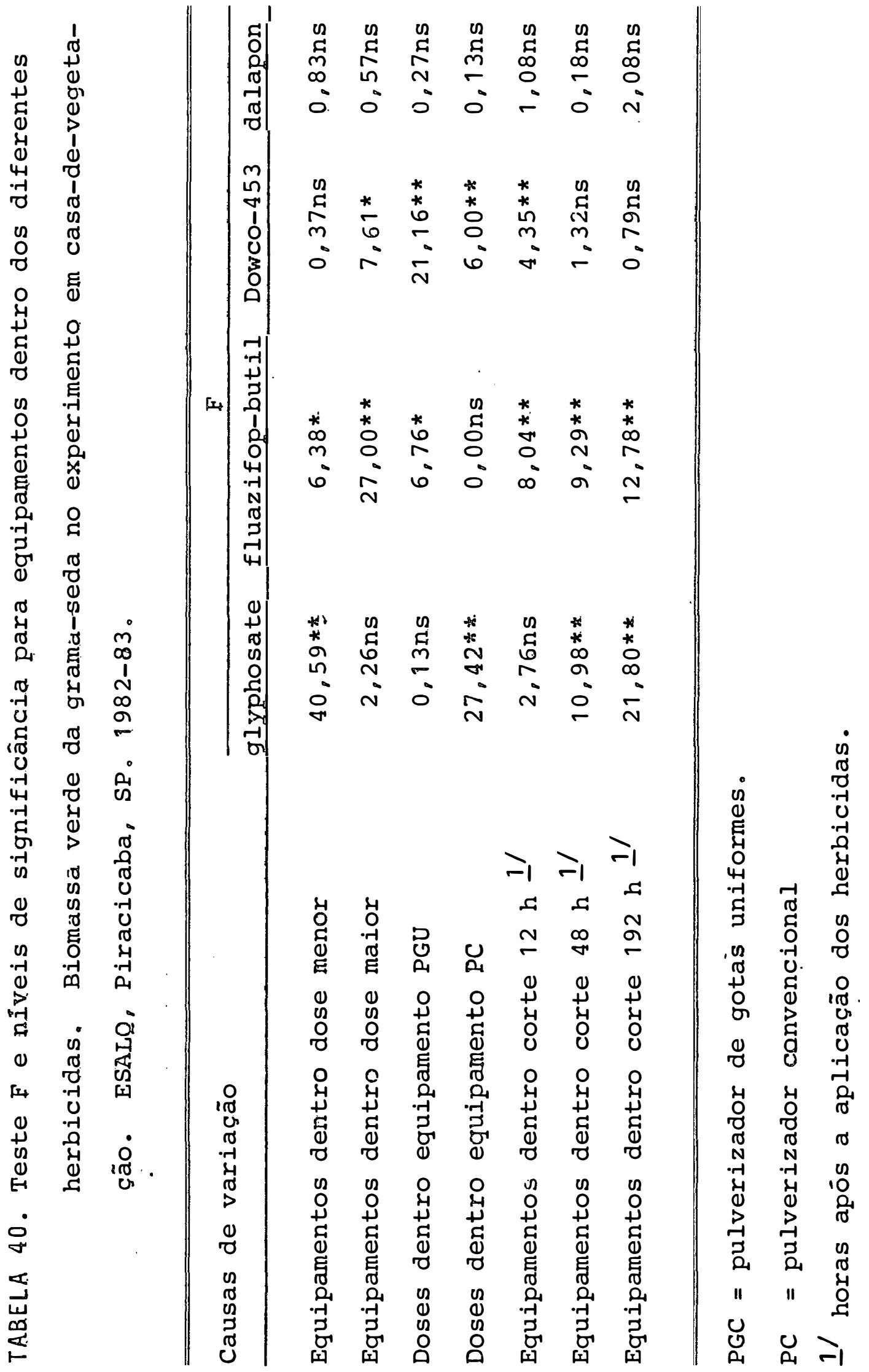


tivos para os herbicidas glyphosate e Dowco-453, porém, para os herbicidas fluazifop-butil e dalapon o teste $F$, para estas causas de variação, não resultou significativo. o desdobra mento das análises de variância para cada herbicida mostraram que o herbicida glyphosate, quando pulverizado pelo equipamento de gotás uniformes, foi significativamente melhor que com o pulverizador convencional, porém estas diferenças só foram estatisticamente significativas nas doses menores.

Também foi observado que a dose maior do glyphosate não diferiu da dose menor, quando aplicadas pelo pul verizador de gotas controladas (Tabela 40 ).

1 O herblicida Dowco-453, de acordo com a Tabela 40, apresentou um comportamento diferente do glyphosate,pois não há diferenças significativas entre os dois equipamentus com a dose menor, e sim com a dose maior; por outro lado, hou ve diferenças significativas entre equipamentos dentro " do corte as 12 horas. Já para os cortes as 48 e 192 horas após a aplicação, estas diferenças não foram significativas. Estas interações resultaram invertidas para o herbicida glypho sate.

As diferenças foram estatisticamente significativas entre equipamentos, tanto nas doses maiores quanto nas menores para o herbicida fluazifop-butil, e somente com - equipamento de gotas uniformes que as diferenças entre dose maior e menor foram significativas. Para o mesmo herbici 
da, as diferenças entre equipamentos foram altamente signifi cativas nas três épocas de corte, ou seja, 12, 48 e 192 horas depois da aplicação; observando-se sempre uma superioridade ảo pulverizador de gotas uniformes.

Os resultados do experimento conduzido em 1983-1984 foram diferentes a aqueles obtidos no primeiro experimento e já descrito em parágrafos anteriores.

Assim, os dados da biomassa produzida pela grama-seda aplicada com o herbicida glyphosate, quando anali sados estatisticamente, não mostraram diferenças significati vas para equipamentos e doses, resultando somente significativos para cortes (Tabela 41)。

Os resultados com o herbicida fluazifop-butil mostraram diferenças significativas somente para doses, o que é observado na Tabela 41 .

Pela Tabela 42, observa-se que os herbicidas Dowco-453 e dalapon apresentaram comportamento similar ao do ano anterior.

O Dowco 453 mostrou diferenças altamente significativas para equipamento dentro das doses maiores e somente significativas dentro das menores; também houve diferenças significativas para equipamentos dentru dos cortes as 12 e 48 após a aplicação. Sempre foi observado um controle melhor do herbicida Dowco-453 quando aplicado com o pulverizador de gotas uniformes. 


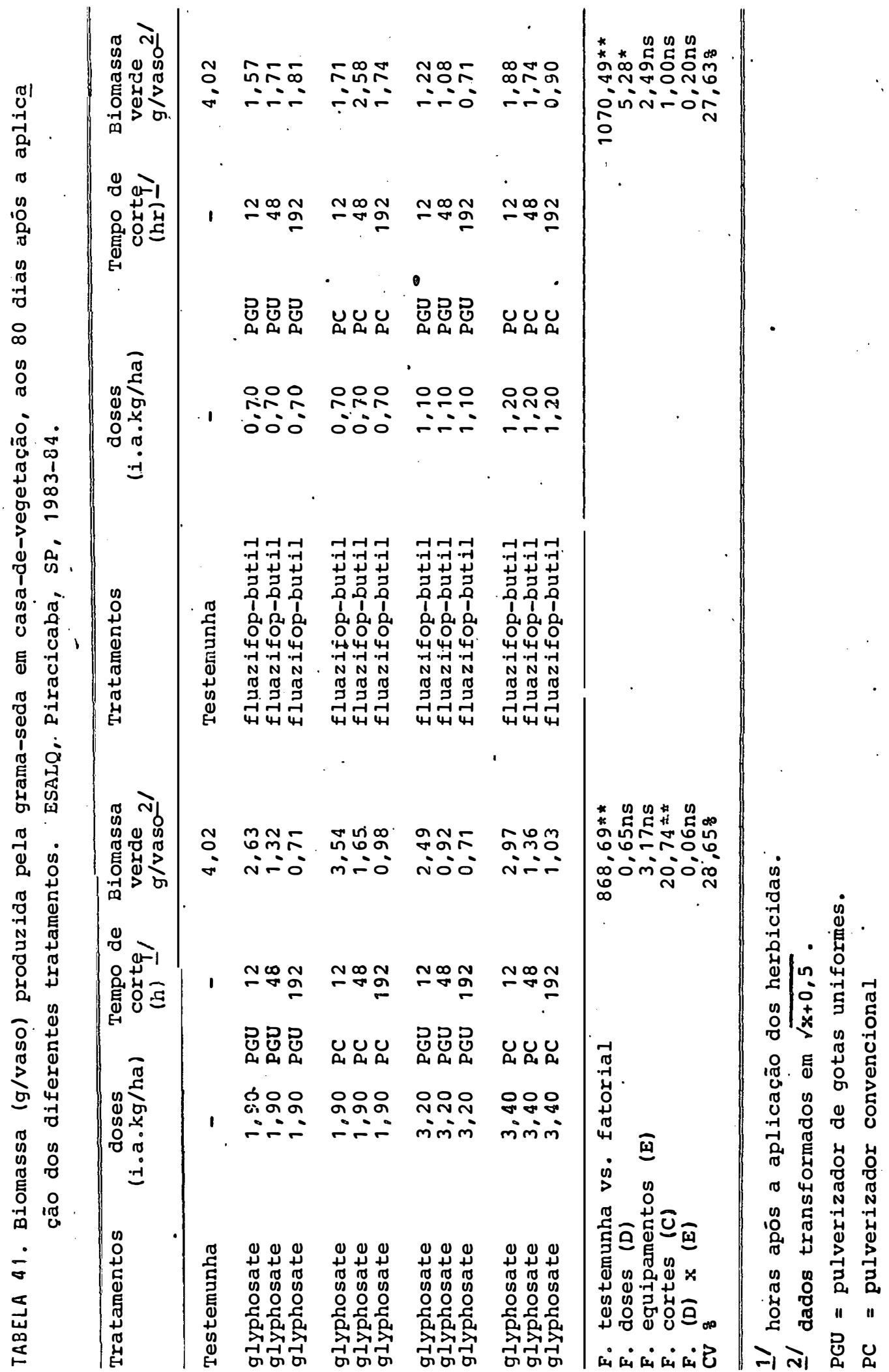




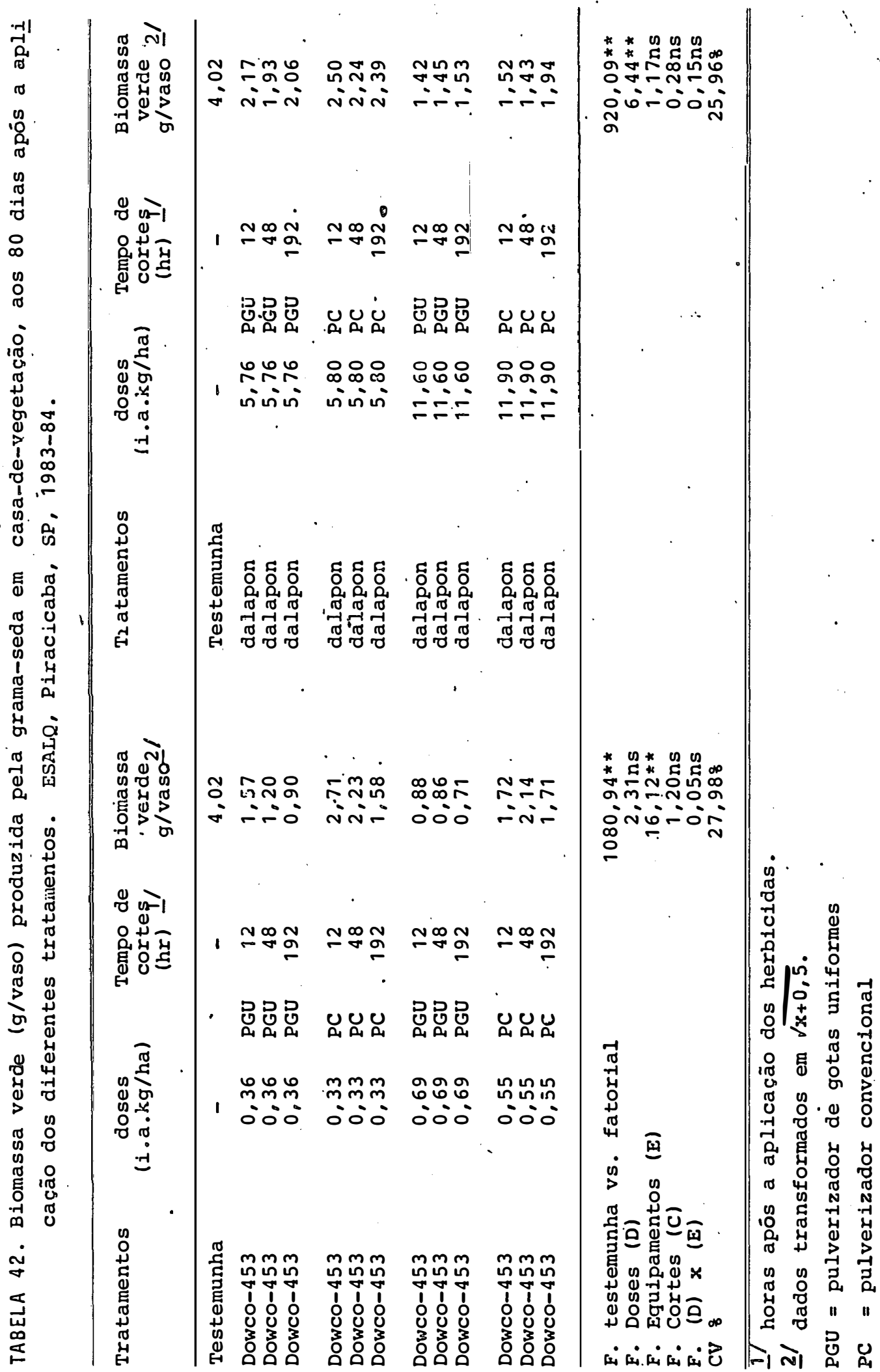


.129.

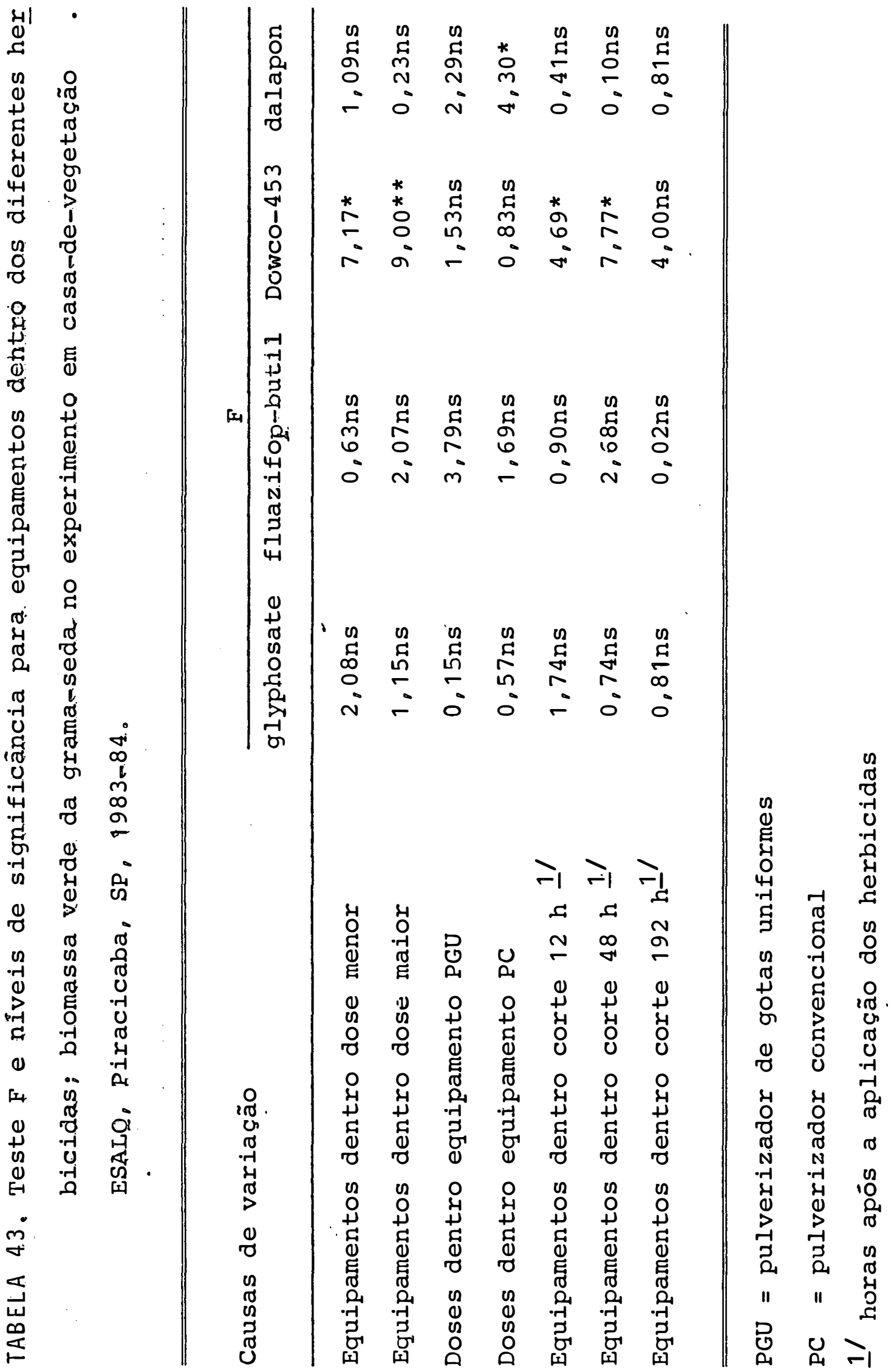


Como no ano anterior o herbicida dalapon não mostrou diferenças significativas para equipamentos e épocas de corte, somente foi significativo o efeito das doses dentro do pulverizador convencional.

A diferença entre os resultados dos dois ex? perimentos pode ser devido principaimente a diferenças nas doses de aplicação para os 4 herbicidas. Assim, no experimen to conduzido nos anos de 1983-84 as duas doses empregadas, tan to para o glyphosate como para o fluazifop-butil, foram pelo menos $20 \%$ maiores que aquelas utilizadas no experimento dos anos 1982-83, exceto nas doses maiores do fluazifop-butil. No entanto, para o Dowco, -453 as doses foram só ligeiramente diferentes, nos dois experimentos.

Outro fator que pode ter influenciado na obtenção de resultados não concordantes nos dois experimentos, foram as condições climáticas que ocorreram depois da aplica ção dos herbicidas. Para o experimento conduzido em 1982-83. nos meses de março, abril e maio, ou seja, depois da aplica ção dos herbicidas, esses meses foram chuvosos, com o que a luminosidade foi diminuida e as temperaturas amenas (Tabelas 49 e 50 do Apêndice). Entretanto, para o experimento dos anos 1983-84, particularmente durante os meses de dezembro, janeiro, fevereivo e março, apresentaram-se altas temperaturas (a média dos 4 meses foi de $25,5^{\circ} \mathrm{C}$ ), pouca precipitação e consequentemente alta luminosidade, com $\circ$ que as conảições dentro da casamde-vegetação foram pouco favoráveis e : muito 
diferentes daquelas observadas no outro experimento.

Nos dois experimentos conduzidos, o herbicida glyphosate apresentou melhor controle da grama-seda, quando foi aplicado pelo pulverizador de gotas uniformes, embora estes resultados só foram significativos em um dos experimen tos. Houve portanto, concordância com os resultados obtidos por TURNER e LOADER (1978), CHARLOTTE e BURRIL (1978), SLACK e WITT (1983) e WILTSE (1983).

Também ficou evidente, como em umildos experimentos de campo, que nas doses menores do glyphosate as dife renças entre os pulverizadores convencional e de gotas uniformès, tornam-se mai's evidentes, e que nas doses maiores es tas diferenças tornaram-se não significantes, concordando as sim COM CHARLOTTE e BURRILL (1979), TURNER e LOADER MCGARVEY e BALS (1979).

O herbicida Dowco-453 também apresentou melho res controles quando aplicado com o pulverizador de gotas uniformes nos deis experimentos, que foram estatisticamente significativos, o que não aconteceu em nenhum dos exper $\underline{i}$ mentos de campo. Isto demonstraria que altas densidades da planta daninha, o qual não aconteceu nos vasos, foram um fator negativo para uma boa cobertura pela pulverização de gotas uniformes, concordando assim com MAYES e BLANCHERD (1978). Resultando desta forma, pelo menos para o Dowco-453, controles iquais ou menores da planta daninha pelo herbicida. 
Os resultados obtidos com o fluazifop-butil

não foram muito consistentes quanto os de glyphosate e Dowco -453, mas, também para este herbicida ficou evidente o melhor controle da grama-seda quando se aplicou o herbicida com o pulverizador de gotas uniformes; resultados semelhan tes àqueles obtidos por DOLL et alii (1983) e CRANMER e DUKE (1983) no controle de uma outra gramínea perene, usando este equipamentos e carregadores oleosos.

Por meio de cortes realizados em três interva los de tempo, 12, 48 e 192 horas depois da aplicação dos her bididas e usando a quantidade de biomassa verde produzida pe lo rebrote, procurou-se uma explicação do porqué dos melhores controles, em particular do glyphosate, quando aplicado pelo pulverizador de gotas uniformes.

As produções de biomassa verde pela grama-seda, foram maiores nos cortes as 12 horas após a aplicação dos herbicidas com o equipamento convencional, ainda que não significativo no caso do glyphosate: por outro lado, para os cortes 48 e 192 horas, estas diferenças foram significatí vas (Tabela 44). Este fato sugere uma maior translocação do glyphosate a partir das folhas para as partes subterrâneas, quando é aplicado com o pulverizador de gotas uniformes. A maior concentração de herbicida nas gotas, citada por LALS (1979); ou a não ailuição dos níveis de surfactante incluido no herbicida (DAVIES e TAYLOR, 1981), acarretariam uma absor - ção e translocação maior do produto, induzindo, consequente - 
mente a controles melhores; em comparação àqueles obtidos pe la pulverização convencional.

TABELA 44. Teste de Tukey para cortes dentro os dois equipamentos. Avaliações de biomassa verde de qrama-se da no experimento com herbicidas aplicados em pós -emergência, em casa-de-vegetação, Piracicaba, SP, $1982-83$ 。

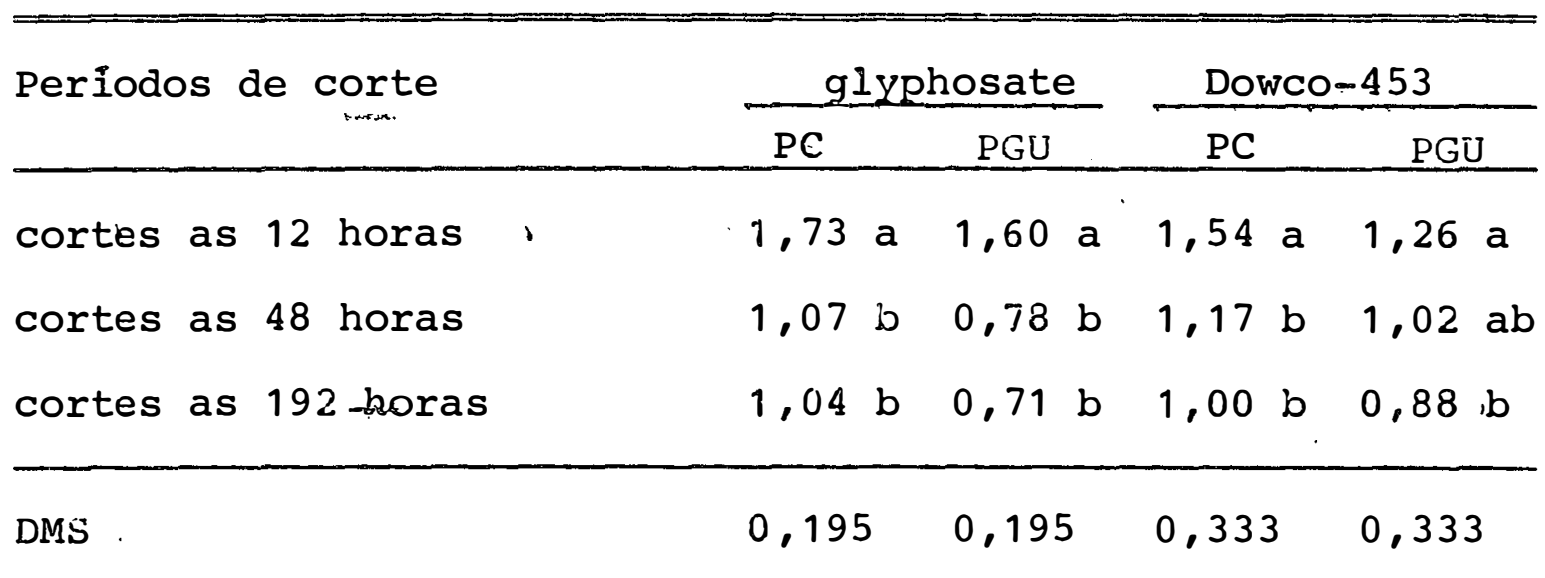

PGU = pulverizador de gotas uniformes

$\mathrm{PC}=$ pulverizador convencional

A translocação lenta do glyphosate, quando aplicado em altos volumes de aspersão (SALINAS, 1981), observada em grama-seda, tambèm seria confirmada pelos resultados obtidos com a pulverização convencional, pois observando as Tabelas 38 e 44 as produções da biomassa verde principalmente na dose menor foram diminuindo quase que proporcionalmen 
te ao periodo de corte.

No experimento de 1983-84, se bem que as diferenças entre equipamentos não foram significativas, também se observou a tendência indicada (Tabelas 41 e 45).

TABELA 45. Teste de Tukey para cortes dentro os dois equipamentos. Avaliações de biomassa verde da grama-se da no experimento com herbicidas aplicados em pós -emergência em casa-de-vegetação. Piracicaba,sP, 1983-84.

\begin{tabular}{|c|c|c|c|c|}
\hline \multirow{2}{*}{ Períodos de corte } & \multicolumn{2}{|c|}{ glyphosate } & \multicolumn{2}{|c|}{ Dowco-453 } \\
\hline & $\mathrm{PC}$ & PGU & PC & PGU \\
\hline corte, as 12 horas & $3,16 a$ & $2,55 \mathrm{a}$ & 2,21 & 1,22 \\
\hline corte as 48 horas & $1,45 \mathrm{~b}$ & $1,06 \mathrm{~b}$ & 2,18 & 1,03 \\
\hline corte as 192 horas & $1,17 \mathrm{~b}$ & $0,71 \mathrm{~b}$ & 1,64 & $0,8 \uparrow$ \\
\hline DMS & 1,136 & 1,136 & & \\
\hline
\end{tabular}

PGU = pulverizador de gotas uniformes

$\mathrm{PC}=$ pulverizador convencional

Os melhores controles obtidos pelos herbicidas Dowco-453 e fluazifop-butil, quando aplicados com o pulverizador de gotas uniformes, também podem ser explicados na 
base de una maior concentração do procuto nas gotas depositadas nas folhas, o qual inăuziria também,a naior translocação doos herbicidas.

Os resultados semelhantes obtidos com $\circ$ Dowco -453 nos dois experimentos (Tabelas 39 e 42), indicaram uma translocação inicial alta, pois com o corte a 12 horas após a aplicação existiram diferenças significativas entre os dois equipamentos (Tabelas 40,41,44 e 45). Já para os cor tes a 48 horas sọ no experimento em 1983-84 houve significância entre os equipamentos, para o corte a 192 horas não existiram diferenças significativas para o rebrote entre os dois equipamentos.

Por outro lado, o Dowco-453, nas duas doses testadas e com os dois equipamentos, permitiu o rebrote da grama-seda, fato este também observado no experimento de cam po conduzido em 1984, nas avaliações aos 60 dias depois da aplicação dos herbicidas.

Com o herbicida dalapon ficou confirmada mais uma vez sua alta velocidade de absorção e translocação e co mo nos experimentos de campo, não foram observados controles satisfatórios nem com as doses maiores ou equipamentos. 


\section{CONCLUSÕES}

Analisando-se os resultados obtidos na presen ce pesquisa, nas condições em que os experimentos foram condu zidos pode-se concluir que:

a. Volumes de aplicação tão baixos como $32 \mathrm{l} / \mathrm{ha}$ do pulveriza dor de gotas uniformes não mudam o comportamento e a efí - ciência biológica dos herticidas apiicados em pré-emergên cia, em comparação a $250 \mathrm{l} / \mathrm{ha}$ da pulverização convencional.

b. O comportamento e ía eficiência biológica dos herbicidas aplicados em pós-emergência, também foram semelhantes para os dois equipamentos.

c. Dos experimentos em casa-de-vegetação, conclui-se que a maior concentração do herbicida nas gotas produzidas pelo pulverizador ảe gotas uniformes favorecem uma maior absor ção e translocação destes produtos para as partes subter- 
râneas dd grama-seda, resultando assim em melhores contro les.

d. Fatores como, formulações, doses altas, coberturas e densidades altas das plantas daninhas, precisam de pesquisa adicional com $\circ$ pulverizador de gotas uniformes. 


\section{LITERATURA CITADA}

ABERNATHY, J.R.; B. BEAN e J.R. GIPSON, 1983. Soil and foliar activity of selective grass herbicides. In: Meeting Weed Science Society of America. Illinois.EUA. Resumos. p. 31 .

AYRES, P., 1978. The influence of application method on the control of wild oats (Avena fatua L. and Avena ludovicia na [rir.) in winter wheat by difenzoquat applied at. a range of growth stages. In: Symposium on controlled drop application, First, Reading Univ. BCPC. Proceedings. Monografia n: 22: 163-170。

AYRES, P. e C.R. MERRITT, 1978. Field experiments with controiled drop applications of herbicides for the control of dicotyledonous weeds. Weed Research, 18: 209217. 
BALS, E.J., 1971. Some thoughts on the concept of ULD (Ultra Low Dosage) spraying. In: F.A.O. Conference of International organisations. 23-26 February 1976. S. ed. $8 \mathrm{p}$.

BALS, E.J., 1975. Development of a c.d.a. Herbicide handsprayer. PANS. $21(3): 345-349$.

BALS, E.J., 1978. Reduction of active ingredient dosiage by selecting appropriate droplet size for the target. In: Symposium on Controlled drop application, First, Reading Univ. BCPC. Proceedings. Monografia no 22:101-106.

BARRENTINE, W.L. e H.R. HURST, 1983. Soyoil-carrier or additive for soybean herbicides. In: Meeting weed Science Society of America. Illinois, EUA. Resumos p. 55.

BARZEE, M.A. e E.W. STROUBE, 1972. Low-volume application of pre-emergence herbicides. Weed Science 20(2): 176-180.

BLACKMAN, G.E.; R.S。 BRUCE e K. HOLLY, 1958. Interrelationships betwen specifc differences in spray retention and selective toxicity. Journal Exp. Bot. 9 : 175-205

BOLETIM INFORMATIVO HATSUTA, (1982)。 Pulverização micronizą da. Resultados de pesquisas s. ed. Série 82, no 1. 9 p. 
BRUGE, G. e F. JEAN, 1978. Low volume herbicide applications. Compte Rendu de la 9: Conference du COLUMA. Lyon France 1977, ACTA 149, 839-847. Apud. Weed Abstracts. Oxford, UK. $\quad 27(6): 2080$

CATTANEO, S.L.F. e J.E. SOARES, 1982. Controle da grama seda (Cynodon dactylon (L.) Pers.) com o herbicida pós-emer gente fluazifop-butil em cultura de citros (Citrus sinensis (L.) Osbek). In: Congresso Brasileiro de Herbicidas e Ervas Daninhas (SBHED), XIV e Congreso latinoamericano de Ia Asciciación Iatinoameticana de Malezas (ALAM). VI. Campinas - SP: Resumos. p. 155-156.

CHARL'OTTE, E. e L.C. BURRIL, 1979. Quackgrass control with glyphosate applied with a controlled droplet applicator. In: Research Progress Report Western Society of Weed Sience. Boise, Idaho, p. 24.

CLIPSHAM, I.D., 1981. The influence of target area on the variability of spray deposits. In: British crop Protection Council, 1980. Oxford, U.K. Proceidings. Monografia 24: 133-138. Apud: Weed Abstracts. $30(2): 785$. COMBELLIICK, J.H.; R.V. HARRIS; R.G. RICHARDSON; K. SWAW e K. TURNBALI, 1978. Spot spraying with hand-held CDA equipament in Australia; a progress report on suitability of equipament and herbicides. In: Symposium on Controlzed drop application, First, Reading Univ. BCPC: Proceedings. Monografia no 22: 199-211. 
COTTON GROWER, 1980. Controlled droplet application through rotary atomizers may be the way of the future for chemical sprays. Cotton Grower. 8-10.

CRANMER, J.R. e W.B. DUKE, 1983. Controlled droplet application (CDA) of fluazifop and Sethoxydim for annual and perennial weed control. In: Meeting Weed Science Society of America IZlinois. EUA. Resumos p. 23-24.

CRUZ, L.S.P.; R. VICTORIA FILHO; J.A. de R. PONCHIO e M.P. LOURO, 1983. Efeito do glyphosate aplicado com diversos tipos de bicos no controle de plantas daninhas na.cultura do café (Cobfea arabic̣a L.). In: Congresso Brasileiro de pésquisas cafeeiràs. X, Poços de Caldas - MG. Anais 164.

CUSSANS, G.W. e W.A. TAYLOR, 1978. Controlled drop application what does it all mean ? Arable Farming, 43-47..

DAVIES, E.L,I.P. e W.A. TAYLOR, 1981. The biological activity of three herbicides when applied by differing hidraulic nozzle types. In: British Crop Protection. Council, 1980. Oxford, U.K. Proceedings. Monografia 24: 49-54. Apud. Weed Abstracts, $30(2): 772$.

DOLL, J.D.: G.S. SIMKINS; P.C. BHOMIK e D.C. DROST, 1983. Selective postemergence quackgrass (Agropyron repens L.) control in soybeans. In: Meeting Weed Science Society of America Illinois, EUA. Resumos. p. 8-9. 
DUNN, P。 e J.M. WALLS, 1978. An introduction to in-line holography and its applications. In: Symposium on Controlled drop application, First, Reading Univ. BCPC. Proceedings. Monografia no 22: 23-24.

FARMERY, H., 1978. Development of the microdrop CDA sprayer. In: Symposium on controlled drop application, First, Reading Univ. BCPC. Proceeding.̈. Monografia n: 22: 107-110。

FISCHER, A. e A. TASISTRO, 1980。 Aspersion de herbicidas pa ra el control de maleza en cebada con equipo convéncional y mediante tecnicas para aplicación de goṭa controlada. In: Congresso Naciónal de la Ciencia de la Maleza, I, Tor reon Coahuila. Memoria p. 214-215.

FOLCNI,L.L. e H.P.A. PRADO FILHO, 1983. Aplicação pós-eme $\underline{r}$ gente de glyphosate puro e em mistura com 2,4-D em cafeei ro em produção, con diferentes tipos de equipamentos: In: Congresso Brasizeiro de Pesquisas Cafeeiras, $\mathrm{X}, \quad$ Poços de Caldas - MG. Anais. 94-96.

FROST, A.R., 1978. Rotary atomization. In: Symposium on controlled drop application, First, Reading Univ. BCPC. Proceedings. Monografia no 22: 7-21.

FURMIDGE, C.G.L., 1962. The retention of spray liquids on leaf surfaces. Journal Sci. Fd. Agric. 13: 127-140. 
GARNETT, R.P., 1980. A low-volume herbicid applicator for tropical samll-holder farmers. In: British Crop Protection Conference Weeds, Oxford, U.K. Proceedings. p. 1-8.

GENTET, C., 1978. Principal techwiques, for reducing spray volume. low and very low spray volumes/ha. Compte Rendu de la 9a Conference $d u$ COLUMA. Lyon France 1977. Acta 149: 823-832. Apuca : Weed Abstracts. Oxford U.K. 27(3) 1698.

GOTTRUP, O.; P.A.O 'SULLIVAN; R.J. SCHRAA E W.H. VANDEN BORN, 1976. Uptake, translocation, metabolism, and selectivity of glyphosate in Canada thistle and leafy spurge. Weed Research 16(3): 197-201.

GUNN, D.L., 1978. The background and role of controlled drop application. In: Symposium on Controlled drop application, First, Reading Univ. BCPC. Proceedings. Monografia no $22: 1-5$.

HAROLD, M. e K. CHAIRMAN, 1979. Cotrolled droplet application workshop. In: Annual Meeting The Western Society of weed Science, Boise, Idaho. Proceedings, 32: 30-32.

HARRIS, P:B., 1978. Mixed results with CDA spraying. Arable farming, $4(2): 62-65 . \quad$ Apud: Weed Abstracts. $27(5): 189$.

HIBBITT, C.J., 1969. Growth and spray retention of wild oat and flas in relation to herbicidal selectivitý. Weed Research, $\underline{9}(2): 95-107$. 
HIND, N.J., 1978. The Richmond Gibson controlled drop application trials sprayer. In: Symposium on controlled drop application, First, Reading Univ. BCPC. Proceedings. Monografia no 22: 117-119。

HOSSEINIPOUR, M。, 1978. Behaviour of single drops and sprays in different climatic conditions in a climate tower. In: Symposium on controlled drop application, First, Reading Univ. BCPC. Proceedings. Monografia no 22: $83-90$ 。

JEAN, F., 1981. Controlled drop application or CDA. In: Compte Rendu de la 10. Conference COLUMA (1979). Be'lville sur Saoné'France, '14-24. Apud: Weed Abstracts. 30 (2): 89 .

JOHNSTONE, D.R., 1978a. Statistical description of spray drop size for controlled drop application. In: Symposium on Controlled drop application, First, Reading Univ. BCPC. Proceedings. Monografia n\& $\underline{22}: 35-42$

JOHNSTONE, D.R., 1978b. The influence of physical and meteorological factors on the deposition and drift spray droplets of controlled size. In: Symposium on controlled drop application, First, Reading Univ. BCPC. Proceedings. Monografia n: 22: 43-58. 
JOHNSTONE, D.R॰; G.G. POPE; M. ANDREWS E G.R.STACEY, 1978. Preliminary trials with a light hovercraf for CDA sprayng. In: Symposium on controlled drop application, First, Reading Univ.. BCPC. Proceedings Monografia no 22: $129-135$.

-.. v KLINGMAN, G.C.; F.M. ASHTON e L.J.NQORDHOOFF, 1975. Weed Science. Principles and practices. $2^{\text {nd }}$ edtion New York. Johns Wiley e Sons. Inc. $431 \mathrm{p}$.

LAKE, J.R., 1977. The effect of drop size and velocity on the performance of agricultural sprays. Pesticide Science, $\underline{8}$ : 515-526.

LAKE, J.R。 e W.A. TAYLOR, 1974. Effect of the form of a deposit on the activity of barban applied to Avena fatua L. Weed Research, 14: 13-18.

LONG, P.J., 1978. The contractor's view of CDA. In: Symposium on Controlled drop opplication, First Reading Univ. BCPC. Proceedings. Monografia no 22: 259-264.

MAKEPEACE, R.J., 1978. Pesticide application and efficacy from the approval point of view. In: Symposium on Controlled drop application, First Reading Univ. BCPC. Proceedings. Monografia no 22: 249-258. 
MARCONDES, D.A.S.; O. BRINHOLI; S. TUACEK, FO; N. FONTANARI; W.J. CORREA e Y. KASHIWAKURA, 1980. Efeitos do glifosato em cana-de-açūcar. In: Congresso Brasileiro de Herbicidas e Ervas Daninhas. XIII. Ilhēus/Itabuna-BA. Resumos. p. $36-37$.

MATTHEWS, E.J., 1983. Electrostatics - Present status and future potential. In: Meeting weed science society of America. Illinois, EUA. Resumos. p. 55.

H.ATTHEWS, G.A., 1975. Determination of particlesize. PANS $\underline{21}(2): 213-225$.

MATTHEWS, G.A., 1977. C.D.A. - Controlled droplet application. PANS, 23(4): 387-394.

MATTHEWS, G.A. , 1978. Controlled droplet application (CDA) of pesticides in pest management. In: Symposium on controlled drop application, First, Reading Univ. BCPC. Proceedings. Monografia no 22: 213-217.

MAY, M.J. e P. AYRES, 1978. A comparison of controlled drop and conventional application of three soil-applied herbicides to an organic soil. In: Symposium on controlled drop application, First, Reading Univ. BCPC. Proceeddings. Monografia no 22: 157-161. 
MAYES, A.J. e T.W. BLANCHARD, 1978. The performance of a prototype microdrop (CDA) sprayer for herbicide application In: Symposium on controlled drop application, First, Reading Univ. BCPC. Proceedings. Monografia no 22: $171-178$.

MAYERS, A.J.; G.B. LUSH e T.W. BLANCHARD, 1979. Further field experience with controlled drop application. In: British Crop Protection Souncil, Nottingham. Proceedings. 729-737. Apua. : Weed Abstracts. 28 (7): 246.

MC CAVISH, W.J., 1978. Forest weed control with different formulations of atrazine, propyzamide and an atrazine/ cyanazine misture' applied by hand-held controlled drop applicator. In: Symposium on controlled drop application, First Reading Univ. BCPC. Proceedings. Monografia n8 22: 193-198.

MC GARVEY, F.X. e E.J. BALS, 1979, Review of C.D.A. herbicide application and current droplet spectra studies. Presented at the $32^{\text {nd }}$ Annul Meeting, Southern weed Science Society。 Atlanta Georgia ll p.

MERRITT, C。R. e W.A. TAYLOR, 1977. Glasshouse trials with controlled drop application of some foliage-applied herbicides. Weed Research. 17: 241-245. 
MERRITT, C.R. e W.A. TAYLOR, 1978. Effects of volume rate and drop size on the retention of an aqueous solution by Avena batua L. In: Symposium on controlled drop application, First, Reading Univ. BCPC. Proceedings. Monografia no 22: 59-66.

MICRON CORPORATION, 1981. Micromax installation and operation manual. Houston, Tx. 8 p.

MOODY, K., 1975. Weeds and shifting cultivation. PANS $21(2): 188-194$.

MOREL, M., 1981. Application of herbicides by rotary atomization. In: Rendu de $l_{a} 10^{e}$ Conference du COLUMA 1979 Epernay France. p. 3-7. Apud ': Weed Abstracts $\underline{20}(2): 91$.

PANS, 1978. Conference reports - BCPC. Symposium on Controlled drop application. PANS 24(3): 367-371.

PHILLIPS, M.C., 1979. A comparison of a field scale controlled drop applicator and fan jet aprayer for broad leave weed control in cereals. In: British Crop Protection Conference. Weeds. 1978. N. York U.K. Proceeding p. 739-743. Apud: Weed Abstracts, 28 (7): 246 . PHILLIPS, M.C.; A. BRADFORD e P. HARRIS, 1981. The effect on weed control of drop size, water volume on rate of a herbicide applied by spining disc. In: British Crop Protection Conference - Weeds 1980. N. York p. 747-752. Apud: Weed abstracts 30(5): 224 . 
PIMENTEL GOMES, F., 1976. Curso de Estatistica Experimental 5. ed., são Paulo. Livraria Nobel, 430 p.

PURISSIMO, C., 1982. Aplicacão de herbicidas com gotas con troladas e suas possibilidades em plantio direto, II, Industria Monsanto, são Paulo, $17 \mathrm{p}$.

ROBINSON, R.C., 1978. The field performance of some herbicides applied by rotary atomiser in spray volumes of 5-50 1/ha. In: Symposium on controlled drop application, First, Reading Univ. BCPC. Proceedings. Monografia n으 22: 185-191.

SALINAS, F.G., 1981.,Evaluacion de herbicidas para el $\checkmark$ control de Zacate Bermuda (Cynodon dactylon)en cultivos perennes. In: Congresso Nacional de Ia Ciencia de Ia Maleza, II, Univ. Chapingo. Resumos p. 23-24.

SAivTOS, J.M.F. dos, 1976. Bicos adequados: fundamentais para o êxito dos defensivos. Agroquimica-Ciba-Geigy. Divisão Agroquímica Ciba Geigy. São Paulo n\& 3: 10-16.

SCOTT, A.I. e G. KAPUSTA, 1983. Evaluation of CDA rotary nozzles for weed control in soybeans. In: Meeting weed Science Society of America, Illinois, EUA. Resumos. p. 54 。 
SETZER, J.,, 1961. Atras climätico scológico do Estacio de são Paulo , Comissão interestadual da Bacia Paraná - UruguaiCESP, $61 \mathrm{p}$.

SILVA, J.B. da, 1982. Equipamentos e métodos de aplicação de

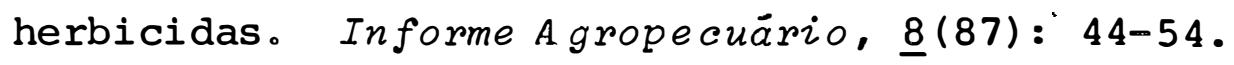

SLACK, C.H. e W.W. WITT; 1983. Herbicide application with CDA. In: Meeting Weed Science Society of America. Illinois, EUA. Resumos. p. 54 。

STRONG, C.D., 1979. Controlled droplet application (CDA): La aspersion controlada del algodón y de otras cosechas. Mìmeógrafo, s. eds 11 p.

TAYLOR, W.A., 1979. Controlled drop application of herbicides. In: Annual Meeting the western Society of Weed Science, Boise, Idaho. Proceedings, 32: 32-33.

TAYLOR, W.A., 1981. Controlled drop application of herbicides. Outlook on Agriculture 10.(7): 333-336.

TAYLOR, W.A. e C.R. MERRIT, 1974. Preliminary field trials with 2,4-D ester, barban and tri-allate applied in spray volumes of 5-20 1/ha. Weed Research. 14(4): 245-250.

TAYLOR, W.A.; C.R. MERRITT E J.A. DRINKWATER, 1976. An experimental tractor-mounted, very low volume uniform-drop-size sprayer. Weed Research. 16(3): 203-208. 
TURNER, D.J. e M.P.C. LOADER, 1978. Controlled drop : application of glyphosate, difenzoquat and dichlorprop. In: Symposium on controlled drop application, First, Reading Univ. BCPC. Proceedings. Monografia no 22: 179-184.

UTULU, S.N. e I.O. AKOBUNDU, 1981. An evaluation of a CDA herbicide sprayer in a tropical enviroment. Weeds an their control in the humid and subhumid tropics. In: Conference at the International Institute of Tropical Agriculture. 1978. Ibadan - Nigéria. Proceedings, p. 379-386. Apud : Weeds Abstracts, $\underline{30}(9): 382$.

WE'ED' SCIENCE SOCIETY' OF AMERICA, 1980. Herbicide hand-book of the Weed Science Society of America. $4^{\text {th }}$ edition. Champaign. Illinois 479 p.

WILSON, B.J.e W.A. TAYLOR, 1978. Field trials.with the controlled drop application of barban and difenzoquat for the control of wild oats (Avena fatua $\mathrm{L}_{0}$ ) in spring barley. Weed Research 18: 215-221.

WILTSE, M.G., 1983. Developments in controlled droplet application for weed control. In: Meeting weed Science Society of America. Illinois, EUA. Resumos p. 53. 
.152 .

A PEN D I C E 
TABELA 46. Dacios nieteorológicios cio mês de dezembro de 1982. ESALC/USP, Piracicalizi, SP.

\begin{tabular}{|c|c|c|c|}
\hline Dia & $\begin{array}{l}\text { Precipitacão } \\
(\mathrm{mm})\end{array}$ & $\begin{array}{c}\text { Umidaçe relativa } \\
(q)\end{array}$ & $\begin{array}{l}\text { Precipitação } \\
\text { méaia (num) }\end{array}$ \\
\hline $\begin{array}{r}1 \\
2 \\
3 \\
4 \\
5 \\
6 \\
7 \\
8 \\
9 \\
10 \\
11 \\
12 . \\
13 \\
14 \\
15 \\
16 \\
17 \\
18 \\
19 \\
20 \\
21 \\
22 \\
23 \\
24 \\
25 \\
26 \\
27 \\
28 \\
29 \\
30 \\
31\end{array}$ & $\begin{array}{c}21,3 \\
- \\
- \\
31,8 \\
1,0 \\
- \\
1,9 \\
9,3 \\
2,3 \\
28,7 \\
4,0 \\
19,9 \\
22,7 \\
4,2 \\
10,6 \\
14,4 \\
9,6 \\
9,0 \\
3,4 \\
4,4 \\
= \\
- \\
-\end{array}$ & $\begin{array}{l}83,6 \\
86,3 \\
77,6 \\
78,3 \\
77,0 \\
89,7 \\
90,0 \\
76,9 \\
74,0 \\
89,5 \\
90,0 \\
87,3 \\
84,7 \\
86,4 \\
90,5 \\
93,5 \\
85,4 \\
88,5 \\
93,5 \\
86,8 \\
87,0 \\
89,2 \\
89,9 \\
70,6 \\
69,2 \\
76,1 \\
84,6 \\
75,2 \\
92,7 \\
38,1 \\
87,3\end{array}$ & $\begin{array}{l}26,1 \\
24,7 \\
22,3 \\
19,0 \\
13,5 \\
23,1 \\
24,6 \\
22,7 \\
20,9 \\
23,6 \\
23,7 \\
22,5 \\
23,5 \\
24,0 \\
24,5 \\
24,5 \\
22,8 \\
22,6 \\
23,2 \\
24,4 \\
24,6 \\
24,4 \\
23,2 \\
22,2 \\
22,0 \\
21,9 \\
24,0 \\
23,5 \\
24,3 \\
22,7 \\
23,7\end{array}$ \\
\hline Total & 215 & & \\
\hline média & & 34,6 & 23,1 \\
\hline
\end{tabular}


TABELA 47. Dados nieteorológicos do riês de janeiro de 1983. ESALQ, Piracicaja, e usina Santa Bárbara, Santa Bárbara, SP.

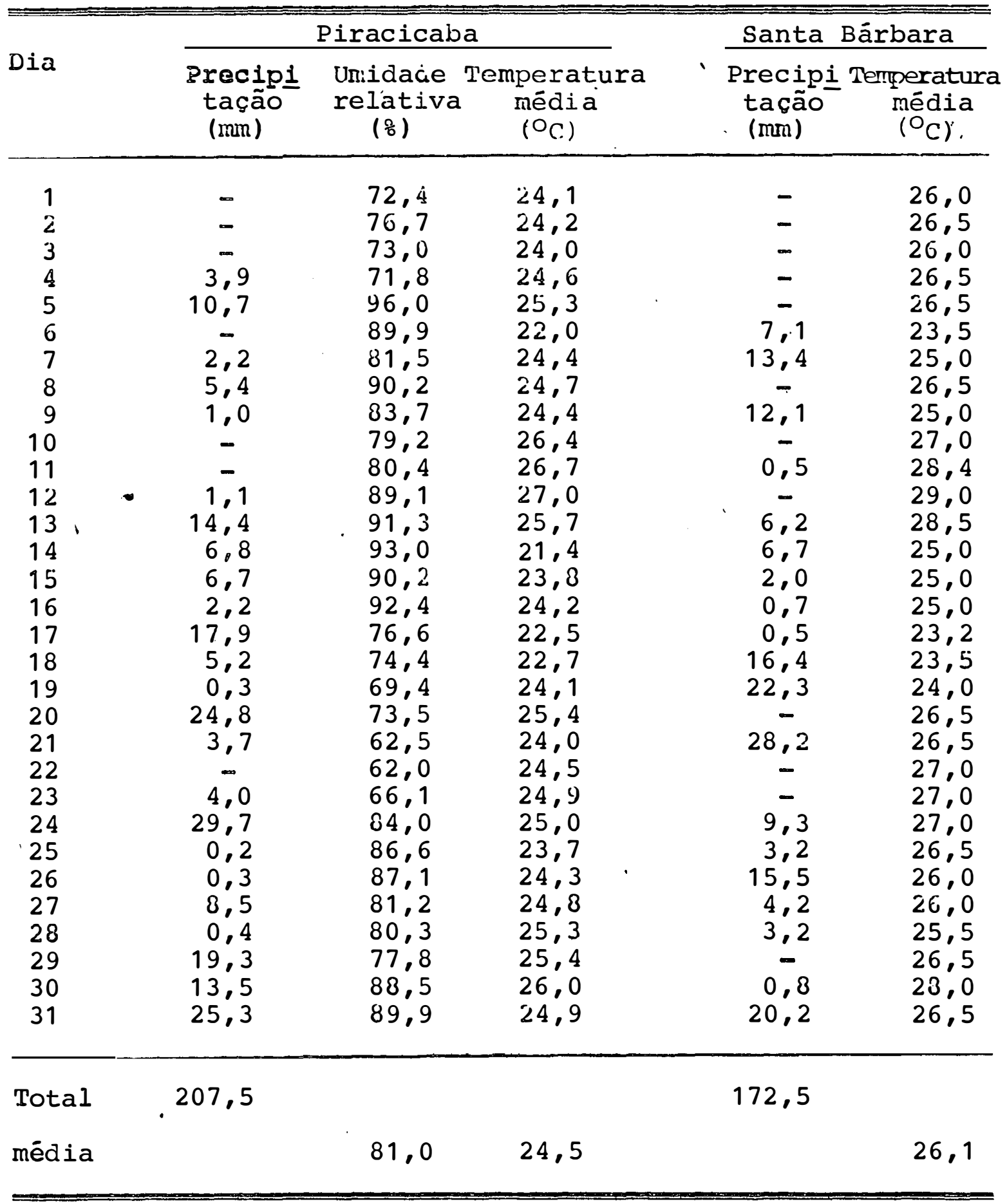


TABELA 48. Dados meteorológicos do mês de fevereiro de 1983. ESALQ, Piracicaba e usina Santa Bárbara, Santa Bārbara, SP.

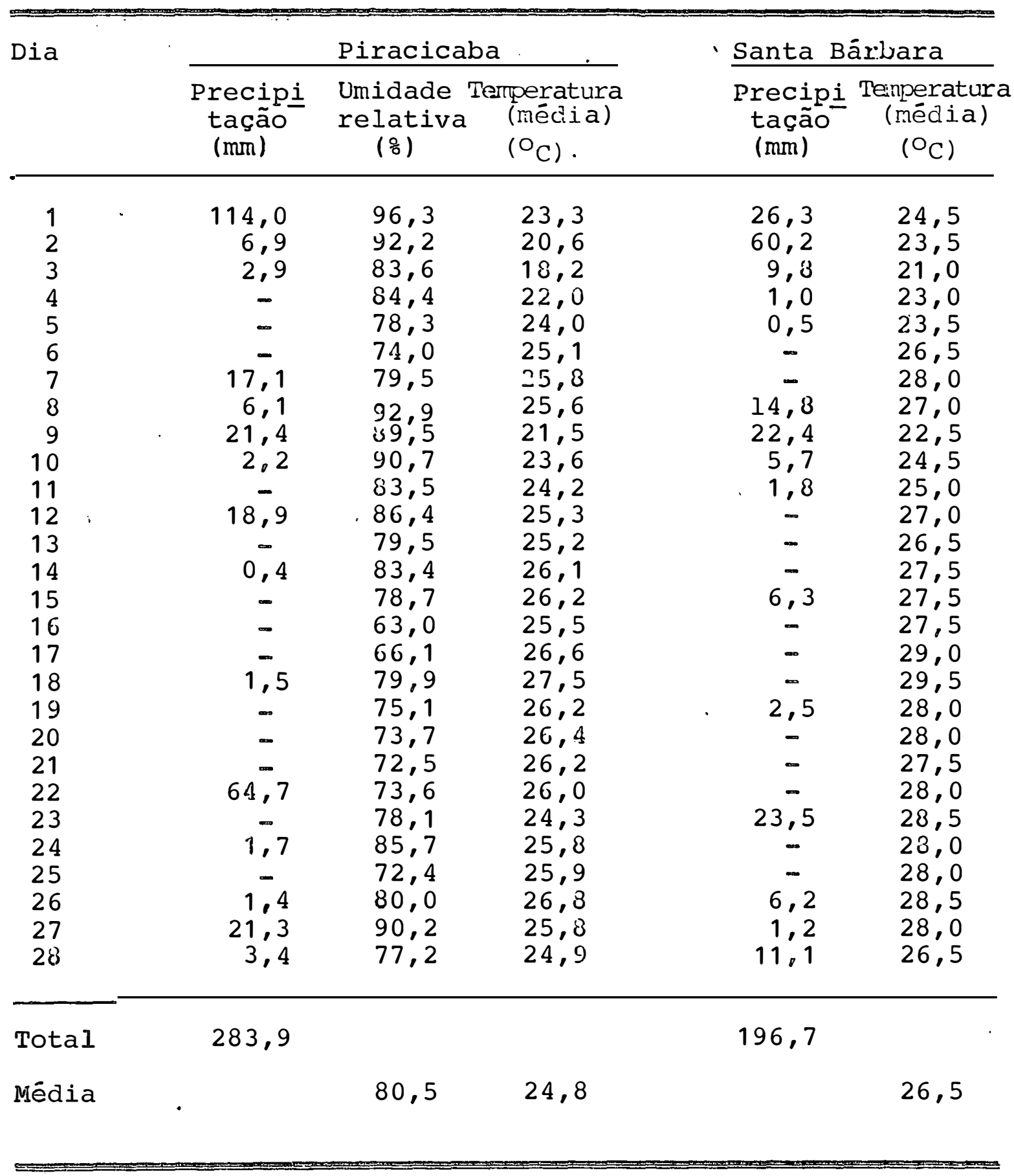


TABELA 49. Dados meteorológicos do mes de março de 1983. ESALQ, Piracicaba e Usina Santa Barbara, Santa Barbara D'Oeste, SP.

\begin{tabular}{|c|c|c|c|c|c|}
\hline \multirow{2}{*}{ Dia } & \multicolumn{3}{|c|}{ Piracicaba } & \multicolumn{2}{|c|}{ Santa Barbara } \\
\hline & $\begin{array}{c}\text { Precipitação } \\
\text { (mm) }\end{array}$ & $\begin{array}{l}\text { umidade } \\
\text { relativa } \\
(\%)\end{array}$ & $\begin{array}{l}\text { Temperatura } \\
\text { mëdia } \\
\left(\begin{array}{c}\mathrm{C}) \\
\end{array}\right.\end{array}$ & $\begin{array}{c}\text { Precipitaçäo } \\
\text { (mm) }\end{array}$ & $\begin{array}{c}\text { Tentperatura } \\
\left({ }^{\circ} \mathrm{C}\right)\end{array}$ \\
\hline $\begin{array}{r}1 \\
2 \\
3 \\
4 \\
5 \\
6 \\
7 \\
8 \\
9 \\
10 \\
11 \\
12 \\
13 \\
14 \\
15 \\
16 \\
17 \\
18 \\
19 \\
20 \\
21 \\
22 \\
23 \\
24 \\
25 \\
26 \\
27 \\
28 \\
29 \\
30 \\
31\end{array}$ & $\begin{array}{c}20,3 \\
67,5 \\
1,8 \\
18,0 \\
0,8 \\
3,3 \\
- \\
- \\
- \\
- \\
18,6 \\
6,3 \\
0,3 \\
- \\
- \\
- \\
16,4 \\
24,4 \\
- \\
0,4 \\
- \\
- \\
- \\
0 \\
35,6 \\
11,3 \\
- \\
-\end{array}$ & $\begin{array}{l}83,0 \\
83,7 \\
81,6 \\
79,9 \\
86,1 \\
90,5 \\
93,5 \\
84,6 \\
73,7 \\
70,7 \\
70,4 \\
89,0 \\
77,8 \\
76,0 \\
71,4 \\
73,4 \\
76,3 \\
82,9 \\
94,1 \\
79,0 \\
86,9 \\
74,5 \\
75,3 \\
73,2 \\
76,0 \\
78,5 \\
88,2 \\
89,5 \\
77,7 \\
76,8 \\
76,2\end{array}$ & $\begin{array}{l}25,1 \\
26,6 \\
24,8 \\
25,7 \\
26,3 \\
25,5 \\
22,6 \\
21,8 \\
24,0 \\
25,7 \\
25,9 \\
27,0 \\
25,4 \\
23,2 \\
22,3 \\
21,6 \\
23,6 \\
24,7 \\
26,0 \\
20,1 \\
19,6 \\
18,9 \\
23,3 \\
21,2 \\
20,9 \\
21,9 \\
22,6 \\
20,6 \\
18,7 \\
23,1 \\
22,6\end{array}$ & $\begin{array}{r}3,8 \\
16,8 \\
2,8 \\
0,3 \\
54,2 \\
1,3 \\
2,0 \\
- \\
- \\
- \\
- \\
8,8 \\
- \\
- \\
- \\
- \\
- \\
11,3 \\
54,3 \\
5,1 \\
- \\
- \\
- \\
- \\
- \\
1,0 \\
2,8 \\
- \\
- \\
-\end{array}$ & $\begin{array}{l}26,5 \\
27,5 \\
27,5 \\
28,0 \\
28,5 \\
28,0 \\
24,5 \\
22,5 \\
25,5 \\
26,0 \\
28,0 \\
28,0 \\
27,5 \\
28,5 \\
24,5 \\
24,0 \\
24,5 \\
24,0 \\
25,5 \\
21,5 \\
22,0 \\
22,5 \\
22,5 \\
22,0 \\
22,5 \\
22,5 \\
22,0 \\
23,0 \\
24,0 \\
23,5 \\
26,0\end{array}$ \\
\hline Potal & 225,6 & & & 198,0 & \\
\hline Nēdia & & 80,3 & 23,2 & & 25,0 \\
\hline
\end{tabular}


TABELA 50. Dados meteorológj.cos dos meses de abril e maio de 1983. ESALQ, Piracicaba, SP.

\begin{tabular}{|c|c|c|c|c|c|c|}
\hline \multirow[b]{2}{*}{ Dia } & \multicolumn{3}{|c|}{ abril } & \multicolumn{3}{|c|}{ maio } \\
\hline & $\begin{array}{l}\text { Precipi } \\
\text { tação } \\
\text { (mm) }\end{array}$ & $\begin{array}{c}\text { Umidade } \\
\text { relativa } \\
\text { ( }) \text { (o) }\end{array}$ & $\begin{array}{l}\text { Tempe- } \\
\text { ratura } \\
\text { raédia } \\
\left(O_{C}\right)\end{array}$ & $\begin{array}{c}\text { Precipi } \\
\text { tação } \\
\text { (mm) }\end{array}$ & $\begin{array}{l}\text { Umidade } \\
\text { relativa } \\
\left(\frac{q}{0}\right)\end{array}$ & $\begin{array}{l}\text { Tempe- } \\
\text { raturara } \\
\text { média } \\
\left(\mathrm{O}_{\mathrm{C}}\right)\end{array}$ \\
\hline $\begin{array}{r}1 \\
2 \\
3 \\
4 \\
5 \\
6 \\
7 \\
7 \\
8 \\
9 \\
10 \\
11 \\
12 \\
13 \\
13 \\
15 \\
16 \\
17 \\
17 \\
18 \\
19 \\
20 \\
21 \\
22 \\
23 \\
23 \\
24 \\
25 \\
26 \\
27 \\
28 \\
29 \\
30 \\
31\end{array}$ & $\begin{array}{c}- \\
- \\
- \\
- \\
56,7 \\
- \\
- \\
- \\
- \\
1,2 \\
11,2 \\
- \\
- \\
- \\
- \\
3,0 \\
- \\
7,4 \\
- \\
27,0 \\
- \\
0,3 \\
45,2 \\
36,7 \\
0,8 \\
- \\
- \\
- \\
-\end{array}$ & $\begin{array}{l}76,0 \\
75,3 \\
77,2 \\
78,2 \\
82,0 \\
96,2 \\
83,6 \\
80,8 \\
74,0 \\
75,0 \\
75,8 \\
82,8 \\
76,8 \\
70,8 \\
82,4 \\
79,8 \\
75,0 \\
78,4 \\
74,3 \\
81,5 \\
84,1 \\
81,4 \\
76,6 \\
94,3 \\
87,2 \\
90,3 \\
78,2 \\
86,0 \\
76,5 \\
74,2\end{array}$ & $\begin{array}{l}23,8 \\
17,1 \\
23,1 \\
23,6 \\
24,0 \\
24,0 \\
20,2 \\
20,3 \\
21,0 \\
22,0 \\
22,0 \\
21,6 \\
20,9 \\
21,8 \\
23,3 \\
23,1 \\
22,1 \\
24,9 \\
24,5 \\
24,8 \\
23,9 \\
22,8 \\
18,6 \\
21,4 \\
18,4 \\
21,9 \\
19,8 \\
22,7 \\
22,6 \\
20,6\end{array}$ & $\begin{array}{c}- \\
- \\
- \\
- \\
- \\
- \\
- \\
5,1 \\
0,2 \\
- \\
- \\
42,0 \\
0,3 \\
- \\
- \\
- \\
1,0 \\
- \\
25,2 \\
- \\
- \\
21,3 \\
60,7 \\
1,1 \\
- \\
- \\
15,6 \\
64,0 \\
36,8 \\
59,0 \\
2,4\end{array}$ & $\begin{array}{l}74,0 \\
78,7 \\
77,3 \\
81,2 \\
77,4 \\
75,2 \\
80,1 \\
89,7 \\
86,3 \\
80,4 \\
79,2 \\
83,2 \\
93,5 \\
93,1 \\
85,7 \\
82,0 \\
68,9 \\
86,9 \\
77,1 \\
62,0 \\
85,7 \\
77,6 \\
76,6 \\
97,9 \\
91,0 \\
81,6 \\
90,0 \\
78,5 \\
93,8 \\
92,7 \\
90,2\end{array}$ & $\begin{array}{l}23,4 \\
24,0 \\
23,7 \\
21,9 \\
20,6 \\
21,7 \\
22,1 \\
22,0 \\
20,7 \\
21,6 \\
22,5 \\
22,3 \\
22,8 \\
20,5 \\
22,1 \\
22,5 \\
27,5 \\
19,7 \\
21,8 \\
22,3 \\
18,6 \\
18,7 \\
19,5 \\
17,6 \\
18,1 \\
18,0 \\
17,1 \\
21,7 \\
19,6 \\
29,7 \\
17,4\end{array}$ \\
\hline Total & 189,5 & & & 334,7 & & \\
\hline Média & & 80,1 & 22,0 & & 82,8 & 21,2 \\
\hline
\end{tabular}


TABELA 51. Dados meteorológicos dos mes de outubro de 1983. ESALQ, Piracicaba e Usina Santa Barbara, Santa Barbara D'Oeste, SP.

\begin{tabular}{|c|c|c|c|c|c|}
\hline \multirow[b]{2}{*}{ Dia } & \multicolumn{3}{|c|}{ Piracicaba } & \multicolumn{2}{|c|}{ Santa Barbara } \\
\hline & $\begin{array}{c}\text { Precipitação } \\
\text { (nm) }\end{array}$ & $\begin{array}{c}\text { unidade } \\
\text { relativa } \\
\left(\begin{array}{c}(0) \\
\vdots\end{array}\right)\end{array}$ & $\begin{array}{c}\text { 'Pemperatura } \\
\text { (mâdi a) } \\
\text { (OC) }\end{array}$ & $\begin{array}{c}\text { Precipitação } \\
(\mathrm{mm})\end{array}$ & $\begin{array}{l}\text { Terperatura } \\
\text { media } \\
\text { (oc) }\end{array}$ \\
\hline $\begin{array}{l}1 \\
2 \\
3 \\
4 \\
5 \\
6 \\
7 \\
8 \\
9 \\
10 \\
11 \\
12 \\
13 \\
14 \\
15 \\
16 \\
17 \\
18 \\
19 \\
20 \\
21 \\
22 \\
23 \\
24 \\
25 \\
26 \\
27 \\
28 \\
29 \\
30 \\
31\end{array}$ & $\begin{array}{c}- \\
- \\
- \\
- \\
4,1 \\
- \\
- \\
- \\
- \\
- \\
32,8 \\
18,1 \\
5,6 \\
- \\
- \\
8,6 \\
11,8 \\
- \\
- \\
18,3 \\
15,1 \\
11,5 \\
- \\
- \\
- \\
- \\
- \\
- \\
- \\
3,2\end{array}$ & $\begin{array}{l}65,6 \\
77,0 \\
67,0 \\
67,1 \\
67,8 \\
75,5 \\
73,7 \\
59,2 \\
58,5 \\
65,4 \\
70,9 \\
74,6 \\
88,8 \\
85,5 \\
75,0 \\
61,2 \\
69,8 \\
78,9 \\
75,9 \\
73,4 \\
69,7 \\
84,9 \\
81,9 \\
64,7 \\
61,0 \\
60,7 \\
62,0 \\
61,0 \\
75,9 \\
64,9 \\
79,7\end{array}$ & $\begin{array}{l}22,5 \\
23,1 \\
20,4 \\
21,8 \\
23,0 \\
23,7 \\
23,6 \\
21,9 \\
23,4 \\
24,6 \\
24,6 \\
23,6 \\
24,0 \\
18,0 \\
20,5 \\
22,1 \\
24,3 \\
25,3 \\
21,0 \\
18,4 \\
22,0 \\
24,6 \\
20,4 \\
16,1 \\
14,9 \\
19,2 \\
20,4 \\
20,7 \\
22,1 \\
23,2 \\
24,1\end{array}$ & $\begin{array}{r}- \\
- \\
- \\
- \\
- \\
- \\
- \\
- \\
- \\
- \\
28,7 \\
10,4 \\
3,4 \\
- \\
10,4 \\
15,8 \\
- \\
0 \\
27,3 \\
13,2 \\
- \\
- \\
- \\
- \\
- \\
-\end{array}$ & $\begin{array}{l}25,0 \\
26,5 \\
22,5 \\
23,5 \\
25,0 \\
25,0 \\
25,0 \\
24,0 \\
25,0 \\
24,5 \\
25,0 \\
23,5 \\
25,0 \\
21,0 \\
22,0 \\
23,5 \\
25,0 \\
27,0 \\
22,5 \\
19,5 \\
23,0 \\
26,0 \\
22,5 \\
18,0 \\
16,5 \\
20,0 \\
21,5 \\
22,5 \\
23,5 \\
25,0 \\
24,0\end{array}$ \\
\hline Total & 129,1 & & & 109,6 & \\
\hline Média & & 70,9 & 21,8 & & 23,4 \\
\hline
\end{tabular}


.159 .

TABELA 52. Dados metereológicos do mes de novembro de 1983. ESALQ, Piracicaba e Usina Santa Barbara, Santa Barbara D'Oeste, SP.

\begin{tabular}{|c|c|c|c|c|c|}
\hline \multirow[b]{2}{*}{ Dia } & \multicolumn{3}{|c|}{ Piracicaba } & \multicolumn{2}{|c|}{ Santa Barbara } \\
\hline & $\begin{array}{c}\text { Precipitação } \\
\text { (mm) }\end{array}$ & $\begin{array}{c}\text { Unidade } \\
\text { relativa } \\
\frac{8}{8}\end{array}$ & $\begin{array}{l}\text { Termeratura } \\
\text { mêclia } \\
\text { (OC:) }\end{array}$ & $\begin{array}{c}\text { Precipitação } \\
\text { (mm) }\end{array}$ & $\begin{array}{l}\text { Tenperatura } \\
\text { média } \\
\text { (OC). }\end{array}$ \\
\hline $\begin{array}{r}1 \\
2 \\
3 \\
4 \\
5 \\
6 \\
7 \\
8 \\
9 \\
10 \\
11 \\
12 \\
13 \\
14 \\
15 \\
16 \\
17 \\
18 \\
19 \\
20 \\
21 \\
22 \\
23 \\
24 \\
25 \\
26 \\
27 \\
28 \\
29 \\
30\end{array}$ & $\begin{array}{c}4,9 \\
16,3 \\
- \\
9,1 \\
- \\
- \\
- \\
- \\
2,8 \\
5,7 \\
9,1 \\
0,2 \\
- \\
2,7 \\
- \\
- \\
- \\
24,8 \\
- \\
12,8 \\
- \\
- \\
- \\
- \\
- \\
- \\
- \\
-\end{array}$ & $\begin{array}{l}74,3 \\
81,1 \\
73,3 \\
90,2 \\
72,0 \\
57,2 \\
60,2 \\
49,5 \\
61,0 \\
77,5 \\
81,0 \\
73,0 \\
73,5 \\
58,0 \\
84,6 \\
58,3 \\
52,2 \\
50,0 \\
64,2 \\
74,8 \\
74,1 \\
77,5 \\
64,0 \\
63,8 \\
52,8 \\
49,0 \\
57,5 \\
63,0 \\
61,7 \\
59,6\end{array}$ & $\begin{array}{l}22,4 \\
18,4 \\
21,9 \\
23,9 \\
17,7 \\
22,1 \\
22,8 \\
24,2 \\
26,2 \\
26,1 \\
24,2 \\
23,6 \\
24,3 \\
23,1 \\
24,9 \\
19,6 \\
21,3 \\
28,0 \\
24,4 \\
26,3 \\
24,6 \\
24,9 \\
21,1 \\
22,0 \\
24,1 \\
24,4 \\
23,3 \\
24,0 \\
22,9 \\
23,7\end{array}$ & $\begin{array}{c}0,4 \\
1,8 \\
40,2 \\
- \\
6,7 \\
- \\
- \\
- \\
- \\
- \\
1,0 \\
3,8 \\
- \\
- \\
- \\
- \\
- \\
- \\
33,7 \\
- \\
32,5 \\
0,1 \\
- \\
- \\
- \\
- \\
- \\
- \\
-\end{array}$ & $\begin{array}{l}24,5 \\
23,5 \\
24,0 \\
25,0 \\
20,0 \\
23,5 \\
24,5 \\
26,0 \\
27,0 \\
28,0 \\
27,0 \\
25,5 \\
26,0 \\
25,0 \\
26,0 \\
21,5 \\
22,5 \\
25,0 \\
25,5 \\
28,0 \\
26,0 \\
26,5 \\
22,0 \\
23,5 \\
25,0 \\
25,0 \\
25,0 \\
24,5 \\
25,5 \\
25,5\end{array}$ \\
\hline Total & 88,4 & & & 120,2 & \\
\hline Média & . & 66,2 & 23,1 & & 24,9 \\
\hline
\end{tabular}


TABELA 53. Dados meteorológicos do mes de dezembro de 1983. ESALQ, Piracicaba e Usina Santa Barbara, Santa Barbara D'Oeste, SP.

\begin{tabular}{|c|c|c|c|c|c|}
\hline \multirow[b]{2}{*}{ Dia } & \multicolumn{3}{|c|}{ Piracicala } & \multicolumn{2}{|c|}{ Santa Barbara } \\
\hline & $\begin{array}{c}\text { Precipitação } \\
\text { (mm) }\end{array}$ & $\begin{array}{l}\text { Unnidade } \\
\text { relativa } \\
\text { (\%) }\end{array}$ & $\begin{array}{c}\text { Temperatura } \\
\text { média } \\
\left({ }^{\circ} \mathrm{C}\right)\end{array}$ & $\begin{array}{c}\text { Precipitação } \\
\text { (mm) }\end{array}$ & $\begin{array}{c}\text { Temperatura } \\
\text { mëdia } \\
\left(\mathrm{O}^{\mathrm{C}}\right)\end{array}$ \\
\hline $\begin{array}{l}1 \\
2 \\
3 \\
4 \\
5 \\
6 \\
7 \\
8 \\
9 \\
10 \\
11 \\
12 \\
13 \\
14 \\
15 \\
16 \\
17 \\
18 \\
19 \\
20 \\
21 \\
22 \\
23 \\
24 \\
25 \\
26 \\
27 \\
28 \\
29 \\
30 \\
31\end{array}$ & $\begin{array}{r}7,0 \\
- \\
- \\
- \\
0, \\
0 \\
- \\
0,4 \\
2,3 \\
9,2 \\
4,4 \\
5,6 \\
17,6 \\
6,4 \\
- \\
8,5 \\
2,1 \\
5,9 \\
6,5 \\
4,6 \\
11,9 \\
3,2 \\
3,3 \\
0,9 \\
10,6 \\
6,7 \\
1,0 \\
10,5 \\
32,0 \\
-\end{array}$ & $\begin{array}{l}65,3 \\
67,6 \\
66,6 \\
60,4 \\
62,3 \\
79,7 \\
59,8 \\
67,6 \\
73,0 \\
76,0 \\
88,6 \\
76,0 \\
84,5 \\
88,2 \\
82,7 \\
76,2 \\
70,2 \\
82,6 \\
82,5 \\
87,7 \\
85,0 \\
92,3 \\
87,7 \\
76,8 \\
75,4 \\
85,9 \\
86,4 \\
79,5 \\
77,6 \\
85,1 \\
78,9\end{array}$ & $\begin{array}{l}24,5 \\
24,5 \\
23,2 \\
23,0 \\
23,7 \\
24,5 \\
23,6 \\
24,9 \\
26,8 \\
24,0 \\
25,1 \\
22,1 \\
25,6 \\
24,0 \\
22,5 \\
22,9 \\
23,7 \\
25,8 \\
24,6 \\
25,4 \\
25,4 \\
25,2 \\
26,6 \\
22,4 \\
24,4 \\
23,2 \\
22,4 \\
23,8 \\
24,7 \\
25,3 \\
25,3\end{array}$ & $\begin{array}{c}- \\
1,9 \\
- \\
- \\
1,4 \\
- \\
- \\
0,8 \\
1,0 \\
6,7 \\
14,8 \\
13,7 \\
16,6 \\
2,7 \\
- \\
33,0 \\
3,7 \\
1,3 \\
9,5 \\
7,2 \\
20,2 \\
7,4 \\
- \\
- \\
6,5 \\
16,4 \\
- \\
31,2 \\
5,8\end{array}$ & $\begin{array}{l}25,5 \\
26,5 \\
24,0 \\
24,5 \\
25,0 \\
25,0 \\
25,0 \\
26,0 \\
27,0 \\
26,5 \\
26,0 \\
24,0 \\
26,0 \\
25,0 \\
23,5 \\
24,5 \\
26,0 \\
20,5 \\
26,0 \\
27,0 \\
26,5 \\
27,0 \\
24,5 \\
22,5 \\
25,5 \\
24,5 \\
24,0 \\
24,5 \\
24,0 \\
26,0 \\
26,5\end{array}$ \\
\hline Total & 161,4 & & & 201,8 & \\
\hline Ivlēâia & $\cdot$ & 77,7 & 24,2 & & 25,3 \\
\hline
\end{tabular}


TABELA 54. Dados meteorológicos do mes de janeiro de 1984. ESALQ, Piracicaba e Usina Santa Barbara, Santa Barbara, SP.

\begin{tabular}{|c|c|c|c|c|c|}
\hline \multirow[b]{2}{*}{ Dia } & \multicolumn{3}{|c|}{ Piracicaba } & \multicolumn{2}{|c|}{ Santa Earbara } \\
\hline & $\begin{array}{c}\text { Precipitação } \\
\text { (mm) }\end{array}$ & $\begin{array}{c}\text { umidade } \\
\text { relativa } \\
\left(\frac{8}{8}\right)\end{array}$ & $\begin{array}{c}\text { Terperatura } \\
\text { média } \\
\left({ }^{\circ} \mathrm{C}\right)\end{array}$ & $\begin{array}{c}\text { Precipitação } \\
\text { (IIm) }\end{array}$ & $\begin{array}{l}\text { Tenperatura } \\
\text { média } \\
\text { (OC) }\end{array}$ \\
\hline $\begin{array}{r}1 \\
2 \\
3 \\
4 \\
5 \\
6 \\
7 \\
8 \\
9 \\
10 \\
11 \\
12 \\
13 \\
14 \\
15 \\
16 \\
17 \\
18 \\
19 \\
20 \\
21 \\
22 \\
23 \\
24 \\
25 \\
26 \\
27 \\
28 \\
29 \\
30 \\
31\end{array}$ & $\begin{array}{c}0,7 \\
8,8 \\
7,9 \\
0,2 \\
- \\
0,4 \\
- \\
- \\
1,9 \\
- \\
- \\
- \\
- \\
- \\
- \\
- \\
- \\
- \\
- \\
2,9 \\
13,8 \\
0,2 \\
0,7 \\
- \\
- \\
25,8 \\
3,5 \\
0,2 \\
- \\
24,5 \\
-\end{array}$ & $\begin{array}{l}73,0 \\
81,3 \\
76,5 \\
79,4 \\
71,0 \\
72,7 \\
71,9 \\
67,5 \\
78,3 \\
76,8 \\
66,1 \\
56,8 \\
58,1 \\
59,7 \\
58,0 \\
61,7 \\
68,0 \\
62,7 \\
65,5 \\
75,2 \\
85,6 \\
87,9 \\
82,0 \\
80,3 \\
92,4 \\
94,3 \\
90,2 \\
83,1 \\
81,9 \\
86,4 \\
70,6\end{array}$ & $\begin{array}{l}24,0 \\
25,7 \\
24,9 \\
24,8 \\
26,0 \\
26,4 \\
26,9 \\
27,2 \\
25,0 \\
26,4 \\
25,5 \\
27,1 \\
26,4 \\
20,1 \\
27,9 \\
28,7 \\
29,3 \\
28,1 \\
27,5 \\
28,3 \\
25,8 \\
25,4 \\
24,1 \\
22,6 \\
24,9 \\
23,2 \\
23,6 \\
22,4 \\
25,5 \\
25,5 \\
25,7\end{array}$ & $\begin{array}{r}- \\
16,3 \\
16,5 \\
15,7 \\
- \\
- \\
3,2 \\
- \\
- \\
13,2 \\
- \\
1,3 \\
- \\
1,3 \\
- \\
- \\
- \\
- \\
- \\
1,0 \\
48,9 \\
1,0 \\
10,0 \\
18,5 \\
- \\
33,0 \\
- \\
6,5 \\
2,8 \\
9,2 \\
-\end{array}$ & $\begin{array}{l}25,0 \\
27,5 \\
26,0 \\
26,0 \\
26,5 \\
28,0 \\
29,5 \\
29,0 \\
30,0 \\
27,5 \\
27,0 \\
28,5 \\
29,5 \\
29,5 \\
30,0 \\
30,5 \\
29,5 \\
29,5 \\
30,0 \\
29,5 \\
27,0 \\
28,0 \\
24,5 \\
25,0 \\
25,0 \\
24,0 \\
24,5 \\
23,5 \\
26,0 \\
27,0 \\
27,0\end{array}$ \\
\hline Total & 91,5 & & & 198,4 & \\
\hline Mēdia & & 74,6 & 25,6 & & 27,4 \\
\hline
\end{tabular}


TABELA 55. Dados meteorológicos do mes de fevereiro de 1984. ESALQ, Piracicaba e Usina Santa Barbara, Santa Barbara D'Oeste, SP.

\begin{tabular}{|c|c|c|c|c|c|}
\hline \multirow[b]{2}{*}{ Dia } & \multicolumn{3}{|c|}{ Piracicaba } & \multicolumn{2}{|c|}{ Santa Barbara } \\
\hline & $\begin{array}{l}\text { Precipitação } \\
\text { (mun) }\end{array}$ & $\begin{array}{l}\text { umidade } \\
\text { relativa } \\
\left(\frac{q}{\delta}\right)\end{array}$ & $\begin{array}{c}\text { Temperatura } \\
\text { média } \\
\left({ }^{\circ} \mathrm{C}\right)\end{array}$ & $\begin{array}{c}\text { Precipitação } \\
\text { (mụ) }\end{array}$ & $\begin{array}{c}\text { Tenperatura } \\
\text { média } \\
\left(\mathrm{O}_{\mathrm{C}}\right)\end{array}$ \\
\hline $\begin{array}{r}1 \\
2 \\
3 \\
4 \\
5 \\
6 \\
7 \\
8 \\
9 \\
10 \\
11 \\
12 \\
13 \\
14 \\
15 \\
16 \\
17 \\
18 \\
19 \\
20 \\
21 \\
22 \\
23 \\
24 \\
25 \\
26 \\
27 \\
28 \\
29\end{array}$ & $\begin{array}{c}4,2 \\
- \\
- \\
- \\
- \\
- \\
- \\
- \\
6,5 \\
2,9 \\
- \\
- \\
- \\
1,5 \\
2,2 \\
- \\
- \\
- \\
- \\
- \\
- \\
- \\
- \\
1,4 \\
-\end{array}$ & $\begin{array}{l}69,3 \\
72,9 \\
66,9 \\
65,4 \\
59,0 \\
68,9 \\
74,7 \\
73,6 \\
70,2 \\
69,1 \\
74,2 \\
79,4 \\
66,6 \\
70,7 \\
72,5 \\
72,1 \\
77,1 \\
70,3 \\
70,5 \\
64,8 \\
64,7 \\
59,9 \\
64,3 \\
70,3 \\
68,3 \\
61,6 \\
65,0 \\
64,2 \\
65,1\end{array}$ & $\begin{array}{l}26,9 \\
27,2 \\
28,5 \\
28,4 \\
28,6 \\
29,0 \\
27,8 \\
24,4 \\
25,5 \\
26,1 \\
26,8 \\
26,4 \\
26,4 \\
27,1 \\
28,2 \\
27,3 \\
27,8 \\
27,0 \\
25,6 \\
26,5 \\
27,2 \\
28,5 \\
28,4 \\
27,9 \\
27,0 \\
26,3 \\
27,0 \\
28,7 \\
28,8\end{array}$ & $\begin{array}{r}- \\
- \\
- \\
- \\
0,5 \\
- \\
- \\
- \\
8,4 \\
2,1 \\
- \\
3,4 \\
- \\
22,3 \\
- \\
- \\
- \\
- \\
- \\
- \\
- \\
- \\
12,5 \\
10,8 \\
8,3\end{array}$ & $\begin{array}{l}27,5 \\
26,5 \\
29,0 \\
30,0 \\
30,0 \\
31,0 \\
29,5 \\
28,0 \\
29,5 \\
29,0 \\
29,0 \\
28,5 \\
28,0 \\
29,5 \\
30,0 \\
30,0 \\
30,0 \\
28,5 \\
28,0 \\
29,5 \\
29,0 \\
30,0 \\
30,5 \\
29,0 \\
30,0 \\
29,0 \\
29,5 \\
29,5 \\
30,0\end{array}$ \\
\hline Total & 18,7 & & & 68,3 & \\
\hline Média & . & 68.7 & $27_{e} 2$ & & 29.2 \\
\hline
\end{tabular}


TABELA 50. Dados de neteorológicos do mes de março de 1984. ESALQ, Piracicaba e Usina Santa Barbara, Santa Barbara D'Oeste, SP.

\begin{tabular}{|c|c|c|c|c|c|}
\hline \multirow[b]{2}{*}{ Dia } & \multicolumn{3}{|c|}{ Piracicaba } & \multicolumn{2}{|c|}{ Santa Barbara } \\
\hline & $\begin{array}{c}\text { Precipitação } \\
\text { (mrn) }\end{array}$ & $\begin{array}{l}\text { Umidade } \\
\text { relativa } \\
\left(\frac{\circ}{6}\right)\end{array}$ & $\begin{array}{c}\text { Termeratura } \\
\text { néaia } \\
\text { (OC) }\end{array}$ & $\begin{array}{c}\text { Precipitação } \\
\text { (mm) }\end{array}$ & $\begin{array}{c}\text { Termperatura } \\
\text { rnédia } \\
\left({ }^{\circ} \mathrm{C}\right)\end{array}$ \\
\hline 1 & - & 67,3 & 28,8 & - & 29,5 \\
\hline 2 & - & 75,7 & 27,9 & - & 29,0 \\
\hline 3 & - & 69,5 & 25,2 & - & 29,0 \\
\hline 4 & 2,0 & 74,0 & 27,4 & - & 30,0 \\
\hline 5 & 9,4 & 80,8 & 27,5 & 1,2 & 29,5 \\
\hline 6 & 5,5 & 81,3 & 27,8 & 12,2 & 29,0 \\
\hline 7 & 10,8 & 87,7 & 24,9 & 0,9 & 28,5 \\
\hline 8 & - & 79,9 & 24,8 & 12,7 & 26,0 \\
\hline 9 & - & 77,4 & 25,0 & - & 26,0 \\
\hline 10 & - & 66,7 & 23,3 & - & 27,0 \\
\hline 11 & - & 65,7 & 27,3 & 1,1 & 28,0 \\
\hline 12 & - & 69,5 & 25,5 & - & 27,5 \\
\hline 13 & - & 66,7 & 23,5 & - & 26,5 \\
\hline 14 & - & 73,1 & 24,2 & - & 26,0 \\
\hline 15 & - & 68,3 & 23,5 & - & 25,5 \\
\hline 16 & - & 70,9 & 25,0 & - & 26,5 \\
\hline 17 & - & 71,0 & 24,4 & - & 27,5 \\
\hline 18 & - & 69,7 & 25,2 & - & 26,5 \\
\hline 19 & - & 75,4 & 25,4 & - & 25,0 \\
\hline 20 & 10,5 & 76,2 & 24,4 & - & 25,5 \\
\hline 21 & 4,0 & 81,1 & 27,8 & 14,8 & 29,0 \\
\hline 22 & - & 74,0 & 24,9 & - & 27,0 \\
\hline 23 & - & 69,8 & 22,4 & - & 25,5 \\
\hline 24 & - & 70.0 & 22,7 & - & 24,5 \\
\hline 25 & - & 70,4 & 24,3 & - & 25,0 \\
\hline 26 & - & 76,2 & 26,1 & 2,5 & 25,0 \\
\hline 27 & - & 78,1 & 25,7 & 1,8 & 27,0 \\
\hline 28 & 2,5 & 72,8 & 23,9 & - & 26,0 \\
\hline 29 & 2,4 & 80,3 & 27,0 & 1,2 & 26,0 \\
\hline 30 & - & 76,6 & 26,3 & - & 27,0 \\
\hline 31 & - & 68,4 & 21,4 & - & 24,0 \\
\hline Total & 47,1 & & & 48,4 & \\
\hline Média & & 73,7 & 25,3 & & 26,9 \\
\hline
\end{tabular}


TABELA 57. Dados meteorológicos do mes de abril de 1984. ESALQ, Piracicaba e Usina Santa Barbara, Santa Earbara D'Oeste, SP.

\begin{tabular}{|c|c|c|c|c|}
\hline \multirow[b]{2}{*}{ Dia } & \multicolumn{2}{|c|}{ Piracicaba } & \multicolumn{2}{|c|}{ Santa Barbara } \\
\hline & $\begin{array}{c}\text { Precipitação } \\
\text { (mm) }\end{array}$ & $\begin{array}{c}\text { Terrperatura } \\
\text { r.jëdja a }\end{array}$ & $\begin{array}{c}\text { Precipitação } \\
\text { (mm) }\end{array}$ & $\begin{array}{c}\text { Terperatura* } \\
\text { médija }\end{array}$ \\
\hline 1 & - & 20,7 & - & - \\
\hline 2 & 6,4 & 23,3 & 0,9 & - \\
\hline 3 & 4,1 & 25,2 & 13,5 & - \\
\hline 4 & 7,0 & 22,8 & 6,4 & - \\
\hline 5 & - & 18,8 & - & - \\
\hline 6 & - & 20,0 & - & - \\
\hline 7 & 3,7 & 21,2 & - & - \\
\hline 8 & - & 22,6 & - & - \\
\hline 9 & - & 23,2 & - & - \\
\hline 10 & - & 23,5 & - & - \\
\hline lotal & 21,2 & & 20,8 & \\
\hline IYédia & & 22,1 & & \\
\hline
\end{tabular}

* Os dados de temperatura não estiveram disponíveis. 
TABELA 58. Temperatura $\left({ }^{\circ} \mathrm{C}\right)$ do ar e do solo, e umidade relativa (\%) durante aplicação dos tratamentos nos ex perimentos com herbicidas pós-emergentes em grama-seda. Usina Santa Barbara ^ Santa Barbara D'Oeste, SP. 1983-84.

\begin{tabular}{lcccc}
\hline Ano - 1983 & \multicolumn{3}{c}{ Hora } \\
\cline { 2 - 5 } remperatura do ar & 24,2 & 26,0 & 27,6 & 29,5 \\
Temperatura do solo & 22,1 & 22,5 & 24,2 & 25,0 \\
Umidade relativa & 55 & 57 & 56 & 52 \\
& & & & \\
Ano - 1984 & $7: 10$ & $9: 00$ & $10: 30$ & $11: 05$ \\
\hline Temperatura do ar & 33,0 & 34,6 & 35,0 & 35,3 \\
Temperatura do solo & 29,0 & 29,5 & 30,0 & 32,0 \\
Umidade relativa & 55 & 53 & 50 & 48 \\
\hline \hline
\end{tabular}


TABELA 59. Temperatura $\left({ }^{\circ} \mathrm{C}\right)$ do ar e do solo e umidade relati va (\&) durante a aplicação dos tratarnentos nos ex perimentos com herbicidas prē-emergentes em miTho e soja. Santa Barbara D'Oeste e Piracicaba, SP. $\quad 1983-84$

\begin{tabular}{|c|c|c|c|c|}
\hline \multirow{2}{*}{$\begin{array}{c}\text { Milho } \\
\text { Santa Barbara }\end{array}$} & \multicolumn{4}{|c|}{ Fiora } \\
\hline & $11: 30$ & $12: 30$ & $14: 30$ & $15: 15$ \\
\hline Temperatura do ar & 34,0 & 33,0 & 33,0 & 31,3 \\
\hline Temperatura do solo & 26,5 & 28,0 & 29,6 & 29,2 \\
\hline Umidade relativa & 55 & 55 & 56 & 59 \\
\hline \multirow[b]{2}{*}{$\begin{array}{l}\text { Milho } \\
\text { Fazenda Areião }\end{array}$} & \multicolumn{4}{|c|}{ kiora } \\
\hline & $8: 45$ & $9: 25$ & $10: 35$ & $11: 05$ \\
\hline Temperatura do ar & 26,0 & 28,1 & 28,0 & 28,2 \\
\hline remperatura do solo & 22,0 & 23,0 & 26,6 & 27,0 \\
\hline Unidade relativa & 74 & 69 & 65 & 65 \\
\hline \multirow{2}{*}{$\begin{array}{c}\text { Soja } \\
\text { Piracicaba }\end{array}$} & \multicolumn{4}{|c|}{ Hora } \\
\hline & $10: 00$ & $10: 30$ & $11: 00$ & $11: 30$ \\
\hline remperatura do ar & 24,0 & 25,5 & 26,0 & 29,8 \\
\hline Temperatura do solo & 23,5 & 25,0 & 25,8 & 28,0 \\
\hline Umidade relativa & 70,0 & 67,0 & 66,0 & 57,0 \\
\hline
\end{tabular}


.167.

TABELA 60. Temperatura $\left({ }^{\circ}\right.$ ) do ar e umidade relativa $\left(\frac{8}{0}\right)$ durante a aplicação dos tratamentos nos experimentos com herbicidas pós-emergentes em grama-seda, em casa-de-vegetação. ESALQ, Piracicaba, SP. 1983-84.

\begin{tabular}{|c|c|c|c|c|}
\hline \multirow{2}{*}{ Ano $1982-83$} & \multicolumn{4}{|c|}{ Hora } \\
\hline & $6: 15$ & $7: 00$ & $7: 50$ & $8: 20$ \\
\hline I'emperatura do ar & 18,0 & 21,0 & 23,0 & 25,0 \\
\hline Umidade relativa & 80,0 & 75,0 & 73,0 & 72,0 \\
\hline \multirow{2}{*}{ Ano $1983-84$} & \multicolumn{4}{|c|}{ Hora } \\
\hline & $27: 15$ & $17: 50$ & $18: 30$ & $19: 15$ \\
\hline 1 & & & & \\
\hline Iemperatura do ax & 27,0 & 26,5 & 25,0 & 24,0 \\
\hline l'emperatura do solo & 69,0 & 70,0 & 72,0 & 80,0 \\
\hline
\end{tabular}

